\title{
VII. Das Oberste Gericht und die Oberste Staatsanwaltschaft: Entstehung, Entwicklung und Justizsteuerung $(1949-1952 / 53)$
}

\section{Die Gründung des Obersten Gerichts und der Obersten Staatsanwaltschaft}

Im Vorfeld der Gründung der DDR war die Errichtung eines Obersten Gerichtshofes einschließlich einer Anklagebehörde unter den Parteien unstrittig gewesen 1 . Die Verfassung der DDR legte in Artikel 126 fest, daß die ordentliche Gerichtsbarkeit "durch den Obersten Gerichtshof der Republik und durch die Gerichte der Länder ausgeübt" werde; Artikel 131 begründete die Wahl der Richter des Obersten Gerichts und des Obersten Staatsanwalts durch die Volkskammer, und Artikel 132 regelte in Absatz 1 bis 3 die Modalitäten von deren Abberufung. Welche Funktion und welche Stellung diesen Justizorganen innerhalb des Justizwesens zukommen sollten, ließ die Verfassung offen. Es war sowohl dem Bedürfnis nach einer Normalität suggerierenden Außenwirkung als auch der Notwendigkeit geschuldet, den Gerichtsaufbau an seiner Spitze zu vervollständigen, wenn sich die Verantwortlichen schon bald an die Ausarbeitung eines Gesetzes über die Errichtung des Obersten Gerichtshofes und der Obersten Staatsanwaltschaft der DDR machten. Dabei wollten sie freilich jeden Anschein von Kontinuität zum Reichsgericht vermeiden².

Der Gesetzentwurf der DDR-Regierung wurde im Justizministerium unter Kooperation mit der Unterabteilung Justiz des SED-Parteiapparats ausgearbeitet und am 25. Oktober 1949 zusammen mit einer ausführlichen Begründung an Grotewohl übersandt ${ }^{3}$. Nachdem das Politbüro am 1 . November zugestimmt hatte ${ }^{4}$, beschloß die Regierung am 3. November „nach kurzer Beratung“, diesen Entwurf als Gesetzesvorlage bei der Volkskammer einzubringen. Da das knappe Sitzungsprotokoll lediglich „Übereinstimmung über die Grundprinzipien dieser

1 Im Verfassungsausschuß des Deutschen Volksrats herrschte darüber offensichtlich Konsens; im Hinblick auf die Rechtspflege wurde vor allem über das Richteramt und das Abberufungsverfahren für Richter kontrovers debattiert: vgl. Travers, Entwicklung, S. 245-251.

2 Vgl. Benjamin, Die Tätigkeit des Obersten Gerichts von 1949-1952, o.D. [1965], BAB, DP1 VA Nr. 6656: „An allem Anfang stand die Erkenntnis und der feste Wille: Das Oberste Gericht der DDR darf kein neues ,Reichsgericht' werden."

3 MdJ an Ministerpräsident, 25. 10. 1949, Abteilung Justiz [sic] an Nathan, 11. 11. 1949, BAB, DP1 VA Nr. 7165.

4 Protokoll der Politbürositzung, 1. 11. 1949, SAPMO, DY 30 J IV 2/2/54, TOP 3; vgl. Mollnau, Staatsanwaltschaftliche Gesetzlichkeitsaufsicht, S. 255. 
Gesetzesvorlage" feststellte, ist es durchaus möglich, daß die CDU- und LDPMinister Einwände vorbrachten. Die Frage der personellen Besetzung beider Institutionen wurde zurückgestellt; zuerst sollte Klarheit über die Anzahl der zu schaffenden Stellen in beiden Behörden gewonnen werden 5 . Das Gesetz konnte jedoch nicht direkt verabschiedet werden, da bei dessen Einbringung in die Volkskammer am 9. November 1949 nicht nur der Regierungsentwurf, sondern auch ein vom Vorsitzenden der LDP-Fraktion, Ralph Liebler, unterzeichneter Gegenentwurf vorlag6. Die personelle Präsenz der LDP in der Regierung hatte die Partei nicht davon abgehalten, von ihrem verfassungsmäßig gesicherten Recht Gebrauch zu machen und ein Gesetz einzubringen, das in wesentlichen Aspekten von der Regierungsvorlage abwich. Der entscheidende Unterschied zwischen beiden Texten bestand in der Festlegung der Zuständigkeit des höchsten DDR-Gerichts. Nach $\ 4$, Abs. 1a des Regierungsentwurfs hatte das Oberste Gericht in Strafsachen von „überragende[r] Bedeutung“ in erster und letzter Instanz Recht zu sprechen und ansonsten als Kassationsgerichtshof zu fungieren?. Während die alleinige Zuständigkeit in Kassationssachen - die Oberlandesgerichte sollten demnach diese Aufgabe verlieren - der Vereinheitlichung der Rechtsprechung dienen sollte, wurde die erstinstanzliche Zuständigkeit mit der Notwendigkeit begründet, solche Verbrechen aburteilen zu müssen, „die unmittelbar an den Bestand des Staates rühren". Eine in dem Gesetz vorzunehmende Abgrenzung dieser Sachen nach bestimmten Straftatbeständen hielt das MdJ für unzweckmäßig, „da Angriffe von überragender Bedeutung gegen die staatliche Ordnung unter den verschiedensten strafrechtlichen Gesichtspunkten erfolgen können“; dabei dachte man dort „in erster Linie [...] an besonders schwerwiegende Wirtschaftsverbrechen und an die in Artikel 6 Abs. 2 der Verfassung aufgezählten Straftaten, soweit sie

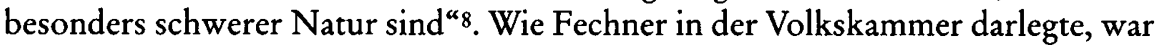
dieses Gesetz „nur ein Anfang“ im Rahmen der Neuorganisation des Justizwesens; damit war indirekt impliziert, daß die Zuständigkeit des Obersten Gerichts im Rahmen einer Änderung der Gerichtsverfassung erweitert werden konnte?.

Nach dem LDP-Entwurf hingegen war der Oberste Gerichtshof ausschließlich ein Revisions- und Kassationsgerichtshof, wobei genau festgelegt wurde, in welchen Fällen Revision eingelegt bzw. Kassationsverfahren durchgeführt werden konnten ${ }^{10}$. In der beigefügten Begründung hieß es sogar: „Tätigkeit in erster Instanz ist dem Obersten Gerichtshof durch Kontrollratsgesetz Nr. 4 verboten." 11 Dies traf zwar im engeren Sinne nicht zu, da KRG 4 nur die Wiedererrichtung der Amtsgerichte, Landgerichte und Oberlandesgerichte vorgesehen hatte. $\mathrm{Da}$ es den

5 Protokoll der Sitzung der Provisorischen Regierung, 3.11. 1949, BAB, DC 20 I/3, Nr. 1, Bl. 37.

6 Darauf hat erstmals Gerd Janke hingewisen: siehe ders., Zur Gründung des Obersten Gerichts, S. 564.

7 Der Regierungsentwurf vom 4.11. 1949 als Drucksache Nr. 14 in: Provisorische Volkskammer, Drucksachen, S. $7 \mathrm{f}$.

8 Begründung des Regierungsentwurfs, BAB, DP1 VA Nr. 7165.

9 Provisorische Volkskammer, Sitzungen, S. 71.

10 Der LDP-Entwurf vom 4. 11. 1949 als Drucksache Nr. 17 in: Provisorische Volkskammer, Drucksachen, S. 9-11.

11 Die Begründung ebenda, S. $11 \mathrm{f}$., hier 12. 
1945 eingerichteten obersten Gerichten der Länder eine erstinstanzliche Tätigkeit untersagte, entsprach diese Auslegung jedoch in einem weiteren Sinne durchaus der mit KRG 4 verbundenen Absicht, bei jedem Gerichtsurteil die Möglichkeit einer Anfechtung durch ein Rechtsmittelverfahren zu gewährleisten ${ }^{12}$. Nach dem LDP-Entwurf sollte das Oberste Gericht vor allem als Revisionsinstanz bei Schwurgerichts- und Todesurteilen, aber auch bei Einziehung des gesamten Betriebs- oder sonstigen Vermögens, bei treuhänderischer Betriebsverwaltung oder höheren Geldstrafen fungieren. Wollte die SED mithin über das Oberste Gericht (unter anderem) eine Verschärfung der Rechtsprechung in der Wirtschaftsstrafjustiz erreichen, verband die LDP mit ihrem Konzept hingegen die Absicht, „die Anwendung der Wirtschaftsstrafverordnung in vernünftige Bahnen zu lenken, um ungerechtfertigte ,gerichtliche Enteignungen' von privaten Unternehmern, Gewerbetreibenden und Großbauern zu verhindern" ${ }^{13}$. Des weiteren sollten nach dem LDP-Vorschlag nicht nur, wie es die Regierung vorsah, der Oberste Staatsanwalt, sondern auch die Angeklagten und Privatkläger berechtigt sein, die Kassation eines Urteils zu beantragen, was eine Stärkung der Rechte des Angeklagten bedeutet hätte. Insgesamt wird bei dem LDP-Entwurf das Bemühen deutlich, den Handlungsrahmen des Obersten Gerichts möglichst präzise festzulegen, um dadurch ein möglichst hohes Maß an Rechtsstaatlichkeit zu sichern; der sehr viel knappere Regierungsentwurf hingegen ließ vieles bewußt im Unklaren, um das Oberste Gericht möglichst effektiv im Sinne der SED-Politik instrumentalisieren zu können ${ }^{14}$.

Der Obersten Staatsanwaltschaft war im Regierungsentwurf ein eigener Abschnitt gewidmet, in dem nicht nur deren Recht zur Kassationsbeantragung, sondern auch das Weisungsrecht des Generalstaatsanwalts gegenüber allen anderen Staatsanwälten sowie dessen Befugnis festgeschrieben wurde, ,jedes bei den Staatsanwaltschaften der Länder schwebende Strafverfahren an sich [zu] ziehen“. In seiner Begründung des Gesetzes vor der Volkskammer verdeutlichte Fechner zudem die weitergehenden Absichten der Regierung: Die Staatsanwaltschaft sollte, wie in der Sowjetunion auch, ,im Zuge unserer staatlichen Entwicklung [...] in steigendem Maße allgemein zur Hüterin der demokratischen Gesetzlichkeit" werden ${ }^{15}$. Im LDP-Entwurf hingegen fehlte der Obersten Staatsanwaltschaft die Gleichrangigkeit mit dem Obersten Gericht und ein Weisungsrecht gegenüber den Staatsanwälten der Länder; sie war lediglich die Institution, der „die Verrichtungen der Staatsanwaltschaft beim Obersten Gerichtshof" oblagen. Dem Obersten Staatsanwalt war es auch nicht gestattet, die ihm beigeordneten Staatsanwälte zu ernennen, da dies nach den Vorstellungen der LDP dem Justizministerium zukam.

12 KRG 4 vom 30. 10. 1945 in: Amtsblatt des Kontrollrats, Nr. 2, 30.11. 1945, S. 26 f., hier Art.II.

13 So zutreffend Janke, Zur Gründung des Obersten Gerichts, S. 567.

14 So ließ etwa der Regierungsentwurf die Anzahl der Zivil- und Strafsenate des Obersten Gerichts offen, der LDP-Entwurf legte sich auf mindestens einen Strafsenat und zwei Zivilsenate fest. Dieser beinhaltete zudem genaue Bestimmungen über die Voraussetzungen, unter denen die Richter des Obersten Gerichts ihr Amt verloren, schrieb Anwaltszwang und die Einrichtung eines Großen Senats vor, der bei voneinander abweichenden Urteilen unterschiedlicher Senate in Aktion treten sollte; über all diese Punkte schwieg der Regierungsentwurf sich aus.

15 Provisorische Volkskammer, Sitzungen, S. 71. 
Als beide Gesetzentwürfe am 9. November in die Volkskammer eingebracht wurden, ging Justizminister Fechner lediglich auf den Regierungsantrag ein, wobei er unter anderem den Unterschied zwischen dem Obersten Gericht und dem ehemaligen Reichsgericht betonte. Die Auffassung der LDP, daß nicht nur der Generalstaatsanwalt, sondern auch der Angeklagte das Recht zur Kassationsbeantragung erhalten sollte, wurde von ihm verworfen. Die LDP-Fraktion begründete den eigenen Gesetzentwurf nicht weiter, so daß beide Drucksachen im Anschluß an Fechners Auftritt ohne weitere Diskussion an den Rechtsausschuß verwiesen wurden ${ }^{16}$. Von den 15 erst am Ende der Volkskammersitzung gewählten Mitgliedern des Ausschusses gehörten lediglich vier (Rudolf Agricola, Hilde Benjamin, Rudolf Helm und Kurt Fischer) der SED-Fraktion an. Mit jeweils zwei Abgeordneten waren LDP, CDU, FDGB und Kulturbund vertreten; jeweils einen stellten DBD, NDPD und die in Opposition zur SPD Schumachers stehende SPD-Fraktion der Volkskammer. Diese Zusammensetzung suggerierte zwar parteipolitischen Pluralismus, verschleierte aber lediglich die Dominanz der SED. Denn die beiden Mitglieder des Kulturbundes, Käthe Kern und Peter A. Steiniger, waren ebenfalls in der SED; auch die FDGB-Mitglieder des Ausschusses, August Heiden und Richard Zänkner, gehörten vermutlich der SED an. Zudem handelte es sich bei den DBD- und NDPD-Vertretern Ernst Goldenbaum und Siegfried Dallmann um ebenso sichere ,Verbündete' der SED wie beim Sozialdemokraten Paul Gräber. Nur von den Liberaldemokraten Erich Damerow und Wilhelm von Stoltzenberg sowie von den Christdemokraten Carl Ruland und Georg Knabe war möglicherweise mit Opposition zu rechnen, die aber aufgrund der Mehrheitsverhältnisse leicht überstimmt werden konnte ${ }^{17}$.

Noch bevor der Rechtsausschuß zusammentrat, wurden die Gesetzentwürfe der zuständigen Abteilung in Karlshorst übersandt ${ }^{18}$; Rückmeldungen an das MdJ kamen von dort offensichtlich nicht. Die Unterabteilung Justiz der SED gab am 11. November in einer Stellungnahme zum Regierungsantrag einen von dritter Seite - möglicherweise der SKK - erhaltenen Hinweis weiter, daß das Oberste Gericht in die Lage versetzt werden solle, nicht nur Urteile, sondern auch andere Entscheidungen zu kassieren. Außerdem war man sich in der Parteizentrale anscheinend noch unsicher, wie weit man den bürgerlichen Parteien entgegenkommen mußte. Wenn man „auf das Drängen der Bürgerlichen hin“ dem Angeklagten das Recht zur Kassationsbeantragung zugestand, schlug Berger vor, daß in einem solchen Falle die Möglichkeit gegeben sein müsse, „den Kassationsantrag als ,offensichtlich aussichtslos' durch Beschluß zu verwerfen" 19.

Der Rechtsausschuß behandelte die beiden Gesetzentwürfe in seiner konstituierenden Sitzung am 29. November ${ }^{20}$. Zusätzlich zu den Ausschußmitgliedern

16 Ebenda, S. 70f.; Begründung des Regierungsentwurfs, BAB, DP1 VA Nr. 7165.

17 Provisorische Volkskammer, Sitzungen, S. 73; vgl. Janke, Zur Gründung des Obersten Gerichts, S. 566.

18 Am 11.11. 1949 wurde der Regierungsentwurf, am 18. 11. der LDP-Entwurf übersandt, BAB, DP1 VA Nr. 7165.

19 Abteilung Justiz [sic] an Nathan, 11. 11. 1949, gez. Berger, ebenda.

20 Siehe Niederschrift der 1. (konstituierenden) Sitzung des Rechtsausschusses der Provisorischen Volkskammer am 29.11. 1949, BAB, DA1 Nr. 937, Bl. 39-49. Dort auch alle folgenden Zitate, wenn nicht anders gekennzeichnet. Die Hervorhebung auf S. 437 im Original. 
waren für die Regierungsseite Justizminister Fechner, Hans Nathan, Staatssekretär Fritz Geyer und Hans Schaul von der Regierungskanzlei anwesend. Die Öffentlichkeit war zwar nicht, wie zwei West-Berliner Zeitungen am 30. November meldeten, ausgeschlossen worden, aber man hatte die Presse auch nicht unterrichtet $^{21}$. Nachdem auf Antrag Nathans der Regierungsentwurf dahingehend geändert worden war, daß sich die Kassation nicht nur auf Urteile, sondern ganz allgemein auf "Entscheidungen“ beziehen sollte, trat der Ausschuß in die Generaldebatte „über die allgemeinen rechtspolitischen Grundsätze der beiden vorliegenden Entwürfe" ein. Die SED kam dabei der LDP in einigen untergeordneten Punkten entgegen - so wurde unter anderem der Errichtung eines Großen Senats zugestimmt und die Geschäftsverteilung für ein Jahr im voraus dem Präsidium des Obersten Gerichts überantwortet, dem der Präsident, der Vizepräsident und die Oberrichter angehören mußten ${ }^{22}$. Außerdem kündigte Fechner an, die Zuständigkeit des Obersten Gerichts im Zuge der Reform des Gerichtsverfassungsgesetzes auch auf Revisionsangelegenheiten auszuweiten. Die SED nahm damit in gewisser Weise der LDP den Wind aus den Segeln; jedenfalls stellte von Stoltzenberg am Ende der Generaldebatte fest, „daß er in keinem grundsätzlichen Widerspruch zu den rechtspolitischen Grundsätzen des Regierungsentwurfes stehe“. Der LDP-Entwurf wurde nun nur noch ergänzend bei der Spezialdebatte über die einzelnen Paragraphen des Regierungsentwurfes hinzugezogen.

Von Stoltzenberg beantragte jedoch direkt zu Beginn der Spezialdebatte die Streichung von $\ 4$, Abs. 1a. Auch Ruland lehnte für die CDU-Fraktion die vorliegende Fassung des umstrittenen Absatzes „als nicht vereinbar mit Art. $134{ }^{23} \mathrm{der}$ Verfassung" ab. Seine Mißbilligung der erstinstanzlichen Zuständigkeit war zwar nicht, wie bei der LDP, prinzipieller Natur; er wollte aber die diesen Verfahren zugrunde gelegten Verbrechenstatbestände durch ein Gesetz spezifiziert sehen. Die Regierungsseite wies die Einwände kategorisch zurück. Fechner erklärte, „daß die Regierung auf die Beibehaltung gerade dieses Absatzes besonderen Wert lege und daß die Regierung diesen Absatz seinerzeit erst nach eingehender Beratung einstimmig angenommen habe ". Die LDP- und CDU-Abgeordneten ließen sich dadurch zwar nicht beeindrucken ${ }^{24}$, erlitten bei der Abstimmung jedoch die durch die Sitzverteilung voraussehbare Niederlage: Zehn Ausschußmitglieder stimmten für die Beibehaltung des Absatzes in seiner ursprünglichen Form, die beiden CDU-Vertreter stimmten dagegen, und die Liberaldemokraten enthielten sich,

21 Siehe die Zitate aus dem „Kurier“ und der „Neuen Zeitung“, vorgetragen von Helm in der Volkskammersitzung am 7. 12. 1949, in: Provisorische Volkskammer, Sitzungen, S. 82 f. Das Sekretariat der Volkskammer hatte am 19.11. 1949 das Verwaltungsbüro angewiesen: „Presse nicht einladen.“ BAB, DA1, Nr. 937, Bl. 142.

22 Der Regierungsentwurf äußerte sich nicht zur Geschäftsverteilung; der LDP-Entwurf sah vor, daß die Regierung die Verteilung der Geschäfte auf die Senate vornehmen sollte. Der Vorschlag Steinigers stellte somit einen Kompromiß dar.

23 Art. 134 lautete: „Kein Bürger darf seinen gesetzlichen Richtern entzogen werden. Ausnahmegerichte sind unstatthaft. Gerichte für besondere Sachgebiete können vom Gesetzgeber nur errichtet werden, wenn sie für im voraus und allgemein bezeichnete Personengruppen oder Streitgegenstände zuständig sein sollen."

24 Vgl. dazu auch Damerow vor dem LDP-Zentralvorstand am 2. 12. 1949, in: DzD II/2, S. 833: „Im Rechtsausschuß hat man uns bei der Diskussion über das Gesetz zum Obersten Gerichtshof erklärt, daß eine Diskussion überflüssig sei, da unsere drei Minister diesem Entwurf vorbehaltlos zugestimmt hätten.“ 
freilich nicht ohne den Hinweis von Stoltzenbergs, daß die LDP sich vorbehalte, "den Antrag auf Streichung im Plenum vorzubringen“. Trotz dieses Eklats setzte der Ausschuß die Diskussion fort, um weitere unbedeutende Änderungen an dem Regierungsentwurf vorzunehmen. Am Ende der Sitzung einigte man sich bei der Schlußabstimmung im Ausschuß, CDU und LDP Gelegenheit zu geben, „nach Rücksprache mit ihren Fraktionen“ ihre schriftliche Zustimmungserklärung bis zum Vorabend der für den 7. Dezember vorgesehenen Schlußdebatte in der Volkskammer beim Ausschußvorsitzenden abzugeben ${ }^{25}$.

Als am 7. Dezember Helm die geänderte Gesetzesvorlage 26 in die Volkskammer einbrachte, betonte er, daß aus den beiden ursprünglichen Entwürfen im Rechtsausschuß „eine vollständige Übereinstimmung zustande gekommen“ sei. Er ging zwar kritisch auf den ursprünglichen LDP-Entwurf ein, erwähnte den Konflikt mit von Stoltzenberg jedoch mit keinem Wort. Auch die Bedenken der CDU führte er an, wies sie aber als substanzlos zurück. Unmittelbar nach dem Beitrag Helms, in dem er im übrigen alle gegenüber dem ursprünglichen Regierungsentwurf vorgenommenen Änderungen erwähnte, wurde das Gesetz ohne Aussprache einstimmig angenommen ${ }^{27}$. Bereits am nächsten Tag vom Volkskammerpräsidenten ausgefertigt, wurde es von Präsident Pieck am 15. Dezember verkündet und trat damit in $\mathrm{Kraft}^{28}$.

Was die bürgerlichen Parteien bewog, schließlich nachzugeben, läßt sich nicht mehr eindeutig klären. Entscheidend war wohl der Grad ihrer Gleichschaltung, die einerseits nicht so weit ging, daß LDP und CDU von vornherein auf den Versuch verzichteten, das ihnen mit dem Parlament und seinen Ausschüssen gegebene Instrumentarium zu nutzen, um rechtsstaatlichen Grundsätzen zum Durchbruch zu verhelfen. Andererseits waren mit dem Übergang von Kaiser zu Nuschke in der CDU und von Külz zu Kastner in der LDP in beiden Parteien 1948 diejenigen in die Führungsetagen gelangt, die nicht auf Konflikt, sondern auf Kooperation mit der SED und der Besatzungsmacht setzten. Außerdem war den CDU- und LDP-Vertretern im Rechtsausschuß deutlich vor Augen geführt worden, daß sie sich mit ihrer Auffassung deutlich in der Minderheit befanden; eine derartige Blamage wollten sie anscheinend vor der Volkskammer nicht noch einmal riskieren. Die SED wiederum hätte am liebsten einen Konflikt vermieden, da sie unmittelbar nach der DDR-Gründung unter dem kritischen Auge der westlichen Öffentlichkeit die parlamentarische Fassade aufrechterhalten wollte. Daher zeigte sie Entgegenkommen in untergeordneten Fragen und verbannte die Auseinandersetzung in den Rechtsausschuß. In der Sache selbst blieb sie freilich hart, so daß das schließlich angenommene Gesetz im Kern ihren Forderungen und nicht denen der bürgerlichen Parteien entsprach.

25 Ob diese Erklärungen bei Dallmann eingingen, war nicht festzustellen; die zweite Sitzung fand nicht, wie von Käthe Kern vorgeschlagen, vor der Volkskammersitzung am 7.12. 1949, sondern erst am 22.3. 1950 statt.

26 Als Drucksache Nr. 26 in: Provisorische Volkskammer, Drucksachen, S. $18 \mathrm{f}$.

27 Provisorische Volkskammer, Sitzungen, S. 82-84. Beckert, Instanz, S. 49 f., irrt, wenn er die Verabschiedung des Gesetzes auf den 8.12.1949 datiert.

28 GBl. 1949, S. $111 \mathrm{f}$. 


\section{Die personelle Besetzung des Obersten Gerichts und der Obersten Staatsanwaltschaft 1949/50}

Wie sehr die Verfassung bereits 1949 dazu diente, die Machtausübung der SEDFührung zu verschleiern, wird an den Modalitäten der personellen Besetzung des Obersten Gerichts und der Obersten Staatsanwaltschaft deutlich. Laut Gesetz mußten die Mitglieder des Obersten Gerichts sowie der Generalstaatsanwalt von der Volkskammer gewählt werden; alle anderen Staatsanwälte der Obersten Staatsanwaltschaft waren auf Vorschlag des Generalstaatsanwalts von der Regierung zu ernennen. Rein formal wurde dem Gesetz dadurch Rechnung getragen, daß die Volkskammer am 7. Dezember den Präsidenten, den Vizepräsidenten, drei Oberrichter des Obersten Gerichts und den Generalstaatsanwalt wählte; am 9. Februar 1950 folgte die Wahl weiterer acht Richter des Obersten Gerichts, und die Regierung ernannte am selben Tag zwei weitere Staatsanwälte der Obersten Staatsanwaltschaft ${ }^{29}$. Damit wurde jedoch letztlich nur legitimiert, was teils mit den anderen Parteien ausgehandelt, teils von der SED im Alleingang festgelegt worden war.

Spätestens seit der SED-Parteivorstandssitzung vom 4. Oktober 1949 stand fest, daß Hilde Benjamin Vizepräsident - und damit die eigentliche Leiterin des Obersten Gerichts - werden sollte ${ }^{30}$. Denn für das Präsidentenamt sahen die SEDSpitze und die sowjetische Führung aus Proporzgründen Eugen Schiffer vor ${ }^{31}$. Angesichts der Verdrängung Schiffers aus der DJV ist es zwar höchst unwahrscheinlich, daß ihm dabei mehr als eine Statistenrolle zugestanden werden sollte; die Außenwirkung einer solchen Besetzung wäre jedoch nicht zu unterschätzen gewesen. Den LDP-Vorsitzenden Kastner und Hamann wurde dies noch am 4. Oktober mitgeteilt; sie waren aber anscheinend nicht sicher, ob Schiffer auf das Angebot eingehen würde und brachten als mögliche Alternative auch von Stoltzenberg ins Gespräch ${ }^{32}$. Schiffer selbst äußerte sich bei dieser Gelegenheit nicht zu seiner Kandidatur, muß aber noch am selben Tag abgelehnt haben, da in den Verhandlungen zwischen den Mitgliedern des CDU-Hauptvorstands und Grotewohl am 6. Oktober für den Präsidentenposten ein NDP-Mitglied vorgesehen wurde ${ }^{33}$. Seine Ablehnung 34 verweist trotz Schiffers zurückliegender Erfahrungen freilich nicht auf einen völligen Bruch mit der SED und der Blockpolitik. Er gab sich vielmehr noch im Dezember 1949 der Illusion hin, daß seine Partei mit der Volkskam-

29 Siehe Provisorische Volkskammer, Sitzungen, S. 85, 217; Protokoll der 15. Sitzung der Provisorischen Regierung, 9. 2. 1950, BAB, DC 20 I/3, Nr. 12, Bl. 4.

30 Stenographische Niederschrift über die Parteivorstandssitzung, 4. 10. 1949, in: Suckut, Entscheidung zur Gründung der DDR, S. 156.

31 Ebenda, S. 155, und Vorschläge des Politbüros an den Parteivorstand der SED zur Bildung einer provisorischen Regierung der DDR, in: DzD II/2, S. 479.

32 Notizen Piecks über die Besprechung mit Hamann und Kastner, 4. 10. 1949, ebenda, S. 544 f. Hamann favorisierte freilich Schiffer: vgl. Protokoll der LDP-Zentralvorstandssitzung (Auszug), 6. 10. 1949 , ebenda, S. 600 .

33 Aktennotiz über die Besprechung zwischen Brandt, Dertinger und Grotewohl, 6.10. 1950, ebenda, S. 608. Die Ablehnung des Präsidentenamtes durch Schiffer ist seit längerem bekannt, nur wird sie irrtümlich auf die Zeit vor seinem Amtsantritt bei der DJV datiert: vgl. Ramm, Schiffer und die Reform, S. 175, Amos, Justizverwaltung, S. 101; Kosch, Biographisches Staatshandbuch, S. 1072, datiert die Absage auf 1948.

${ }^{34}$ Nach Suckut lehnte Schiffer aus Altersgründen ab: ders., Entscheidung zur Gründung der DDR, S. 155, Anm. 21. 
mer die Möglichkeit erhalten habe, "große Politik zu treiben, ohne daß wir gehängt werden können“. Zwar sah er auch die Gefahr, daß diese zu einem „Scheinparlament" gemacht werden könne, wollte dies aber nach Kräften verhindern. Nach wie vor stellte er sich auf den "Standpunkt der Blockpolitik" und umschrieb die Rolle der LDP im Parlament als „loyale Opposition“35.

Bereits vor der SED-Parteivorstandssitzung am 9. Oktober 1949 stand fest, daß Kurt Schumann von der NDPD als Präsident des Obersten Gerichts vorgesehen war ${ }^{36}$. Schumann, damals als Landgerichtspräsident in Erfurt tätig, konnte nicht auf jene lupenreine antifaschistische Vergangenheit zurückblicken, die die SED von derartig hochrangigen Mitgliedern des Staatsapparats erwartete. Geboren 1908 in Eisenach als Beamtensohn, studierte er nach seiner Schulzeit von 1927 bis 1931 in Jena und Göttingen Jura und legte 1935 sein zweites juristisches Staatsexamen ab. Nach kurzzeitiger Tätigkeit bei zwei Rechtsanwälten trat er noch im selben Jahr in den Heeresjustizdienst ein und wurde Wehrmachtsrichter. Seit dem 1. Mai 1937 NSDAP-Mitglied, versah er auch 1939 seinen Dienst als Kriegsgerichtsrat an einem Gericht des Feldheeres, bis er 1942 bei Stalingrad in sowjetische Kriegsgefangenschaft geriet. Dort wurde er Mitglied des Nationalkomitees Freies Deutschland und des Bundes Deutscher Offiziere und besuchte eine AntifaSchule. Diese Biographie prädestinierte ihn geradezu zu einem Engagement in der im Frühjahr und Sommer 1948 auf sowjetische Weisung begründeten NDPD. Unmittelbar nach seiner Rückkehr aus der Kriegsgefangenschaft im September 1948 beteiligte er sich dann auch maßgeblich am Aufbau des Kreisverbands der Nationaldemokratischen Partei in Altenburg, wo er am Landgericht sein Auskommen fand ${ }^{37}$. Anscheinend hatte er bei der NDPD und bei den thüringischen Justizbehörden zwar seine Tätigkeit als Kriegsgerichtsrat, nicht aber seine Mitgliedschaft in der NSDAP angegeben. Die konnte er bis 1958 weitgehend geheim halten, als er in einer Broschüre des Untersuchungsausschusses Freiheitlicher Juristen enttarnt wurde ${ }^{38}$. 1948/49 machte er jedenfalls Karriere: Vom Landgerichtsrat stieg er noch 1948 zum Landgerichtspräsidenten auf und wechselte nach Erfurt, wo er in der gleichen Position auch Vorsitzender einer Großen Strafkammer nach Befehl Nr. 201 wurde. Einen Höhepunkt erreichte seine Laufbahn im Dezember 1949, als er zum Präsidenten des Obersten Gerichts gewählt wurde. Warum die SED-Führung ausgerechnet auf ihn kam, ist nicht klar; vermutlich war die Zahl der vermeintlich unbelasteten Juristen in der als Auffangbecken für ehemalige NS-Anhänger gedachten Partei nicht sehr groß. Schumann erwies sich aus Sicht der SED als eine gute Wahl. Benjamin, die möglicherweise die Vergangenheit Schumanns kannte ${ }^{39}$, charakterisierte ihn mit den Worten: „Gewisses Geltungsbedürfnis, aber sich anpassend und lenkbar.“ ${ }^{40}$ An anderer Stelle schrieb sie: „Seine

35 Aus dem Protokoll der LDP-Zentralvorstandssitzung, 2. 12. 1949, in: DzD II/2, S. $831 \mathrm{f}$.

36 Aus der erweiterten Sitzung des SED-Parteivorstandes, 9. 10. 1949, ebenda, S. 656.

${ }_{37}$ Zu Schumann vgl. Barth u. a., Wer war wer in der DDR, S. 673; SBZ-Biographie, S. 319; BStU, MfS AS 24/55; nach BAB, NSDAP-Mitgliedskartei, erhielt er die Mitgliedsnummer 5777794.

38 Vgl. Bericht der HA V/5 des MfS, 2. 10. 1958, BStU, MfS AP 59/61, Bl. 35; Auszug aus der UfJBroschüre ebenda, Bl. 36 .

39 So ihr Sohn Michael Benjamin in einem Interview mit Andrea Feth: siehe Feth, Benjamin, S. 80, Anm. 313.

40 Anlage zum Schreiben Benjamins an SKK-Justizabteilung, 22. 5. 1950, BAB, DP1 VA Nr. 7939. 
Bereitschaft zur Zusammenarbeit mit dem Vizepräsidenten und den übrigen Mitgliedern der SED ist offensichtlich. Für ihm gegebene Winke ist er stets aufgeschlossen und kommt allen Anregungen bereitwillig nach." ${ }^{41}$ Gerade weil Schumann um seine Gefährdung als ehemaliges NSDAP-Mitglied wußte, war er anscheinend darauf bedacht, sich als treuer Diener der Staatspartei zu zeigen. Das Kalkül der SED, den Präsidentenposten des Obersten Gerichts mit einem loyalen Mitglied einer anderen Blockpartei zu besetzen, selbst aber über die Vizepräsidentin die Zügel fest in der Hand zu behalten ${ }^{42}$, ging auf.

Die verbleibenden drei Oberrichterstellen sollten nach dem Willen der SEDFührung von Mitgliedern der anderen Parteien besetzt werden. Deren Vorschlagsrecht war dabei freilich stark eingeschränkt, was aus Piecks verräterischer Formulierung vom 4. Oktober 1949 hervorgeht: „Als Beisitzer des Obersten Gerichthofes wird von uns Hilde Benjamin vorgeschlagen; die anderen Parteien haben ihre Vertreter noch nicht benannt. Wir haben in Aussicht genommen, von der CDU [Carl Günter] Ruland vorzuschlagen; die beiden anderen Parteien werden morgen ihre Vorschläge machen, nachdem wir ihnen das nahegelegt haben." ${ }^{43}$ Aufgrund der Bedeutung des Obersten Gerichts für die Herrschaftssicherung beanspruchte die SED offensichtlich nicht nur ein Mitspracherecht, sondern sogar die Vorauswahl. Ruland, seit Mai 1948 Oberlandesgerichtspräsident in Dresden, zählte für die Einheitspartei „zu den fortschrittlichen bürgerlichen Juristen “ und wurde wie folgt charakterisiert: „Er verschließt sich nie den Notwendigkeiten der Zeit und geht laufend mit der Entwicklung mit. Für die in Aussicht genommenene Stellung beim Obersten Gericht scheint Ruland nach meiner Ansicht durchaus geeignet." ${ }^{44}$ Als sich bei den Beratungen über das Gesetz zur Errichtung des Obersten Gerichtes und der Obersten Staatsanwaltschaft jedoch herausstellte, daß Ruland zu den heftigsten Kritikern des SED-Entwurfs gehörte, schied er als Kandidat für einen Oberrichterposten umgehend aus. An seiner Stelle griff man auf Wilhelm Heinrich zurück, der seit Dezember 1945 als Ministerialdirektor der mecklenburgischen Justizverwaltung vorgestanden hatte. Als Rechtsanwalt und Notar hatte er das Dritte Reich in Stettin miterlebt, ohne sich im Widerstand zu engagieren. 1945 trat das ehemalige DDP-Mitglied der CDU bei. Weder in der mecklenburgischen Union noch in der Justizverwaltung gehörte er zu denen, die sich der zunehmenden Gleichschaltung seit 1948 widersetzten ${ }^{45}$. Daher erschien er der SED hinreichend loyal, um im Dezember 1949 als Oberrichter gewählt zu werden. Auch in Heinrich hatte sich die Einheitspartei nicht getäuscht: Bis 1964 blieb er als Oberrichter am Obersten Gericht, ohne jemals oppositionell hervorzutreten ${ }^{46}$.

41 Beurteilung Schumanns, o.D., gez. Benjamin und Ziegler, BStU, MfS AP 59/61, Bl. 3.

42 Der Spiegel 12/1959, S. 30, zitierte folgende Aussage Benjamins: „Ich bin über jeden seiner [Schumanns] Schritte informiert, denn ich habe den Mann meiner Wirtschafterin Sophie als Fahrer bei ihm eingesetzt; er berichtet mir alles, was Schumann tut."

43 Stenographische Niederschrift über die Parteivorstandssitzung, 4. 10. 1949, in: Suckut, Entscheidung zur Gründung der DDR, S. 156.

44 Beurteilung über Ruland, o.D. [vermutlich Oktober 1949], BAB, DP1 VA Nr. 7939.

45 Vgl. Heinrich, Politische Erinnerungen und Erkenntnisse, insbesondere S. 78, 90 f., 96-100, 110; SBZ-Handbuch, S. 925; Bartusel, Politisierung der Justiz in Mecklenburg-Vorpommern, S. $31 \mathrm{f}$.

4h Siehe die Charakteristik Heinrichs von Benjamin vom 22.5. 1950, BAB, DP1 VA Nr. 7939; vgl. 
Für die DBD kandidierte Maximilian Stegmann. Geboren 1920 als Sohn eines Taxifahrers, hatte er 1938 eine Banklehre begonnen und trat nach 1945 in den gehobenen Justizdienst beim Amtsgericht Zwickau ein, bevor er 1946 den ersten sächsischen Richterlehrgang besuchte. Anschließend am Amtsgericht Auerbach und am Landgericht Zwickau eingesetzt - unter anderem in einer 201-Strafkammer -, besuchte er von April bis Juni 1949 einen Dreimonatslehrgang für Juristen an der DVA. Parteipolitisch engagierte sich Stegmann 1945 zunächst in der SPD und, nach 1946, in der SED. Erst im November 1949 trat er auf Weisung der SEDFührung in die DBD ein, damit diese ihn als Kandidaten für die Richterwahl in der Volkskammer präsentieren konnte. Ein Parteisoldat, der sich so ergeben erwies, daß er im Parteiauftrag sogar die Partei wechselte, war dazu prädestiniert, der SED keine Schwierigkeiten zu bereiten. Auch die in ihn gesetzten Hoffnungen erfüllten sich; die SED-Richter des Obersten Gerichts behandelten ihn „wegen seines politischen Auftretens stets wie einen Genossen“47.

Der einzige aus Sicht der SED potentiell unsichere Kandidat war Kurt Cohn (LDP). Als jüdischer Kaufmannssohn 1899 geboren, studierte er von 1918 bis 1922 Jura und war nach Referendariat und Promotion 1925 an den Amtsgerichten Plauen und Leipzig und von 1929 bis 1933 am Landgericht Chemnitz als Landgerichtsrat tätig. 1933 wurde der Jurist, der der DDP und dem Republikanischen Richterbund angehört hatte, aufgrund des "Gesetzes zur Wiederherstellung des Berufsbeamtentums" aus dem Justizdienst entlassen; hauptberuflich war er seit 1934 als geschäftsführender Vorsitzender des Landesverbands Mitteldeutschland des Centralvereins deutscher Staatsbürger jüdischen Glaubens tätig. Nach dem Novemberpogrom von 1938 bis 1939 im KZ Buchenwald inhaftiert, emigrierte er anschließend nach England, wo er - unterbrochen durch einen Aufenthalt in einem Internierungslager in Australien - bis 1947 blieb. Unmittelbar nach seiner Rückkehr nach Chemnitz im April 1947 wurde er erneut als Landgerichtsrat eingesetzt, im August zum Landgerichtsdirektor befördert und zum 1. Januar 1948 von Kastner als Ministerialrat ins sächsische Justizministerium einberufen. Nachdem Kastner zum 1. April 1948 an die DWK gewechselt war, zog er Anfang 1949 auch Cohn in die Berliner Behörde ${ }^{48}$. Cohn, der der SED-Justizabteilung als „Rechtsstaatler westlicher Prägung“ und „hemmender, schwieriger und rückschrittlicher Formaljurist" erschien"4, trat am 1. April 1949 der LDP bei und wurde ab September 1949 Vorsitzender des Rechtsausschusses seiner Partei. Trotz der Vorbehalte Benjamins gegen seine Person ${ }^{50}$ wurde Cohn von der SED akzeptiert, möglicherweise deshalb, weil man die LDP nicht unnötig vor den Kopf stoßen wollte und angesichts der Loyalität der anderen Oberrichter glaubte, diesen

auch den Treffbericht des MfS mit GI „Spree“ (Rothschild) vom 17.3. 1955, BStU, MfS AIM 19222/63, T.II, Bl. 132.

47 Zu Stegmann, den das MfS am 3. 3. 1958 als GI „Lutz“ verpflichtete, siehe den Vorschlag zur Kontaktaufnahme, 18. 12. 1957, BStU, MfS AIM 9759/84, Bd. 1, Bl. 68-72 (das Zitat Bl. 70), sowie die Beurteilungen der DVA vom 28. 6. 1949, und Benjamins vom 22. 5. 1950, BAB, DP1 VA Nr. 7939. Im April 1957 schied er aus dem Obersten Gericht aus, um Rechtsanwalt zu werden.

48 Zum Lebenslauf von Cohn siehe Auszug aus der Personalakte des Dr. Cohn, 2. 9. 1952; Kurzbiographie, o.D., BStU, MfS AKK 3020/79, Bl. 3, 44 f.; Biographisches Handbuch, S. 115.

49 Beurteilung über Cohn, o.D. [vermutlich Frühjahr 1949], BAB, DP1 VA Nr. 7939.

so Vgl. Beckert, Instanz, S. 46, 322, Anm. 56. 
ausgeprochen bürgerlichen Juristen einbinden zu können. „Wider Erwarten“, so Benjamin, gelang dies: Er wurde zwar mißtrauisch beobachtet, unternahm vor allem in der Anfangszeit des Obersten Gerichts vereinzelte Vorstöße gegen SEDRichter und „die fortschrittliche Linie in der Rechtsprechung", fügte sich dann aber doch in das ,Kollektiv' ein und blieb dort bis zum Eintritt in den Ruhestand im Jahre 197451.

Mit der einstimmigen Wahl Schumanns, Benjamins, Heinrichs, Stegmanns und Cohns durch die Volkskammer am 7. Dezember 1949 standen erst Präsident und Vizepräsident sowie die Senatsvorsitzenden fest, die laut Gesetz Oberrichter sein mußten. Da Hilde Benjamin sich frühzeitig entschloß, den für erstinstanzliche Sachen zuständigen ersten Senat zu leiten, ergab sich bereits aus der Wahl die Bildung von insgesamt vier Senaten, die jeweils drei Mitglieder aufweisen mußten. Es fehlten also noch acht Richter, die möglichst rasch zu bestimmen waren. Die Vorauswahl nahm Benjamin in Absprache mit der SED-Unterabteilung Justiz vor und übersandte die Liste dem Vorsitzenden der Zentralen Kommission für Staatliche Kontrolle, Fritz Lange ${ }^{52}$, der ebenfalls sein Plazet geben mußte. Bevor die Aufstellung der Regierung vorgelegt wurde, gab am 23. Januar 1950 das SED-Sekretariat seine Zustimmung ${ }^{53}$. Regierung und Volkskammer traten erst am Ende des Nominierungsverfahrens in Aktion: Formell auf Antrag von Regierungsstaatssekretär Geyer wurden am 9. Februar die acht Richter der Volkskammer zur Wahl vorgeschlagen, die noch am selben Tag einstimmig erfolgte ${ }^{54}$. Anders als bei der Besetzung der Spitzenpositionen des Obersten Gerichts wurde bei der Auswahl der Beisitzer nicht mehr auf eine gleichmäßige Berücksichtigung aller Parteien geachtet: Von den acht Richtern gehörten jeweils einer der CDU (Wolfgang Melz) und der LDP (Alfred Trapp) an; die verbleibenden sechs waren SED-Mitglieder.

Bemerkenswert war, daß sich unter den insgesamt 13 Richtern des Obersten Gerichts mit Maximilian Stegmann, Alfred Trapp, Helene Drechsler und Elfriede Göldner vier Volksrichter befanden. Dies läßt sich auf den maßgeblichen Einfluß Benjamins zurückführen, die freilich auch versucht hatte, nur äußerst qualifizierte Personen zu gewinnen. Trapp, geboren 1915, Absolvent des zweiten sächsischen Richterlehrgangs, war am 1. Juli 1949 zum Präsidenten des Landgerichts Plauen ernannt worden und wurde auch von Benjamin wegen seinen herausragenden fachlichen Kenntnisse geschätzt. Helene Drechsler (Jahrgang 1908) vom zweiten brandenburgischen Lehrgang, zum Zeitpunkt ihrer Wahl Oberrichterin am Landgericht Eberswalde, wurde vom Potsdamer Justizministerium als „eine der besten Richterkräfte des Landes bezeichnet“. Elfriede Göldner (geboren 1915), die Ben-

51 Charakteristik Cohns von Benjamin, 22. 5. 1950, BAB, DP1 VA Nr. 7939; Aktennotiz betr. Cohn, 18. 3. 1955, BStU, MfS AKK 3020/79, Bl. 17.

52 Benjamin an Lange, 28. 12. 1949, BAB, DP1 VA Nr. 7939; die von ihr übersandte Liste trug die Überschrift: „Mit der Abteilung Justizdienst [sic] des Zentralsekretariats vorgeschlagene Besetzung der Senate". Bis zum Sekretariatsbeschluß vom 23. Januar wurden noch einige Umstellungen vorgenommen und die ursprünglich vorgesehenen Fritz Pogorschelsky, Helmut Ostmann und Ernst Hegewisch gestrichen.

53 Protokoll der Sekretariatssitzung, 23. 1. 1950, SAPMO, DY 30 J IV 2/3/80, TOP 35.

54 Protokoll der 15. Sitzung der Provisorischen Regierung, 9. 2. 1950, DC 20 I/3, Nr. 12, Bl. 4, und Geyer an Ministerrat, 4. 2. 1950, ebenda, Bl. 58; Provisorische Volkskammer, Sitzungen, S. 217. 
jamin persönlich seit dem Krieg kannte und von dieser zum Besuch des ersten brandenburgischen Richterlehrgangs veranlaßt worden war, leitete seit Februar 1949 das Amtsgericht in Berlin-Pankow. Alle drei waren außerdem an 201-Strafkammern, teilweise als Vorsitzende, tätig gewesen; Drechsler und Göldner erwarben sich durch den Besuch eines DVA-Juristenlehrgangs eine gern gesehene $\mathrm{Zu}$ satzqualifikation ${ }^{55}$.

Die fachliche Qualifikation der fünf gewählten Richter mit akademischer Juristenausbildung stand außer Frage. Hans Rothschild (SED), Jahrgang 1895, hatte in Prag Jura studiert, war 1921 promoviert worden, und hatte nach dem Äquivalent des deutschen Referendariats die Advokatenprüfung abgelegt. Ende 1945 mit einem der Antifa-Transporte in die SBZ umgesiedelt, war er nach einem sechswöchigen Lehrgang auf der Landesparteischule zunächst bei der Staatsanwaltschaft, dann bei der Generalstaatsanwaltschaft in Dresden eingesetzt worden, wo er in erster Linie Revisionssachen bearbeitet hatte ${ }^{56}$. Heinrich Löwenthal (SED), geboren 1913, hatte in Berlin und Bern ein juristisches Universitätsstudium absolviert, war aber nicht zum Referendariat zugelassen worden; seit dem 15. Februar 1949 war er als Oberstaatsanwalt am Ost-Berliner Kammergericht tätig57. Der Volljurist Kurt Paschke (SED), Jahrgang 1880, war seit September 1945 als Senatspräsident am Oberlandesgericht Gera angestellt und nach dem Tode von Arno Barth sogar mit der Führung der Geschäfte des Oberlandesgerichtspräsidenten beauftragt worden ${ }^{58}$. Walter Ziegler (SED), geboren 1912, hatte während des Dritten Reiches seine juristische Ausbildung absolviert und war nach 1945 in den Justizdienst des Landes Sachsen-Anhalt eingetreten, wo er im Oktober 1949 zum Landgerichtspräsidenten in Halle ernannt wurde ${ }^{59}$. Auch Wolfang Melz (CDU), Jahrgang 1907, konnte eine akademische Juristenausbildung vorweisen und hatte zuletzt dem Amtsgericht Görlitz als Direktor vorgestanden ${ }^{60}$.

Bei der Auswahl dieser acht Richter wurden an den kommunistischen kaderpolitischen Prinzipien Abstriche vorgenommen. Lediglich zwei von ihnen entstammten nachweislich Arbeiterfamilien ${ }^{61}$, und nur drei hatten vor 1933 der Kommunistischen Partei angehört ${ }^{62}$. Vier der acht Männer und Frauen hatten das Dritte Reich nicht unbeschadet überstanden. Da Rothschild als Anwalt in Teplitz seit 1930 insbesondere proletarische Organisationen vertreten hatte, floh er nach dem Münchner Abkommen zunächst aus dem Sudetenland nach Prag und emigrierte nach der „Zerschlagung der Rest-Tschechei“ im März 1939 nach Eng-

55 Vgl. die biographischen Angaben zu Trapp, Drechsler und Göldner in DC 20 I/3, Nr. 12, Bl. 59 f.; Charakteristik Trapps von Benjamin, 22. 5. 1950, Stellungnahme des Potsdamer Justizministeriums zu Drechsler, o.D., BAB, DP1 VA Nr. 7939; Erinnerungen Elfriede Göldners, SAPMO, SgY 30 Nr. 2077.

56 Lebenslauf Rothschild, 13. 2. 1951, SAPMO, DY 30 IV 2/11/176, Bl. 378, 380; Lebenslauf Rothschild, 17. 3. 1950, BStU, MfS, AIM 19222/63, T.I, Bl. 15.

57 Lebenslauf Löwenthal, 14. 2. 1951, SAPMO, DY 30 IV 2/11/175, Bl. 222-225, 230.

58 Lebenslauf Paschke, o.D. [Februar 1951], SAPMO, DY 30 IV 2/11/176, Bl. $26 \mathrm{f}$.

59 Lebenslauf Ziegler, 14. 2. 1951, SAPMO, DY 30 IV 2/11/177, Bl. 760-762; Bericht betr. Ziegler, 30. 5. 1959, BStU, MfS AKK 4628/80, unpaginiert.

60 Auszug aus der Personalakte von Melz, BStU, MfS AP 6926/71, Bl. 8.

61 Elfriede Göldner, geborene Röblitz, und Walter Ziegler; Helene Drechslers Herkunft war nicht festzustellen.

62 Rothschild (Kommunistische Partei der Tschechoslowakei), Ziegler und Drechsler. 
land ${ }^{63}$. Elfriede Göldner hatte zwar nicht der KPD angehört, sich aber in den Anfangsjahren des Dritten Reiches an der Herstellung und Verbreitung regimekritischer Flugblätter des kommunistischen Jugendverbands beteiligt; infolgedessen war sie 1937 verhaftet und zu zwei Jahren und drei Monaten Gefängnis verurteilt worden ${ }^{64}$. Heinrich Löwenthal war als sogenannter „Mischling“ - sein Vater entstammte einer jüdischen Arztfamilie - und als Mitglied der „Deutschen Liga für Menschenrechte" bedroht und entzog sich möglichen Repressionen im März 1933 durch Flucht nach Bern, wo er von April 1934 bis Januar 1936 sein juristisches Studium fortsetzte. Er kehrte nach Berlin zurück, fand jedoch aufgrund seiner jüdischen Herkunft nur Arbeit bei jüdischen Anwälten65. Paschke, seit 1930 SPDMitglied, war 1933 für drei Monate in "Schutzhaft" genommen worden, verlor aufgrund des "Gesetzes zur Wiederherstellung des Berufsbeamtentums" seine Stellung im Justizdienst als Oberlandesgerichtsrat in Breslau und erhielt erst 1940 wieder eine Anstellung als Bankangestellter66. Die anderen hingegen hatten das Dritte Reich relativ unbeschadet überstanden. Trapp, Jahrgang 1915, hatte eine kaufmännische Lehre absolviert und war bis zur Einziehung zur Wehrmacht bei Kriegsausbruch bei AEG tätig gewesen ${ }^{67}$. Melz hatte zwar von 1930 bis 1933 dem Zentrum angehört, blieb aber ohne Karriereknick im Justizdienst beschäftigt, wozu wahrscheinlich seine Mitgliedschaft im NSRB und in der NSV beitrug68. Ziegler war 1931 der KPD beigetreten, hatte in der Partei jedoch keine Funktionen übernommen. 1933 brach er die Verbindungen zur KPD ab und konnte sein 1932 begonnenes Studium fortsetzen. Nach seinem ersten Examen im Jahre 1937 trat er dem NSRB bei, um im Referendariat einen Unterhaltszuschuß zu bekommen. Ein weiterer aus Sicht der SED ,dunkler Fleck' in seiner Karriere war, daß er 1945 nicht in die KPD, sondern in die SPD eingetreten war und erst mit der Vereinigung der beiden Arbeiterparteien SED-Mitglied wurde. Seine Karriere behinderte dies jedoch nicht: Mit dem Wechsel Benjamins zum Justizministerium im Juli 1953 wurde er Vizepräsident des Obersten Gerichts ${ }^{69}$.

Bei der Einstellung der Richter des Obersten Gerichts 1949/50 war neben der eingeschränkten Beachtung des parteipolitischen Proporzes die fachliche Eignung ausschlaggebend. Demgegenüber trat die Bedeutung der allgemeinen kaderpolitischen Grundsätze der SED deutlich zurück. An der ,Mindestanforderung' - keine Belastung durch NSDAP-Mitgliedschaft - hielt man zwar, abgesehen von dem Sonderfall Schumann, fest; die Herkunft aus bürgerlichen Verhältnissen, Zugehörigkeit zu einer anderen als der kommunistischen Partei vor 1933 und zum NSRB und zur NSV nach 1933 wurden jedoch angesichts des Mangels an gut qualifizierten kommunistischen Fachjuristen akzeptiert, wenn von einer insgesamt DDR-

63 Lebenslauf Rothschild, 13. 2. 1951, SAPMO, DY 30 IV 2/11/176, Bl. 378-380; Lebenslauf Rothschild, 17. 3. 1950, BStU, MfS, AIM 19222/63, T.I, Bl. 15.

64 Erinnerungen Elfriede Göldners, SAPMO, SgY 30 Nr. 2077; Betr.: Göldner, 19. 3. 1960, BStU, MfS AKK 7460/79, Bl. 37.

65 Lebenslauf Löwenthal, 14. 2. 1951, SAPMO, DY 30 IV 2/11/175, Bl. 222-226.

66 Lebenslauf Paschke, o.D. [Februar 1951], SAPMO, DY 30 IV 2/11/176, Bl. $26 \mathrm{f}$.

67 Bericht betr. Trapp, 28. 8. 1952, BStU, MfS AP 6949/71, Bl. 5.

68 Auszug aus der Personalakte von Melz, BStU, MfS AP 6926/71, Bl. 8.

69 Lebenslauf Ziegler, 14. 2. 1951, SAPMO, DY 30 IV 2/11/177, Bl. 760 f.; Bericht betr. Ziegler, 30.5. 1959, BStU, MfS AKK 4628/80, unpaginiert; Barth u.a., Wer war wer in der DDR, S. 824. 
loyalen Haltung ausgegangen werden konnte. Hilde Benjamin als der für die Personalentscheidungen Verantwortlichen war klar, daß bei Kassationsentscheidungen juristischem Sachverstand eine sehr viel größere Bedeutung zukam als einer lupenreinen proletarisch-politischen Vergangenheit.

Während das Oberste Gericht mit seinen insgesamt 13 Richtern im Februar 1950 arbeitsfähig war, dauerte dies bei der Obersten Staatsanwaltschaft bis zum September 1950. Vor der DDR-Gründung hatten KPdSU- und SED-Führung sich auf Ernst Melsheimer als Generalstaatsanwalt der DDR geeinigt ${ }^{70}$. In der Regierungssitzung vom 1. Dezember 1949 vorgeschlagen, wählte ihn die Volkskammer zusammen mit der Spitze des Obersten Gerichts am 7. Dezember in sein neues $\mathrm{Amt}^{71}$. Die übrigen Staatsanwälte der Obersten Staatsanwaltschaft wurden, wie vom Gesetz vorgesehen, auf Vorschlag des Generalstaatsanwalts von der Regierung ernannt. Da keine Beteiligung der Volkskammer an dem Verfahren vorgesehen war, fiel es der DDR-Führung offensichtlich leichter, bei der Besetzung dieser Posten auf die Berücksichtigung von Blockprinzipien zu verzichten und ausschließlich SED-Mitglieder zu berufen. Vor der Einschaltung der Regierung wurde jedoch auch in diesen Fällen meistens eine Entscheidung des SED-Sekretariats herbeigeführt.

Dies galt auch für Otto Grube und Karl Kohn, deren Einsatz bei der Obersten Staatsanwaltschaft vom Sekretariat am 23. Januar 1950 beschlossen wurde. Ihre Ernennung durch die Regierung am 9. Februar war demgegenüber reine Formsache $^{72}$. Kohn war ein 1904 geborener sudetendeutscher Volljurist jüdischer Abstammung, der seine juristische Ausbildung von 1923 bis 1933 in Prag absolviert hatte, bevor er sich 1933 in Teplitz-Schönau als Rechtsanwalt selbständig machte ${ }^{73}$. Seit 1936 Mitglied der Deutschen Sozialdemokratischen Partei der Tschechoslowakei, arbeitete er als Anwalt für die „Rote Hilfe“ und leistete politischen Flüchtlingen aus Deutschland meist unentgeltlichen Rechtsbeistand. Nach dem Münchener Abkommen zunächst nach Prag geflohen, emigrierte Kohn 1939 nach England, wo er sich seit 1940 als Buchhalter bei verschiedenen Firmen durchschlug und 1942 der Kommunistischen Partei der Tschechoslowakei beitrat. Ende Oktober 1945 aus eigenem Entschluß zurückgekehrt, um „am Aufbau einer sozialistischen CSR mitzuwirken", schlug ihm auch bei den Kommunisten eine „chauvinistische[.] Grundstimmung“ entgegen, so daß er auf Rat der Partei Anfang 1946 mit einem Antifa-Transport nach Sachsen auswanderte. Dort trat er unverzüglich der KPD bei und wurde zunächst als Staatsanwalt in Leipzig eingesetzt, bevor ihn Generalstaatsanwalt Schroeder im Mai 1946 zu seinem Stellvertreter berief. Kohn engagierte sich 1946/47 auch als Dozent an der sächsischen

70 Vorschläge des Politbüros zur Bildung einer provisorischen Regierung der DDR, in: DzD II/2, S. 479; Stenographische Niederschrift über die Parteivorstandssitzung, 4. 10. 1949, in: Suckut, Entscheidung zur Gründung der DDR, S. 155.

71 Protokoll der 8. Sitzung der Provisorischen Regierung, 1.12. 1949, Bl. 139; Provisorische Volkskammer, Sitzungen, S. 85.

72 Protokoll der Sekretariatssitzung, 23. 1. 1950, SAPMO, DY 30 J IV 2/3/80, TOP 38; Protokoll der 15. Sitzung der Provisorischen Regierung, 9. 2. 1950, DC 20 I/3, Nr. 12, Bl. 4; Geyer an Ministerrat, 4. 2. 1950, ebenda, Bl. 61 .

73 Vgl. Lebenslauf Kohn, 29. 1. 1951, SAPMO, DY 30 IV 2/11/174, Bl. 233-235; Lebenslauf Kohn, 26. 11. 1952, BStU, MfS AP 3860/82, Bl. 3-6. 
Volksrichterschule, wo er sich - allerdings vergebens - für eine subsidiär anzuwendende Generalklausel aussprach, „nach der alle Handlungen strafbar sein sollten, die vorsätzlich die Interessen der antifaschistischen Demokratie beeinträchtigten "74. Seine Bewährungsprobe bestand er 1948 bei dem ersten großangelegten, von der ZKK vorbereiteten Prozeß gegen Textilfabrikanten in Glauchau-Meerane, in dem er die Anklage vertrat ${ }^{75}$.

Otto Grube (Jahrgang 1913), der seit 1931 dem KJVD angehört hatte, betätigte sich auch nach 1933 für den kommunistischen Jugendverband, wurde 1935 verhaftet und im Jahr darauf zu sieben Jahren Zuchthaus verurteilt. Im Anschluß an seine Strafverbüßung nach Buchenwald überführt, kam er erst mit der Befreiung des Konzentrationslagers nach fast zehnjähriger Haft wieder frei. Unmittelbar nach der Wiedergründung der KPD in Dresden im Juni 1945 trat er der Partei bei, die ihn zunächst zur Kriminalpolizei, dann zum Jugendausschuß, zum 1. März 1946 aber zum Richterlehrgang in Bad Schandau schickte. Seit Oktober 1946 war er als Staatsanwalt tätig, zunächst in Leipzig, dann, im Anschluß an einen Kurzlehrgang für Juristen an der DVA, ab Februar 1949 unter Beförderung zum Oberstaatsanwalt in Plauen ${ }^{76}$. Schon bald nach seinem Eintritt in die Oberste Staatsanwaltschaft verpflichtete er sich im Juni 1950 dem MfS und wurde unter dem Decknamen „Paul“" als Geheimer Informant registriert ${ }^{77}$.

Verstärkung erhielt die Oberste Staatsanwaltschaft mit der Ernennung von Gustav Rieger am 30. März 195078. Geboren 1908, kam er, wie Kohn und Rothschild, aus dem Sudetenland. Nach Wehrdienst, Studium und Promotion an der Universität Prag war er 1935 von der Anwaltskanzlei von Rothschild und Beckmann eingestellt worden; 1946 gab er an, damals in die Kommunistische Partei eingetreten zu sein. Im Zuge der Besetzung des Sudetenlandes durch die Deutschen verhaftet, kam er im April 1939 nach Dachau und wurde im August nach Mauthausen verlegt. Ende 1942 freigelassen, schlug er sich mit verschiedenen Tätigkeiten durch; 1945 gelang es ihm, nach Reichenberg zurückzukehren. 1946 siedelte er mit einem der letzten Antifa-Transporte in die SBZ über und wurde dem Generalstaatsanwalt von Sachsen-Anhalt als Staatsanwalt zugewiesen. Nachdem er sich als aufsichtsführender Staatsanwalt nach Befehl Nr. 201 beim Landgericht Halle bewährt hatte, wurde er Weihnachten 1949 zum Oberstaatsanwalt beim Landgericht Magdeburg berufen 79 .

Daß als Staatsanwälte ausschließlich ideologisch zuverlässige SED-Mitglieder in Frage kamen, zeigt auch die Ernennung der als Stellvertreterin Melsheimers vorgesehenen Hildegard Heinze, die sich bereits als Leiterin der Kontrollabtei-

74 Lebenslauf Kohn, 18. 3. 1970, ebenda, Bl. 12f. Vgl. dazu auch Kohn, Der Beginn einer neuen Justiz nach 1945, 14. 11. 1974, SAPMO, SgY 30 Nr. 1730, Bl. 10-16.

75 Lebenslauf Kohn, 18. 3. 1970, BStU, MfS AP 3860/82, Bl. 12. Der ZKK-Vorsitzende Lange hatte "einen besonders tüchtigen, energischen und einwandfreien Staatsanwalt" angefordert, zit. nach Klawitter, Rolle der ZKK, S. 31.

76 Lebenslauf Grube, 30. 1. 1950, SAPMO, DY 30 IV 2/11/172, Bl. 403-405; Lebenslauf Grube, o.D., BStU, MfS AIM 1287/89, T.I, Bl. 48.

77 Aktenvermerk, 28. 4. 1954, ebenda, Bl. 52, demzufolge Grube am 29.6. 1950 als GI registriert wurde.

78 Protokoll der Sekretariatssitzung am 3. 3. 1950, SAPMO, DY 30 J IV 2/3/89, TOP 8; Protokoll der 21. Sitzung der Provisorischen Regierung, 30. 3. 1950, BAB, DC 20 I/3, Nr. 15, Bl. 78.

79 Lebenslauf Rieger, 13. 2. 1951, SAPMO, DY 30 IV 2/11/176, Bl. 300-305. 
lung in DJV und MdJ bewährt hatte. Außerdem wurde sie an der Durchführung der Waldheimer Prozesse beteiligt. Bereits am 6. April nahm sie an der Beratung über die Einrichtung der Sonderstrafkammern teil; Anfang Mai wurde sie in die Kommission berufen, die die Arbeit des Untersuchungsorgans und der Strafkammern in der Strafanstalt Waldheim koordinierte und lenkte ${ }^{80}$. Danach sollte sie vom MdJ zur Obersten Staatsanwaltschaft wechseln, wohl um dort den Aufbau der Behörde voranzutreiben. Melsheimer schlug jedenfalls vor, Heinze mit Wirkung vom 17. Juli zum Staatsanwalt bei der Obersten Staatsanwaltschaft zu ernennen. Dies traf innerhalb der Regierung am 10. August auf den heftigen Widerspruch Otto Nuschkes, der auf Veranlassung seines Parteifreundes Helmut Brandt eine Überprüfung der Waldheim-Urteile anstrebte und den Aufstieg Heinzes in die Oberste Staatsanwaltschaft verhindern wollte ${ }^{81}$. Nachdem ihm in der Regierungssitzung vom 17. August eine nochmalige Verschiebung der Ernennung gelungen war, ließ Grotewohl am 31. August sowohl über den Antrag zur Überprüfung der Waldheim-Urteile als auch über die Ernennung von Hildegard Heinze abstimmen. In beiden Fällen wurden Nuschke und die anwesenden CDU-Minister Georg Dertinger und Friedrich Burmeister überstimmt, und Heinze konnte nun endlich zur Obersten Staatsanwaltschaft wechseln ${ }^{82}$.

Bis Anfang September 1950 war damit die Oberste Staatsanwaltschaft mit insgesamt fünf Personen besetzt, die nicht nur der SED angehörten, sondern auch die Gewähr für absolute Loyalität zu bieten schienen. Bis auf Melsheimer und Heinze waren sie zuvor als Staatsanwälte tätig gewesen und verfügten somit auch über die erforderliche Erfahrung. Auffällig ist schließlich, daß zwei von ihnen aus dem Sudetenland kamen und zu jenen Antifa-Kadern gehörten, die zur Unterstützung der KPD/SED von der Tschechoslowakei 1945/46 in die SBZ transferiert wurden ${ }^{83}$. Zusammen mit dem Sudetendeutschen Hans Rothschild vom Obersten Gericht gehörten sie zu den wenigen Personen, die sowohl eine kommunistische Vergangenheit als auch ein juristisches Studium aufwiesen und von daher für den Aufstieg in die obersten Justizorgane geradezu prädestiniert waren.

\section{Die strukturelle und personelle Entwicklung des Obersten Gerichts (1950-1952)}

Bevor das Oberste Gericht in Aktion treten konnte, mußten eine Reihe struktureller Entscheidungen getroffen werden. Dabei hielt sich Benjamin eng an die Gesetzesgrundlage, die freilich einiges offengelassen hatte. So galt es zunächst, Anzahl, Zuständigkeit und Zusammensetzung der Senate festzulegen. Die Regie-

$80 \mathrm{Vgl}$. Eisert, Waldheimer Prozesse, S. 57, 107.

81 Protokoll der 36. Sitzung der Provisorischen Regierung, 10. 8. 1950, BAB, DC 20 I/3, Bl. 6; beigefügt war der Antrag an den Ministerrat, auf Melsheimers Vorschlag Heinze mit Wirkung vom 17. 7. 1950 zum Staatsanwalt zu ernennen, ebenda, Bl. 213. Zu Nuschkes Absichten vgl. Brandt, Hinter den Kulissen, S. 9.

82 Protokolle der 37. und 39. Sitzung der Provisorischen Regierung, 17. 8., 31. 8. 1950, BAB, DC 20 I/3, Nr. 27, Bl. 7, Nr. 28, Bl. 100; Brandt, Hinter den Kulissen, S. 9.

83 Vgl. dazu Foitzik, Kadertransfer. 
rung legte auf Vorschlag Schumanns am 9. Februar 1950 fest, daß, wie durch die Wahl der obersten Richter präjudiziert, vier Senate zu bilden seien ${ }^{84}$. Daß es dabei nicht bleiben würde, war zu diesem Zeitpunkt schon klar: Denn Benjamin führte in der ersten Sitzung des Präsidiums des Obersten Gerichts am 13. Februar aus, daß in dem Strukturplan für ihre Behörde von 69 Stellen und sechs Senaten ausgegangen worden sei ${ }^{85}$. Schumann hatte der Regierung nur mitgeteilt, daß ein Senat für erstinstanzliche Strafsachen, ein weiterer für Kassationen in Zivilsachen und zwei für Kassationen in Strafsachen angestrebt seien. Am 21. Februar wurde dies vom Präsidium des Obersten Gerichts präzisiert, das den ersten Senat für erstinstanzliche Strafsachen, den zweiten für die Kassationen in Wirtschaftsstrafverbrechen, den dritten für Kassationen in Strafsachen nach Befehl Nr. 201 und in allgemeinen Strafsachen und den vierten für Kassationen in Zivilsachen für zuständig erklärte. Auf Vorschlag von Schumann und Benjamin faßte das Präsidium ebenfalls einen einstimmigen Beschluß über die Besetzung der Senate und regelte die Vertretungen. Dabei wurden die insgesamt vier LDPund CDU-Richter gleichmäßig auf alle Senate verteilt, so daß sie von den jeweils zwei SED-Richtern (zu denen auch das DBD-Mitglied Stegmann gezählt werden muß), überstimmt werden konnten ${ }^{86}$. Dem ersten Senat gehörten Benjamin, Rothschild und Trapp, dem zweiten Stegmann, Melz und Drechsler, dem dritten Cohn, Löwenthal und Göldner und dem vierten Heinrich, Paschke und Ziegler $\mathrm{an}^{87}$.

Weitere Festlegungen beinhaltete die vom Präsidium gebilligte „Vorläufige Geschäftsordnung", die die Regierung am 16. März bestätigte ${ }^{88}$. Sie ging im ersten Teil auf die „Organe“ des Obersten Gerichts ein, wozu sie den Präsidenten und den Vizepräsidenten, das Präsidium, den Großen Senat und die Senate zählte; der zweite Teil enthielt ergänzende Verfahrensbestimmungen etwa über Urteile, Beschlüsse und Entscheidungsammlungen. Eine Reihe dieser Ausführungen blieben tote Buchstaben: So trat der Große Senat, der entscheiden mußte, wenn ein Senat in einer grundlegenden Rechtsfrage von einem anderen Senat abweichen wollte, nie zusammen, da dies am Obersten Gericht der DDR aus naheliegenden Gründen nie vorkam ${ }^{89}$. Die Geschäftsordnung enthielt des weiteren die wichtige Aussage, daß dem Vizepräsidenten unter anderem „alle Angelegenheiten des Perso-

84 Protokoll der 15. Sitzung der Provisorischen Regierung, 9. 2. 1950, BAB, DC 20 I/3, Nr. 12, Bl. 4, TOP 6. Der Vorschlag Schumanns in: Geyer an Ministerrat, 4. 2. 1950, ebenda, Bl. 58.

85 Protokoll der 1. Präsidiumssitzung, 13. 2. 1950, BAB, DP2, Nr. 339, TOP 1. Dem Präsidium gehörten der Präsident, der Vizepräsident und die Oberichter an.

86 Vgl. die Aussage Trapps in einem Rundfunkinterview vom 24. 9. 1952, daß Benjamin auf die bürgerlichen Richter am Obersten Gericht keinen Druck ausüben mußte, weil die Senate jeweils so zusammengesetzt waren, „daß einem sog. bürgerlichen Koll[egen] jeweils zwei SED-Richter gegenüberstanden, so daß in jedem Falle durch entsprechenden Mehrheitsbeschluß das gewünschte Ergebnis zusammen kommen mußte“, BStU, MfS AP 6949/71, Bl. 16.

87 Protokoll der 2. Präsidiumssitzung, 21.2. 1950, BAB, DP2 Nr. 339, TOP 2. Die Aussage von Debes und Weinke, Aufklärung von DDR-Justizunrecht, S. 1025, Anm. 64, daß während der Amtszeit von Benjamin am OG kein offizieller Geschäftsverteilungsplan existierte, ist daher so nicht zutreffend.

88 Protokoll der 1. Präsidiumssitzung, 13. 2. 1950, ebenda, TOP 2; Protokoll der 19. Sitzung der Provisorischen Regierung, 16.3.1950, Bl. 4.

89 Vgl. Sarge u.a., Oberstes Gericht, S. 22. 
nals und der Schulung " oblagen, und bildete somit das einzige regierungsamtliche Dokument, in dem diese maßgebliche Kompetenz Benjamins festgehalten war ${ }^{90}$.

Eine Regelung über das Auftreten von Rechtsanwälten enthielt das am 7. Dezember 1949 angenommene Gesetz - im Unterschied zu dem verworfenen LDPEntwurf - nicht. Es war daher sicher kein Zufall, daß ausgerechnet Kurt Cohn von der LDP in der ersten Präsidiumssitzung die Frage aufwarf, welche Rechtsanwälte vor dem Obersten Gericht zugelassen werden sollten. Der daraufhin gefaßte Beschluß, demzufolge ,jeder bei einem Gericht der Deutschen Demokratischen Republik zugelassene Rechtsanwalt" dort auftreten könne91, war bei seiner Veröffentlichung am 23. Mai $1950 \mathrm{im}$ Ministerialblatt ${ }^{92}$, schon stark relativiert worden. Abgesehen davon, daß Berliner Anwälte mit dieser Regelung ausgeschlossen werden konnten ${ }^{93}$, machte Benjamin am 22. Mai vor dem Präsidium deutlich, daß das Oberste Gericht - im Gegensatz zu seinem Beschluß vom 13. Februar - in Kassationsverfahren keineswegs jeden in der DDR zugelassenen Anwalt zum Verteidiger bestellen könne. Vielmehr müsse das Präsidium über jeden einzelnen Fall entscheiden, um zu verhindern, daß etwa „ein politischer Feind der demokratischen Ordnung" oder einer, "der an seinem Wohnsitz als Begünstigter von Wirtschaftsverbrechen gelte“, durch seine Zulassung vor dem Obersten Gericht „einen moralischen und politischen Vertrauensbeweis" erhalte. Außerdem bestehe "nach den bisherigen Erfahrungen keine Notwendigkeit [...], im Kassationsverfahren Verteidiger zu bestellen" 94 .

In den ersten beiden Jahren seines Bestehens änderte sich die Struktur des Obersten Gerichts mehrfach. Zu Beginn des Jahres 1951 stand eine Erweiterung um zwei Senate an. Nachdem das Präsidium am 10. Januar auf Vorschlag Schumanns beschlossen hatte, einen „1a Strafsenat“ und einen „1a Zivilsenat“ zu bilden, unterrichtete dieser den Chef der Regierungskanzlei darüber, vertrat aber die Auffassung, daß es für die Neubildung dieser beiden Parallelsenate keines Regierungsbeschlusses bedürfe, da dafür keine zusätzlichen Richter benötigt würden und sich diese Maßnahme „lediglich als eine andere Form der internen Geschäftsverteilung" darstelle. Die Regierung war anderer Meinung und beschloß in ihrer Sitzung am 25. Januar, „die Zahl der zu bildenden Senate beim Obersten Gericht der Deutschen Demokratischen Republik von vier auf sechs zu erhöhen “95. Der 1a Zivilsenat wurde besonders für familienrechtliche Sachen errichtet. Die Besetzung entsprach der des 1. Zivilsenats bis auf den Austausch des ersten Beisitzers: An die Stelle von Paschke trat Elfriede Göldner. Nur so konnte man nach Schumanns Darlegungen der in der Öffentlichkeit vorgebrachten Forderung nach Teil-

90 Vorläufige Geschäftsordnung in: BAB, DP1 VA Nr. 5595. Schumann bezeichnete sie als „vorläufig“, da eine endgültige „sich erst nach längerer Praxis und weiterer Entwicklung der Aufgaben des Obersten Gerichts ergeben“" werde, Protokoll der 1. Präsidiumssitzung, 13.2. 1950, BAB, DP2 Nr. 339, TOP 2.

91 Ebenda.

92 Ministerialblatt 1950, S. 43.

93 In der 3. Präsidiumssitzung am 16.3. 1950 (TOP 4) wurde ausdrücklich festgelegt, daß über die Zulassung eines Berliner Anwalts in jedem Fall ein Präsidiumsentschluß herbeigeführt werden müsse, BAB, DP2 Nr. 339.

94 Protokoll der 7. Präsidiumssitzung, 22. 5. 1950, ebenda, einziger TOP.

95 Protokoll der 18. Präsidiumssitzung, 10. 1. 1951, ebenda; Protokoll der 9. Regierungssitzung, 25. 1. 1951, BAB, DC 20 I/3 Nr. 42, Bl. 6, Schumann an Geyer, 12. 1. 1951, ebenda, Bl. 182. 
nahme einer Richterin an familienrechtlichen Streitigkeiten gerecht werden. Der 1a Strafsenat sollte für alle Kassationsverfahren aus dem im Dezember 1950 verabschiedeten Friedensschutzgesetz, Befehl Nr. 201, Artikel III A III von Kontrollratsdirektive Nr. 38 und Artikel 6 der DDR-Verfassung zuständig sein. Die Einheitlichkeit der Rechtsprechung des ersten Senats und des 1a Strafsenats wollte man dadurch gewährleisten, daß mindestens ein Richter in beiden Senaten zugleich tätig war. Durch diese Erweiterung und Neuaufteilung der Kompetenzen innerhalb des Obersten Gerichts erreichte man schließlich - und darin ist wohl das entscheidende Motiv zu sehen - eine Anpassung an die im Januar 1951 gleichfalls verordnete Geschäftsverteilung der Gerichte, derzufolge die ersten Strafkammern für politische Strafverfahren, die zweiten für Wirtschaftsstrafverfahren und die dritten für sonstige Strafverfahren für zuständig erklärt wurden ${ }^{96}$.

Die mit Verordnung vom 20. Dezember 1951 von der Regierung beschlossene Erweiterung des Obersten Gerichts um einen Senat zur Kassation von Arbeitsgerichtsurteilen besaß eine lange Vorgeschichte. Bereits am 23. März 1950 hatte Nathan die Abteilung Staatliche Verwaltung auf dieses Defizit aufmerksam gemacht. Trotz wiederholter Nachfragen Nathans dauerte es bis zum Sommer $1951^{97}$, bevor eine Entscheidung vorbereitet wurde. Am 28. September unterbreitete Arbeitsminister Roman Chwalek Grotewohl offiziell einen entsprechenden Vorschlag. Darin verwies er auf den durch die Verfassung gegebenen Auftrag zur Errichtung einer einheitlichen Arbeitsgerichtsbarkeit ${ }^{98}$ und darauf, daß in diesem Zusammenhang über die Errichtung eines obersten Arbeitsgerichts diskutiert werde. Dies lehnte Chwalek zwar ab, machte aber gleichwohl darauf aufmerksam, daß keine Stelle existiere, „die in der Rechtsprechung der Arbeitsgerichte und Landesarbeitsgerichte wegweisend in prinzipiellen Fragen Entscheidungen trifft". Er trat daher für die Errichtung eines arbeitsrechtlichen Kassationssenats beim Obersten Gericht ein, dessen Beisitzer vom FDGB vorgeschlagen werden könnten ${ }^{99}$. Schumann entsprach der Forderung Chwaleks durch Ausarbeitung einer entsprechenden knappen Verordnung, die von der Regierung am 20. Dezember 1951 verabschiedet wurde ${ }^{100}$. Obwohl die Verordnung am Tage ihrer Verkündung in Kraft trat und das Oberste Gericht 1952 deren Umsetzung plante ${ }^{101}$, dauerte es - wahrscheinlich weil das geeignete Personal fehlte ${ }^{102}$ - noch bis zum 25. Oktober 1952, als mit Verfügung Benjamins ein dritter, ausschließlich für Kassationen in Arbeitssachen zuständiger Zivilsenat eingerichtet wurde ${ }^{103}$.

${ }_{96}$ Rundverfügung Nr. 8/51 vom 26. 1. 1951, BAB, DP1 VA Nr. 6284, Bl. 14.

97 Nathan an Abteilung Staatliche Verwaltung, 20. 7. 1951, BAB, DP1 SE Nr. 1199. In dem auch an Benjamin übersandten Schreiben verwies er auch auf seine Bemühungen in dieser Sache seit März 1950.

98 Art. 18, Abs. 1 der Verfassung lautete: „Die Republik schafft unter maßgeblicher Mitbestimmung der Werktätigen ein einheitliches Arbeitsrecht, eine einheitliche Arbeitsgerichtsbarkeit und einen einheitlichen Arbeitsschutz.“

${ }_{99}$ Chwalek an Grotewohl, 28. 9. 1951, BAB, DC 20 I/3, Nr. 86, Bl. 187 f. Die Meinung Chwaleks war Nathan bei der Abfassung seines Schreibens vom 20. 7. 1951 bekannt.

100 Schumann an Geyer, 28. 11. 1951, ebenda, Bl. 190 f.; Protokoll der 60. Regierungssitzung, 20.12. 1951, ebenda, Bl. 7; GBl. 1951, S. 1179.

101 Vgl. die Arbeitspläne für das 1. und 2. Quartal 1952 in: DP2 Nr. 374.

102 Darauf deutet ein Schreiben Schumanns an Staatssekretär Geyer vom 13. 10. 1952 hin, BAB, DP1 VA Nr. 5597.

103 Verfügung Benjamins, 25. 10. 1952, BAB, DP1 VA Nr. 6799. 
Unmittelbar nach der Moskau-Reise führender DDR-Juristen im Frühsommer 1952 beschloß das Präsidium des Obersten Gerichts am 23. Juni zudem, die Organe des Obersten Gerichts nach sowjetischem Vorbild ${ }^{104}$ um ein aus allen Richtern bestehendes Plenum zu erweitern, das vor allem „zum Erlaß von allgemein geltenden Richtlinien über die Auslegung und Anwendung der Gesetze der Republik" zuständig sein sollte ${ }^{105}$. Eine endgültige Neustrukturierung des Obersten Gerichts ergab sich dann durch das am 2. Oktober 1952 beschlossene Gerichtsverfassungsgesetz, das die Kompetenzen des Plenums stark erweiterte. Es war nicht nur zum Erlaß von Richtlinien, sondern auch zur Entscheidung in Fällen, in denen zuvor der - nie zusammengetretene - Große Senat zuständig gewesen war, und zur Kassation von Entscheidungen des Obersten Gerichts befugt. Damit entfiel die Möglichkeit, einen Großen Senat einzusetzen; sehr viel weiterreichende Wirkungen hatte aber die Tatsache, daß auch das Präsidium seine Tätigkeit einstellte, als die Verabschiedung des neuen GVG absehbar wurde ${ }^{106}$. Es gab fortan kein Organ mehr, das die Geschäftsverteilung des Obersten Gerichts festlegte, so $\mathrm{da} ß$ nun auch die letzte formale Schranke fiel, die die Willkür Benjamins und ihres Nachfolgers bei den Entscheidungen über Zuständigkeit und Besetzung der Senate noch eingeengt hatte.

Im Zuge der dem Obersten Gericht mit dem GVG von 1952 neu zugewachsenen Aufgabe, Verhandlungen auch in zweiter Instanz zu führen - die sinnvoller Weise den Kassationssenaten auferlegt wurde -, legte Benjamin auch die Zuständigkeiten innerhalb des höchsten Gerichtshofs neu fest. Mit Verfügung vom 25. Oktober blieben lediglich die Kompetenzen des 1. und 1a Strafsenats erhalten. Die anderen Senate wurden unter Aufhebung der fachlichen Trennung für alle Strafsachen außer den politischen zuständig, wobei der zweite Strafsenat für die Berufungen und Kassationen aus den Bezirken Leipzig, Gera, Erfurt, Suhl, Halle, Magdeburg und Schwerin und der dritte für die Bezirke Chemnitz, Dresden, Frankfurt, Cottbus, Potsdam, Rostock und Neubrandenburg verantwortlich gemacht wurde. Auch zur Abgrenzung der Zuständigkeiten der ersten beiden Zivilsenate wurde die gleiche, aus der Sowjetunion übernommene territoriale Aufteilung vorgenommen; der dritte Zivilsenat war als Kassationssenat für Arbeitsrechtssachen vorgesehen ${ }^{107}$. Eine weitere Differenzierung nahm Benjamin noch einmal zum Jahresbeginn 1953 vor, als auch für die politischen Strafsachen zwei Kassations- und Rechtsmittelsenate eingerichtet wurden ${ }^{108}$ - ein Ergebnis des rapiden Anstiegs der politischen Strafsachen im Zeichen des verstärkten „Aufbaus des Sozialismus" nach der 2. SED-Parteikonferenz vom Juli 1952.

Ein Problem bestand für das Oberste Gericht darin, daß die ohnehin knapp bemessene Anzahl der Richter nicht in dem Maße wuchs, wie es die vermehrten Aufgaben erfordert hätten. Es verfügte seit der Wahl von Irmgard Eisermann im

104 Vorläufiger Bericht der Studiendelegation der Juristen, o.D., und die Auswertung der Ergebnisse, BAB, DP1 VA Nr. 176.

105 Protokoll der 43. Präsidiumssitzung, 23. 6. 1952, BAB, DP2 Nr. 339.

106 Dessen letzte Sitzung fand am 1.9. 1952 statt, ebenda.

107 Verfügung Benjamins, 25. 10. 1952, BAB, DP1 VA Nr. 6799.

108 Analyse und zusammenfassender Bericht über die Tätigkeit des Obersten Gerichts im 1. Halbjahr 1953, BAB, DP1 VA Nr. 176, Bl. 9. Auch die Errichtung eines dritten Senats für politische Strafsachen wurde darin nicht ausgeschlossen, ebenda, Bl. 7. 
September 1950 neben dem Präsidenten vorübergehend über 13 Richter, wobei jedoch Elfriede Göldner krankheitsbedingt des öfteren ausfiel109. Im August 1951 wechselte Helene Drechsler, der von der SED-Sonderkommission besonderes Klassenbewußtsein attestiert worden war, auf eine Hauptabteilungsleiterstelle in der Regierungskanzlei110. Mit der Erhöhung der Anzahl der Senate auf sechs im Januar 1951 wurde auch die Belastung der Richter erhöht: Rothschild, Göldner, Cohn, Heinrich und Ziegler wurden nicht mehr, wie bisher nur in jeweils einem, sondern in jeweils zwei Senaten eingesetzt ${ }^{111}$. Zur Personalknappheit kam im Laufe der Zeit noch hinzu, daß gerade die älteren Richter häufiger krank geschrieben und andere für Sonderaufgaben eingesetzt wurden. Aufgrund derartiger Ausfälle kam es Anfang Mai 1952 kurzfristig dazu, daß vorübergehend Eisermann und Ziegler insgesamt fünf Senaten zugeteilt wurden ${ }^{112}$.

Die dringend erforderlichen Neueinstellungen ließen freilich auf sich warten. Obwohl das Sekretariat am 14. Februar 1952 zur „Verstärkung des Obersten Gerichts" die SED-Genossen Karl-Heinz Hintze, Max Möbius, Fritz Etzold und Helene Kleine als Richter bestätigte und der entsprechende Regierungsbeschluß am 6. März folgte, wählte die Volkskammer sie - aus unbekannten Gründen - erst am 23. Mai113. Mit Hermann Ziegler kam Anfang Oktober 1952 ein weiterer regulär gewählter Richter ans Oberste Gericht ${ }^{114}$; die durch das Ausscheiden von Trapp und Melz im September bedingten Personalausfälle wurden damit jedoch nur teilweise ausgeglichen. Ende des Jahres ernannte die DDR-Regierung nach einem entsprechenden Sekretariatsbeschluß am 19. Dezember Herbert Klar, Irene Rechner, Willy Seidel und Horst Schilde für die Dauer des Jahres 1953 zu Hilfsrichtern ${ }^{115}$. Dabei handelte es sich um ein nach dem neuen GVG ermöglichtes Verfahren, das die Wahl der Richter unnötig machte und vermutlich eingeführt worden war, um die Personalengpässe am Obersten Gericht schneller als bisher beheben zu können. Die „Neuen“ des Jahres 1952 waren, soweit sich deren Parteizugehörigkeit und Werdegang feststellen ließ, SED-Mitglieder und Absolven-

109 Zur Vorgeschichte der Wahl von Eisermann am 8. 9. 1950 als Ersatz für die aus Gesundheitsgründen ausgefallene Elfriede Göldner: Protokoll der Sekretariatssitzung, 1. 9. 1950, SAPMO, DY $30 \mathrm{~J}$ IV 2/3/135, TOP 21; Protokoll der 40. Sitzung der Provisorischen Regierung, 7. 9. 1950, DC 20 I/3 Nr. 30, Bl. 7; Schumann an Grotewohl, 2. 9. 1950, ebenda, Bl. 93; Provisorische Volkskammer, Sitzungen, S. 502. Eisermann hatte nach ihrer Volksrichterausbildung am Landgericht Güstrow, am Amtsgericht Rostock und nach einem Lehrgang an der DVA seit August 1949 am Oberlandesgericht Schwerin Karriere gemacht; Lebenslauf Eisermann, 13. 2. 1951, SAPMO, DY 30 IV 2/11/171, Bl. 476-480. Sie war an den Waldheimer Prozessen beteiligt: siehe Bericht, 15. 4. 1957, BStU, MfS AKK 4628/80, und Beurteilung Eisermanns in: Mollnau, Sozialistische Gesetzlichkeit, S. $100 \mathrm{f}$.

110 Protokoll der Sekretariatssitzung, 6. 8. 1950, SAPMO, DY 30 J IV 2/3/221, TOP 20; Abschlußeinschätzung der Sonderkommission, 25. 8. 1951, Anlage Nr. 10, SAPMO, DY 30 IV 2/11/167, Bl. 305.

111 Protokoll der 18. Präsidiumssitzung, 10. 1. 1951, BAB, DP1 Nr. 339.

112 Präsident des Obersten Gerichts an die Mitglieder des Präsidiums, 6. 5. 1952, ebenda.

113 Protokoll der Sekretariatssitzung, 14. 2. 1952, SAPMO, DY 30 J IV 2/3/269, TOP 18; Protokoll der 72. Regierungssitzung, 6. 3. 1952, BAB, DC 20 I/3, Nr. 95, Bl. 105; Volkskammer, Sitzungen, S. $623 \mathrm{f}$.

114 Protokoll der 100. Regierungssitzung, 11. 9. 1952, BAB, DC 20 I/3, Nr. 131, Bl. 15; Volkskammer, Sitzungen, S. 748. Ein Sekretariatsbeschluß wurde vorher nicht gefaßt.

115 Protokoll der Sekretariatssitzung, 11. 12. 1952, SAPMO, DY 30 J IV 2/3/347, TOP 29; Protokoll der 109. Regierungssitzung, 19. 12. 1952, BAB, DC 20 I/3 Nr. 161, Bl. 16. 
ten der Volksrichterlehrgänge ${ }^{116}$. Eine Reihe von ihnen hatte bereits vor $1952 \mathrm{Kar}$ riere gemacht und sich, wie etwa Max Möbius, Helene Kleine und Herbert Klar, im Sinne des Regimes profiliert ${ }^{117}$; es scheint jedoch, daß deren fachliche Qualifikation nicht an die der 1949/50 eingestellten Richter heranreichte ${ }^{118}$. Das Verhältnis zwischen Volljuristen und Volksrichtern verschob sich bis Ende 1952 zusehends zugunsten der letzteren: Hatten im Februar 1950 noch neun der insgesamt dreizehn Richter eine akademische Juristenausbildung und nur vier einen Lehrgang absolviert, waren von den 20 Richtern des Obersten Gerichts Ende 1952 acht Volljuristen und zehn Volksrichter.

Die Personallage am Obersten Gericht wurde 1952 zusätzlich dadurch verschärft, daß zwei Richter Ende August in den Westen flohen. Es handelte sich dabei mit Alfred Trapp und Wolfgang Melz um zwei Angehörige der bürgerlichen Parteien ${ }^{11}$. Trapp hatte als Beisitzer des ersten Senats unter anderem an den Strafverfahren gegen Burianek und andere sowie gegen Mitglieder der Zeugen Jehovas mitgewirkt, die mit Todesstrafen und langjährigen Haftstrafen endeten. Seine nachträglichen Aussagen, dabei für mildere Strafen eingetreten, aber überstimmt worden zu sein ${ }^{120}$, werden durch zeitgenössische Beurteilungen des MfS ${ }^{121}$ und Benjamins bestätigt. Die Vizepräsidentin beurteilte ihn vor seiner Flucht folgendermaßen: „Er hat ausgesprochen bürgerliche Vorstellungen von persönlicher Freiheit, deshalb versagt er auch am 1 . Strafsenat in Fällen, bei denen eine harte Verurteilung notwendig ist. Insbesondere hat er bisher in allen Fällen seine $\mathrm{Zu}$ stimmung zu Urteilen versagt und sich überstimmen lassen, wenn es sich um eine Verurteilung zu lebenslänglicher Haft (3 Prozesse vor dem 1. Strafsenat) handelte." 122 Über die genaueren Umstände der Flucht von Melz ist nichts bekannt;

$116 \mathrm{Zu}$ Hermann Ziegler und Willy Seidel ließen sich keine Angaben über Herkunft und Werdegang ermitteln.

117 Möbius hatte Richterstellen am Landgericht Dessau und am Oberlandesgericht Halle bekleidet: siehe Rottleuthner, Steuerung der Justiz, S. 563. Kleine war vom 1.3.1948 bis 31.1.1949 als Beisitzerin in der großen 201-Strafkammer beim Landgericht Magdeburg und anschließend beim Oberlandesgericht Halle eingesetzt gewesen. Mit ihrer 201-Rechtsprechung gewann sie "das Wohlwollen und die Schätzung der Gen. Benjamin": siehe Lebenslauf Kleine, 27. 2. 1952, Bericht von GI „Spree“, 20.10. 1955, BStU, MfS AKK 7479/79, Bl. 10, 33. Klar war als einer der ersten sächsischen Volksrichter am 1.10. 1949 zum Präsidenten des Landgerichts Zwickau befördert worden: siehe Sächsische Absolventen der Richterlehrgänge in leitende Stellungen der Justiz aufgerückt, 19. 10. 1949, BAB, DP1 VA Nr. 6335, Bl. 249.

118 Etzold etwa hatte nur ausreichende fachliche Kenntnisse und kaum Berufserfahrung: siehe Beurteilung Etzolds, 1. 3. 1952, Lebenslauf Etzold, 26. 2. 1952, BStU, MfS AIM 373/58 T.I, Bl. 27, 25 f. Möbius wurde 1953 als „alter linientreuer Kommunist aus der Zeit vor 1933, [aber] fachlich unqualifiziert" bezeichnet: Bericht, 19.11. 1953, AdsD, Ostbüro 0048a.

119 Trapp war am 25. 8. 1952 nach einem Wochenende nicht zur Arbeit erschienen: siehe Aktenvermerk Kienbergs, 26. 8. 1952, BStU, MfS AP 6949/71, Bl. 10. Der Fluchttermin von Melz ließ sich nicht ermitteln; am 29. 8. 1952 sammelte das MfS Angaben zu seiner Person: siehe BStU, MfS AP 6936/71, Bl. 8. In seiner 44. Sitzung am 1. 9. 1952 änderte das Präsidium des OG die Geschäftsverteilung, da Trapp und Melz geflohen waren, BAB, DP2 Nr. 339.

120 Vgl. Hoher Volksrichter floh in den Westen, in: Der Telegraf, 19.11. 1952, BAB, DP1 VA Nr. 5596.

121 Bericht betr. Trapp, 28. 8. 1952, BStU, MfS AP 6949/71, Bl. 5-7.

122 Beurteilung Trapps von Benjamin, o.D., ebenda, Bl. 9. Vgl. auch die Aussage von Werner Barfus, Trapp habe sich gegen die Todesstrafe für Burianek ausgesprochen und seine Meinung in einem Sondervotum niedergelegt: siehe Feth, Benjamin, S. 104. Trapp hatte im Westen aufgrund seiner Tätigkeit im 1. Senat des obersten Gerichts zunächst Probleme, als politischer Flüchtling anerkannt zu werden; im August 1995 wurde er wegen seines Verhaltens im Prozeß gegen die Zeugen 
da er aber offensichtlich zur selben Zeit wie sein Freund Trapp Ost-Berlin verließ, ist eine gemeinsame Flucht aufgrund ähnlicher Motive wahrscheinlich. Obwohl damit zwei qualifizierte Richter verloren gingen, hatte das Ausscheiden der beiden den willkommenen Nebeneffekt, daß nunmehr nur noch zwei - völlig konforme - Mitglieder von CDU und LDP am Obersten Gericht verblieben ${ }^{123}$. Das Oberste Gericht wurde zwar, wie alle Regierungsbehörden, vom MfS überwacht ${ }^{124}$; da die bürgerliche Rechtskultur in der DDR im Verlauf der Zeit jedoch verkümmerte und in zunehmenden Maße nur noch angepaßte SED-Kader als Richter akzeptiert wurden, konnte auch das MfS kein abweichendes Verhalten bei den Mitgliedern des höchsten DDR-Gerichts mehr feststellen.

\section{Die strukturelle und personelle Entwicklung der Obersten Staatsanwaltschaft (1950-1952)}

Die Oberste Staatsanwaltschaft, die sehr viel mehr Zeit für ihren Aufbau benötigte als das Oberste Gericht, war anfangs anscheinend noch ziemlich unstrukturiert. Wahrscheinlich war der Rundverfügung vom 14. September 1950, die unter anderem die Generalstaatsanwälte der Länder anwies, „ein besonderes Dezernat“ für politische Strafverfahren zu bilden ${ }^{125}$, eine entsprechende Gliederung der Obersten Staatsanwaltschaft vorangegangen. Erst im ersten Halbjahr 1951 wurde, ausgehend von den beiden Hauptaufgaben der Obersten Staatsanwaltschaft Kassationstätigkeit und Beobachtung wichtiger Prozesse in den Ländern -, eine Aufteilung der Arbeit in zwei große Bereiche vorgenommen: Für die sogenannte "operative“ Tätigkeit, die Beobachtung, Anleitung und Kontrolle der Strafverfahren in den Ländern sowie die Anklagevertretung in erstinstanzlichen Prozessen vor dem obersten Gericht umfaßte, wurde die Hauptabteilung I verantwortlich gemacht, während die Hauptabteilung II ausschließlich für Kassationen zuständig wurde ${ }^{126}$. In beiden Hauptabteilungen richtete die Oberste Staatsanwaltschaft Abteilungen ein, von denen die erste politische Strafsachen, die zweite Wirtschaftsstrafsachen und die dritte sonstige Strafsachen bearbeitete ${ }^{127}$; in der Haupt-

Jehovas vor dem Berliner Landgericht wegen Rechtsbeugung angeklagt, das Verfahren wurde jedoch am 17. 8. 1995 wegen Verjährung eingestellt: siehe Verfahren gegen DDR-Richter eingestellt, in: Berliner Zeitung, 18. 8. 1995; DDR-Richter bat um Verzeihung, in: Die Welt, 18. 8. 1995; Richter leistet späte Abbitte, in: Frankfurter Rundschau, 9. 8. 1995. Vgl. auch Fricke, Opposition und Widerstand in der DDR-Strafjustiz, S. 32.

$123 \mathrm{Vgl}$. zu Cohn und Heinrich Treffbericht vom 21.11. 1955 und Bericht zu den in Zivilsachen tätigen Richtern, 27. 7. 1955, BStU, MfS AIM 19222/63, T.II, Bl. 159. 140.

${ }^{124}$ Für den Untersuchungszeitraum konnte nur Rothschild als GI ermittelt werden, der sich am 17.7. 1951 als GI „Spree" verpflichtete, BStU, MfS AIM 19222/63, T.I, Bl. 17. Etzold verpflichtete sich als GI „Peter“" erst am 21. 8. 1956, BStU, MfS AIM 373/58, T.I, Bl. 16. Für die spätere Zeit Vollnhals, Nomenklatur und Kaderpolitik, S. 232-234.

125 Gemeinschaftliche Rundverfügung des MdJ und GStA der DDR, Nr. 121/50, 14. 9. 1950, BAB, DP1 SE Nr. 1199.

126 Vgl. „Chronik der Abt. III“ von Jahnke, o.D., BAB, DP3 III Nr. 121, und Bericht Melsheimers auf der Arbeitstagung der Generalstaatsanwälte der Länder, 21. 9. 1951, BAB, DP3 Nr. 25, Bl. 306 f.; zur Systematik siehe auch den Bericht über die Tätigkeit der Obersten Staatsanwaltschaft im 2. Halbjahr 1952, BAB, DP3 I Nr. 133.

127 Rundverfügung Nr. 19 des GStA der DDR, 9. 5. 1951, BAB, DP3 Nr. 19, Bl. 68 f. 
abteilung II existierte zusätzlich eine Abteilung II/4, die für Kassationen von Zivilsachen verantwortlich war ${ }^{128}$. Zweck dieser Gliederung, die in den Ländern ihre Entsprechung hatte, war eine Angleichung der Strukturen von Gericht und Staatsanwaltschaft, um eine effektivere Justizsteuerung zu ermöglichen.

In der nächsten Zeit blieb diese Grundstruktur erhalten, sie wurde lediglich ergänzt und ausgeweitet. Dabei zog die „Verordnung über Maßnahmen zur Vereinfachung der Justiz" vom 27. September 1951'29, mit der die Staatsanwaltschaft zentralisiert und die Personalpolitik beim Generalstaatsanwalt der DDR zusammengefaßt wurde, wahrscheinlich einen Ausbau der Verwaltungs- und Personalabteilung der Obersten Staatsanwaltschaft nach sich. Eine Erweiterung der Hauptabteilung I ergab sich durch den Ministerratsbeschluß vom 27. März 1952, mit dem der Staatsanwaltschaft unter anderem die Aufsicht über die Haftanstalten übertragen wurde. Daher errichtete die Oberste Staatsanwaltschaft eine Abteilung Haftaufsicht (I/4), die für die der HVDVP direkt unterstehenden Anstalten und für die Überwachung der entsprechenden Tätigkeit der Landesstaatsanwälte zuständig war ${ }^{130}$. Den stärksten Ausbau der Obersten Staatsanwaltschaft bewirkte freilich das Staatsanwaltschaftsgesetz vom 23. Mai 1952. Die darin nach sowjetischem Vorbild eingeführte, als besonders wichtig erachtete Aufgabe, „die höchste Aufsicht über die strikte Einhaltung der Gesetze und Verordnungen der Deutschen Demokratischen Republik zu führen"131 machte die Bildung einer neuen Hauptabteilung erforderlich. Man hatte jedoch das sowjetische Vorbild zu schnell kopiert und war sich „über das Wesen und den Inhalt der Allgemeinen Aufsicht [und] über die bei ihrer Ausübung anzuwendenden Arbeitsmethoden" noch gar nicht im klaren, so daß der Aufbau dieser Hauptabteilung nur sehr schleppend in Gang kam. Nachdem im Juli und August die dabei anfallenden Aufgaben vom Sekretariat der Obersten Staatsanwaltschaft erledigt worden waren, machte sich erst Ende August ein Staatsanwalt an den Aufbau der Hauptabteilung, deren Stellenplan einen Leiter und sieben Staatsanwälte vorsah. Auch im Oktober 1952 war die Hauptabteilung III erst mit zwei Staatsanwälten besetzt ${ }^{132}$.

Der Aufgabenzuwachs bedingte auch einen personellen Ausbau. Die völlige Verselbständigung der Staatsanwaltschaft, ihre Zentralisierung und ihr erhöhtes Gewicht bei der Justizsteuerung führten jedoch dazu, daß ihr Stellenplan weitaus schneller wuchs als der des Obersten Gerichts: Sah dieser Anfang 1951 neben dem Generalstaatsanwalt und seinem Vertreter nur fünf weitere Staatsanwälte vor, waren es im August 1952 bereits 50133. Die Personalbewegungen lassen sich bei wei-

128 Bericht über die Entwicklung der Abteilung Zivilrecht bei der Obersten Staatsanwaltschaft seit 1949, 17. 8. 1954, BAB, DP3 III, Nr. 121.

129 In: GBl. 1951, S. 877.

130 Beschluß über die Maßnahmen zur weiteren Festigung der demokratischen Gesetzlichkeit, 27. 3. 1952, in: Ministerialblatt 1952, S. 35; Die Aufsicht über die Haftanstalten, o.D., BAB, DP3 III Nr. 121; Rundverfügung Nr. 10/52 des GStA der DDR, 31. 3. 1952, ebenda.

131 Gesetz über die Staatsanwaltschaft der Deutschen Demokratischen Republik, $\$ 1$.

132 Die Entwicklung der Allgemeinen Aufsicht der Staatsanwaltschaft, BAB, DP3 III Nr. 121 (dort auch das Zitat); Bericht über die Durchführung des Gesetzes über die Staatsanwaltschaft in der DDR, August 1952, ebenda.

133 Struktur der Obersten Staatsanwaltschaft, 1951, BAB, DP1 VA Nr. 5577, Bl. 68; Bericht über die Durchführung des Gesetzes über die Staatsanwaltschaft in der DDR, August 1952, BAB, DP3 III Nr. 121. 
tem nicht so detailliert verfolgen wie beim Obersten Gericht, da weder die formellen noch die informellen Regeln bei den Stellenbesetzungen eingehalten wurden. Im Widerspruch zu der gesetzlichen Vorschrift erfolgten Ernennung und Abberufung der Staatsanwälte keineswegs immer durch einen Regierungsbeschluß; außerdem traten vielfach Staatsanwälte ohne vorherige Befragung des Sekretariats ihren Dienst an ${ }^{134}$. Die Tatsache, daß die Personalentscheidungen nicht durch die Volkskammer ,abgesegnet' werden mußten, förderte anscheinend eine gewisse Laxheit im Umgang mit den selbst gesetzten Regeln.

Nachdem die Staatsanwaltsstellen 1949/50 nur sehr schleppend besetzt worden waren, wurden nach Dienstantritt von Hildegard Heinze vermehrt Einstellungen vorgenommen. Als erster ihrer Kandidaten kam nach den entsprechenden Sekretariats- und Regierungsbeschlüssen zum 1. Oktober 1950 Karl Kennecke zur Obersten Staatsanwaltschaft ${ }^{135}$; am 1. Januar 1951 folgte - ohne eine vorherige Beschlußfassung in Sekretariat oder Regierung - auch auf Heinzes Initiative hin die Einberufung von Ilse Kühne als Staatsanwältin ${ }^{136}$. Ebenfalls als Heinzes Mann galt Josef Streit, der zum 1. Mai 1951 aus dem Justizministerium ausschied und in die Oberste Staatsanwaltschaft eintrat ${ }^{137}$. Alle drei stammten aus Arbeiterkreisen, waren im Dritten Reich tatsächlich oder angeblich Verfolgungen ausgesetzt gewesen ${ }^{138}$ und hatten sich durch Volksrichterlehrgänge die notwendige juristische Qualifikation erworben. Kennecke war anschließend als Richter am Amtsgericht Königswusterhausen und ab Februar 1949 in der Berliner Justiz, zuletzt als Oberstaatsanwalt beim Ost-Berliner Kammergericht tätig gewesen, bevor er an den Waldheimer Prozessen teilnahm. Kühne wurde nach Abschluß des sächsischen Richterlehrgangs im November 1949 als Staatsanwältin bei der Staatsanwaltschaft Dresden eingesetzt und im Frühjahr 1950 nach Waldheim abgeordnet, wo sie als Vorsitzende einer Großen Strafkammer fungierte. Heinze hatte die beiden dort offensichtlich als zuverlässige Genossen kennengelernt und daraufhin für die Oberste Staatsanwaltschaft rekrutiert. Streit kannte sie aus dem Justizministerium, wo er als Pressereferent tätig gewesen war und - wie Heinze - der gegen Fechner eingestellten Gruppierung angehört hatte.

134 Die Regelung, daß vor Ernennung der Mitglieder der Obersten Staatsanwaltschaft die höchsten Parteigremien entscheiden mußten, war mit Sekretariatsbeschluß vom 28. 5. 1951 über die Funktionsnomenklatur bestätigt worden. Das Politbüro mußte den Generalstaatsanwalt und die Oberstaatsanwälte, das Sekretariat die Staatsanwälte bestätigen: SAPMO, DY 30 J IV 2/3/199, TOP 28, Anlage 19.

135 Protokoll der Sekretariatssitzung, 1. 9. 1950, SAPMO, DY 30 J IV 2/3/135, TOP 21; Protokoll der 43. Sitzung der Provisorischen Regierung, 28. 9. 1950, BAB, DC 20 I/3 Nr. 32, Bl. 6. Zum Verhältnis Heinze-Kennecke siehe Bericht von GI „Spree“, 22. 6. 1951, und Zur Lage bei der Staatsanwaltschaft, o.D., BStU, MfS AP 2257/55, Bl. 11, 31.

136 Ebenda, Bl. 12, 33; Lebenslauf Kühne, 13. 2. 1951, SAPMO, DY 30 IV 2/11/174, Bl. 402.

137 Zur Lage bei der Staatsanwaltschaft, o.D., BStU, MfS AP 2257/55, Bl. 34; Notiz Fechners, 9. 5. 1951, in: Personalakte Streit, BAB, DP1 SE Nr. 2488.

138 Kennecke gab an, als Sanitätssoldat falsche Tauglichkeitsatteste ausgestellt zu haben und daraufhin wegen Wehrkraftzersetzung verhaftet worden zu sein, Lebenslauf Kennecke, 14. 2. 1951, SAPMO, DY 30 J IV 2/11/174, B1. 77 f.; Kühne hatte illegal für die KPD gearbeitet und war 1935 wegen Hochverrat zu zwei Jahren Gefängnis verurteilt worden, Lebenslauf Kühne, 13. 2. 1951, SAPMO, DY 30 IV 2/11/174, Bl. 400; Streit war als sudetendeutscher Kommunist 1938 von der Gestapo verhaftet worden und bis 1945 in den KZs Dachau und Mauthausen inhaftiert gewesen, Lebenslauf Streit, 15. 1. 1951, SAPMO, DY 30 IV 2/11/177, Bl. 365. 
Heinze nahm vor allem aufgrund ihrer engen Kontakte zur Abteilung Staatliche Verwaltung beim ZK, insbesondere zu Paul Hentschel und Erwin Reisler, zwischen Herbst 1950 und Frühjahr 1952 eine Schlüsselstellung in der Obersten Staatsanwaltschaft ein ${ }^{139}$. Während sie Reisler aus ihrer Abteilung in der DJV kannte und nach Waldheim mitgenommen hatte, war sie mit Hentschel in der Koordinierungskommission bei den Waldheimer Prozessen zusammengetroffen. Diese Verbindungen nutzte Heinze offensichtlich dazu, um an der Obersten Staatsanwaltschaft unter Ausschaltung des Personalleiters die Personalpolitik zu gestalten ${ }^{140}$. Ihr Wirken als Vertreterin des Generalstaatsanwalts stieß jedoch auf Widerstand. Nach den Berichten Rothschilds an das MfS war vor allem Karl Kohn, dem der Stellvertreterposten in Aussicht gestellt worden war, keineswegs damit einverstanden, daß Heinze seit September 1951 diese Stellung einnahm. Da auch Melsheimer offensichtlich mehr zu Heinze tendierte als zu Kohn und diese ebenfalls Otto Grube auf ihre Seite bringen konnte, konnte Kohn zunächst von ihr und ihren Anhängern weitgehend isoliert werden ${ }^{141}$. Problematisch wurde dies erst, als im Zuge der Parteiüberprüfung auch der Obersten Staatsanwaltschaft im Februar aufgedeckt wurde, daß Kennecke 1950 über mehrere Monate hinweg mit seinen Mitgliedsbeiträgen für den FDGB und die SED im Rückstand geblieben war. Außerdem stellte sich heraus, daß er nicht, wie er in seinem Lebenslauf angegeben hatte, in ein Verfahren wegen Wehrkraftzersetzung verwickelt gewesen war und eine Vorstrafe aus dem Jahr 1936 verschwiegen hatte. Kennecke wurde daraufhin im Frühjahr in den Kandidatenstand zurückversetzt und aus der Obersten Staatsanwaltschaft entlassen ${ }^{142}$. Dennoch konnte sich Heinze, die Kennecke ja gefördert hatte, aufgrund ihres guten Verhältnisses zum Generalstaatsanwalt und ihrer Verbindungen zum ZK halten; hinzu kam offensichtlich, daß sie aufgrund ihres Organisationstalents - das der als "Schreibtischmensch“ charakterisierte Melsheimer offensichtlich nicht in dem Maße besaß - an der Obersten Staatsanwaltschaft gebraucht wurde ${ }^{143}$. Erst nach einer weiteren Überprüfung der Obersten Staatsanwaltschaft im Februar 1952 - an der auch das MfS beteiligt war wendete sich für sie das Blatt, zumal auch Reisler im April aufgrund einer Parteistrafe aus dem Justizsektor ausschied, so daß Heinze im Frühjahr diese Justizbehörde wieder verließ und ab Mai 1952 beim Ministerium für Arbeit tätig wurde ${ }^{144}$.

${ }^{139}$ Reisler soll durch Heinze sogar zum ZK gekommen sein: Berichte von GI „Spree“, 22.6. 1951, 24. 7. 1951, BStU, MfS AP 2257/55, Bl. 11 f., 16.

140 Bericht über die Überprüfung der Gerichte und Staatsanwaltschaften, 2. 4. 1952, BStU, MfS AS 24/55, Bl. 204.

141 Protokoll der Sonderkommission, SAPMO, DY 30 IV 2/11/174, Bl. 232; Einschätzung des Genossen Dr. Karl Kohn [von Rothschild], 24. 7. 1951, Zur Lage bei der Staatsanwaltschaft, BStU, MfS AP 2257/55, Bl. 24f., $32 \mathrm{f}$. Rothschild kannte freilich Kohn seit längerem und bezeichnete sich offen als seinen Freund.

142 Protokoll der Sonderkommission, 15. 2. 1951, SAPMO, DY 30 J IV 2/11/174, Bl. 76; Auskunftsbericht über Kennecke, BStU, MfS SdM 996, Bl. 117 f.; Bericht von GI „Spree“, 22. 6. 1951, BStU, MfS AP 2257/55, Bl. 11. Kennecke wurde dennoch weiter im Staatsapparat (im Minsterium für Land- und Forstwirtschaft) beschäftigt: siehe Aktennotiz betr. Kennecke, o.D., BStU, MfS Vorl. AIM 20559/80, Bl. $22 \mathrm{f}$.

${ }_{143}$ Zur Lage bei der Staatsanwaltschaft, BStU, MfS AP 2257/55, Bl. 34.

144 In einem Bericht darüber hieß es: "Für die Oberste Staatsanwaltschaft hat sich insbesondere schädlich ausgewirkt die Arbeit des "Gen. Reisler. Durch seine enge Bindung mit der Genossin Heinze, die zum Teil auch den Genossen bekannt war, beeinflußten diese beiden die fachliche und politische Arbeit bei der Obersten Staatsanwaltschaft in nicht immer förderndem Sinne." 
Insgesamt war der Personalbestand bis zu diesem Zeitpunkt deutlich gewachsen. Nachweislich wurden 1951 neben Kühne und Streit noch Hermann Rodewald, Ernst Pustalla, Louis Schaudt, Herbert Geyer, Käthe Veit und der ehemalige brandenburgische Generalstaatsanwalt Helmut Ostmann eingestellt; im Februar 1952 folgten Helmut Seidemann und der ehemalige thüringische Generalstaatsanwalt Kurt Schmuhl, der als Stellvertreter Melsheimers zu Heinzes Nachfolger avancierte. Unter diesen Staatsanwälten, die alle der SED angehörten, befanden sich ein Volljurist (Ostmann), ein Staatsanwalt im Soforteinsatz (Schaudt) und sieben Volksrichter ${ }^{145}$. Auch in den verbleibenden Monaten des Jahres 1952 wurden - parallel zu den wachsenden Aufgaben der Behörde - zahlreiche Neueinstellungen vorgenommen; allein das Sekretariat bestätigte am 3. April elf, am 24. April vier und am 18. August zwei weitere Staatsanwälte der Obersten Staatsanwaltschaft $^{146}$, über die in den meisten Fällen außer den Namen jedoch nichts bekannt ist. Der Trend, fast ausschließlich Volksrichter an die Oberste Staatsanwaltschaft zu holen, setzte sich jedenfalls fort. Nach späteren Angaben Benjamins waren zum Jahresende 1952 allein 31 Staatsanwälte bei der Obersten Staatsanwaltschaft Absolventen der Lehrgänge ${ }^{147}$. Dazu kamen mit Melsheimer und Ostmann nur zwei akademische Juristen, so daß man insgesamt wohl von 33 Staatsanwälten ausgehen muß. Eine beträchtliche Anzahl von ihnen war fachlich ungeeignet, was Melsheimer intern heftig beklagt haben soll. Insbesondere durch Sonderlehrgänge weiterqualifizierte Volksrichter lehnten er und Benjamin nach Aussage eines ehemaligen ,Insiders' ${ }^{6} b^{148}$ : Trotz aller Wertschätzung der Volksrichter als Garanten einer systemkonformen Rechtsprechung erwiesen sie sich auch aus der Sicht ihrer Förderer für Führungspositionen im DDR-Justizwesen oftmals als ungeeignet.

Die recht hohe Personalfluktuation war jedoch nicht nur auf fachliche Mängel zurückzuführen. Dies zeigt nicht nur der Fall Kennecke, sondern auch die Entlassung Gustav Riegers nach der Parteiüberprüfung im Frühjahr 1951 am 5. April, bei der sich herausstellte, daß er nach dem Krieg fälschlicherweise angegeben hatte, der tschechoslowakischen KP angehört zu haben. Er wurde daraufhin aus der Partei ausgeschlossen und unmittelbar danach aus der Obersten Staatsanwalt-

(SAPMO, DY 30 IV 2/13/419). Der UfJ meldete in seinem "Informationsbrief“ am 1.4. 1952, S. 210, Heinzes Absetzung beruhe auf Vorwürfen, ,sich während ihrer Haftzeit im Dritten Reich unkameradschaftlich zu anderen Häftlingen verhalten zu haben“; die Ursache seien aber „Machtkämpfe innerhalb der SED-Führungsclique". Zum Übergang Heinzes zum Arbeitsministerium siehe Protokoll der Regierungssitzung, 27. 11. 1952, BAB, DC 20 I/3 Nr. 155, TOP 32, und Ministerium für Arbeit an MdJ, 26. 12. 1954, BAB, DP1 SE Nr. 74.

145 Lebenslauf Rodewald, 14. 2. 1951, SAPMO, DY 30 IV 2/11/176, Bl. 332-334; tabellarische Lebensläufe von Schaudt, Pustalla und Seidemann in: Bericht über die Überprüfung bei der Obersten Staatsanwaltschaft, SAPMO, DY 30 IV 2/13/419; Lebensläufe von Veit, Geyer, Ostmann, Schmuhl in: BStU, MfS AS 24/44, Bl. 244, 246, 254, 252. Der Ausbildungsgang von Geyer ließ sich nicht ermitteln.

146 Siehe die Protokolle der Sekretariatssitzungen am 3. 4., 24. 4., 18. 8. 1952, SAPMO, DY 30 IV J $2 /$ $3 / 280$, TOP 11, 285, TOP 14, 317, TOP 41. Am 3. 4. wurden Rudolf Wunsch, Alfred Wagenbreth, Rudolf Purkert, Walter Piehl, Kurt Fleming, Heinz Gold, Ernst Leim, Max Haberkorn, Hilde Weiße, Helmuth Löser und Max Junius, am 24. 4. Louis Schaudt, Ernst Pustolla [sic, wohl Pustalla], Karl Venediger und Otto Szerwon und am 18. 8. Walter Schulze [sic, wohl Schultz] und Irma Thorn bestätigt.

147 Benjamin, Volksrichter, S. 745.

148 Bericht, 19. 11. 1953, AdsD, Ostbüro 0048a. 
schaft abberufen ${ }^{149}$. Der Fall des Staatsanwalts Rodewald zeigte, daß man unter bestimmten Umständen bereit war, über fachliche und andere Mängel längere Zeit hinwegzusehen. Obwohl Rodewald den Volksrichterlehrgang "nur mit Milde ausreichend" bestanden hatte und sein Hang zu übermäßigem Alkoholgenuß sowie sein unsteter Lebenswandel bekannt waren, hatte dies seinen Einsatz bei der Obersten Staatsanwaltschaft nicht behindert, da er als ehemaliger Vertrauensmann des MWD/MGB in Thüringen von der Besatzungsmacht protegiert wurde. Noch bei der Parteiüberprüfung am 1. März 1951 war er als „ideologisch klarer, klassenbewußter und parteiverbundener Genosse“ charakterisiert worden, der „beste Voraussetzungen zum Staatsanwalt“ besitze. Erst im Frühjahr 1952 mußte er nach der Überprüfung der Obersten Staatsanwaltschaft ausscheiden ${ }^{150}$. Schließlich verließen im Frühjahr 1952 auch Kohn und Grube die Oberste Staatsanwaltschaft: Während Kohn am 31. März vom Sekretariat als stellvertretender Vorsitzender des Staatlichen Vertragsgerichts eingesetzt wurde, ging Grube zum 26. Mai als Generalstaatsanwalt zur Berliner Justiz ${ }^{151}$. Die Hintergründe dieser Entscheidungen, die immerhin die beiden dienstältesten Staatsanwälte betrafen, sind unklar; möglicherweise sollte mit Heinzes Abgang ein grundsätzliches personelles Revirement herbeigeführt werden. Die große Fluktuation verschärfte indes das Problem der Personalknappheit. Von 50 vorgesehenen Planstellen für Staatsanwälte waren einem Bericht Melsheimers zufolge im August 1952 lediglich 28 besetzt ${ }^{152}$. Während politische Loyalität und Zuverlässigkeit der Obersten Staatsanwaltschaft außer Frage standen, stellten sowohl die mangelnde Eignung zahlreicher Staatsanwälte als auch der eklatante Personalmangel ein erhebliches Problem dar, das nicht ohne Auswirkungen auf deren Funktionsfähigkeit bleiben konnte.

\section{Justizsteuerung durch das Oberste Gericht}

Das höchste Gericht der DDR war unmittelbar nach seiner Gründung nicht in den Instanzenzug eingebunden, so daß ihm die Anleitung der unteren Gerichte über diesen Weg versagt war. Daß es alle anderen Möglichkeiten der Anleitung ausschöpfen mußte, stand jedoch für Hilde Benjamin außer Frage. Auf einer Arbeitstagung der Richter des Obersten Gerichts am 18. Oktober 1952 begründete sie die Notwendigkeit von direkten Weisungen an die unteren Gerichte interes-

149 Protokoll der Sonderkommission, 1.3. 1951, SAPMO, DY 30 IV 2/11/176, Bl. 298f.; Protokoll der 19. Regierungssitzung, 5. 4. 1951, BAB, DC 20 I/3, Nr. 49, Bl. 5. Er wurde anschließend Verwaltungsdirektor bei der Akademie der Wissenschaften; durch Sekretariatsbeschluß vom 28. 8 . 1952 wurde er erneut als Staatsanwalt bei der Obersten Staatsanwaltschaft bestätigt, SAPMO, DY 30 J IV 2/3/320, TOP 26.

150 Charakteristik Rodewalds, gez. Benjamin und Fechner, 24. 3. 1949, BAB, DP1 VA Nr. 7297; Protokoll der Sonderkommission, 1.3. 1951, SAPMO, DY 30 IV 2/11/176, Bl. 331; Bericht über die durchgeführte Überprüfung bei der Obersten Staatsanwaltschaft, DY 30 IV 2/13/419; Bericht über die Überprüfung der Gerichte und Staatsanwaltschaften, 2.4. 1952, BStU, MfS AS 24/55, Bl. 207; Weber, Justiz und Diktatur, S. $148 \mathrm{f}$.

151 Protokolle der Sekretariatssitzungen, 31. 1., 26. 5. 1952, SAPMO, DY 30 J IV 2/3/150, TOP 12 , 293, TOP 9.

152 Bericht über die Durchführung des Gesetzes über die Staatsanwaltschaft der DDR, August 1952, BAB, DP3 III Nr. 121. 
santerweise mit Blick auf die Verhältnisse in der Sowjetunion. Dort, so Benjamin, sei das „sozialistische Rechtsbewußtsein“ der Richter so weit entwickelt, daß die Achtung vor dem höheren Gericht die Befolgung von dessen Ansichten garantiere; in der DDR hingegen müsse man „von dem geringeren Bewußtseinsstand unserer Richter ausgehen und von dem Recht der Weisungen Gebrauch machen“. Dabei sollten sich die Weisungen nicht „auf reine Rechtsfragen beschränken“, sondern vielmehr auch im Hinblick auf die Beweiswürdigung ergehen ${ }^{153}$.

Dabei war „sozialistisches Rechtsbewußtsein“ nicht einfach mit politischer Zuverlässigkeit gleichzusetzen; es ging vielmehr darum, daß die Richter sich neue „sozialistische“ Rechtsbegriffe aneigneten und danach urteilten. Die Richter des Obersten Gerichts verfügten nicht über solche Kenntnisse, weil eine „sozialistische“ Rechtswissenschaft 1949/50 noch nicht existierte. Auch für die Lenkung der unteren Gerichte mußte diesen daher das, richtige' Rechtsbewußtsein vermittelt werden. Dies hatte Benjamin wohl im Auge, als sie am 4. März 1950 verfügte, jeden Samstag „zur Vertiefung der wissenschaftlichen Arbeit des Obersten Gerichts“ $\mathrm{zu}$ nutzen, um „gemeinsam wichtige Rechtsfragen zu klären“154. Von Anfang an war für diese Sitzungen, an denen immer einige Staatsanwälte der Obersten Staatsanwaltschaft und bisweilen Angehörige des MdJ teilnahmen, die Auswertung der Rechtsprechung der Oberlandesgerichte vorgesehen; einen wesentlichen Bestandteil bildeten zudem „Referate über grundsätzliche Themen “ und Informationen über neue Gesetze ${ }^{155}$. Während man sich zunächst vor allem über das Kassationsprinzip und dessen Handhabung klar werden wollte, stand zwischen Oktober 1950 und April 1951 eine vom Dekan der juristischen Fakultät der DVA, Herbert Kröger, gehaltene Vorlesung über das „Wesen des Staates und des Rechts" auf dem Programm ${ }^{156}$. Von sehr viel größerer Relevanz für die Rechtsprechung des Obersten Gerichts waren die strafrechtlichen Referate, die zwischen Oktober 1951 und Juni 1952 von Hans Gerats, Joachim Renneberg und John Lekschas gehalten wurden ${ }^{157}$. Renneberg und Lekschas hatten dem von Benjamin und Gerats betreuten Strafrechtszirkel im Rahmen des Dozentenkurses an der DVA angehört ${ }^{158}$. Unmittelbar nach Beendigung des Lehrgangs wurden alle drei herangezogen, um ihre von sowjetischen Lehrbüchern weitgehend übernommenen Erkenntnisse den Mitgliedern des Obersten Gerichts, der Obersten Staatsanwaltschaft und des MdJ nahezubringen. Hinzu kamen im ersten Halbjahr 1952 Vorträge von Richtern des Obersten Gerichts über einzelne Aspekte der 1951 in deutscher Übersetzung erschienenen Gerichtsreden Wyschinskis. So referierte Göldner beispielsweise über „Fragen der Strafzumesung“, Kleine über „Die Funktion

153 Niederschrift über Arbeitsbesprechung der Richter des OG und der Staatsanwälte der OStA am 18. 10. 1952, BAB, DP2 Nr. 347; auch zit. bei Gängel, Das Oberste Gericht, S. 261.

154 Verfügung Benjamins, 4. 3. 1950, BAB, DP2 Nr. 343.

$155 \mathrm{Vgl}$. dazu auch Benjamins Äußerung auf der Arbeitstagung der Richter des OG und der Staatsanwälte der OStA am 24.6. 1950, ebenda.

156 Siehe die Niederschriften über Arbeitstagungen der Richter des OG und der Staatsanwälte der OStA am 21. 10. 1950, 11.11. 1950, 20.1. 1951, 28. 2. 1951, 7.4. 1951, ebenda und BAB, DP2 Nr. 344.

157 Es handelte sich um insgesamt 10 Referate, die am 13.10. 1951, 10.11. 1951, 1.12. 1951, 19.1. 1952, 26. 1. 1952, 9. 2. 1952, 1. 4. 1952, 22. 4. 1952, 3. 5. 1952, 7. 6. 1952 gehalten wurden: siehe die entsprechenden Niederschriften der Arbeitstagungen, ebenda und BAB, DP2 Nr. 347.

158 Vgl. Jessen, Kämpfer der Arbeiterklasse, S. 85. 
des Gerichts im Staat" und Eisermann über „Verantwortlichkeit“159. Einen weiteren Schub erlebte die Rezeption sowjetischer Rechtswissenschaft nach der Reise einer SED-Juristendelegation in die Sowjetunion, so daß ab Ende August 1952 etwa das sowjetische Lehrbuch zum Arbeitsrecht und einzelne Aufsätze sowjetischer Rechtswissenschaftler in den Arbeitstagungen des Obersten Gerichts behandelt wurden ${ }^{160}$.

Betrachtet man vor diesem Hintergrund die Justizsteuerung des höchsten DDR-Gerichts zwischen 1950 und 1952/53, so ist neben den Kassationen auch die erstinstanzliche Rechtsprechung jener Jahre zu erwähnen. Die in den bekannten Prozessen gefällten erstinstanzlichen Urteile des Obersten Gerichts ${ }^{161}$ verfolgten zwar primär das Ziel, echte oder vermeintliche Gegner der DDR unschädlich zu machen, waren aber zudem fast immer darauf angelegt, erzieherisch und abschreckend zu wirken und die Gerichte zur Nachahmung anzuregen. Dies wurde freilich nicht dem Zufall überlassen, sondern auf Anweisung des Justizministeriums durch Schulungen entsprechend gefördert ${ }^{162}$. In einigen Fällen fungierten diese Verfahren zudem als Musterprozesse, nach denen - wie etwa im Fall der Zeugen Jehovas - die unteren Gerichte „auf Grund der Urteile des Obersten Gerichts" weitere Beschuldigte aus demselben Personenkreis aburteilten ${ }^{163}$.

Mit dem Druck seiner Urteile versuchte das Oberste Gericht - wie die höchsten Gerichte anderer Staaten auch -, präjudizierend auf die Rechtsprechung insgesamt zu wirken. Der Unterschied zu Rechtsstaaten westlicher Prägung bestand dabei jedoch im politischen Inhalt und in dem Verbindlichkeitsgrad, den das Oberste Gericht für seine Entscheidungen beanspruchte. Als die „Neue Justiz“ im Juni 1950 damit begann, kommentierte Urteile des Obersten Gerichts abzudrucken, wurde ausdrücklich hervorgehoben, daß diese höchstrichterlichen Entscheidungen „die formelle Geltung für das gesamte Gebiet der Deutschen Demokratischen Republik haben, zugleich aber den sachlichen Anspruch erheben, zur Richtschnur für eine fortschrittliche demokratische Rechtsprechung in ganz Deutschland zu werden" 164 . Handelte es sich um ein Kassationsurteil, so war dieses für das betroffene untere Gericht bindend: „Wer gegen die in einem Urteil des Obersten Gerichts der Republik ausgesprochenen Weisungen verstößt“, so Benjamin, „verstößt damit gegen eine entscheidende Grundlage unserer Rechtsordnung. “165 Das Oberste Gericht erwartete darüber hinaus, daß alle anderen Gerichte sich eben-

$159 \mathrm{Vgl}$. Analyse und Zusammenfassung der Gerichtstätigkeit des OG, 1. Halbjahr 1952, BAB, DP1 VA Nr. 7939.

160 Siehe die Niederschriften der Arbeitstagungen am 30. 8., 6. 9., 13. 9., 20. 9., 18. 10., 1. 11., 8. 11. und 6. 12. 1952, BAB, DP2 Nr. 347.

161 Vgl. dazu u. a. Fricke, Zur politischen Strafrechtsprechung des Obersten Gerichts; Beckert, Instanz; Werkentin, Politische Strafjustiz; Wendel, Ulbricht als Richter und Henker.

162 Vgl. etwa die MdJ-Rundverfügungen Nr. 80/50 vom 24.6. 1950, Betr.: Dessauer Prozeß, und Nr. 26/51 vom 12. 2. 1951, Betr.: Entscheidungen des Obersten Gerichts, BAB, DP1 VA Nr. 5576, DP1 SE Nr. 1199.

${ }_{163}$ Vgl. Analyse und Zusammenfassung der Gerichtstätigkeit des OG, 1. Halbjahr 1952, BAB, DP1 VA Nr. 7939. Hier ist das Verfahren „Freies Parlament" genannt.

164 Kommentar der NJ-Redaktion in: NJ 4 (1950), S. 211; vgl. Gängel, Das Oberste Gericht, S. 256.

165 Kommentar zu einem OG-Urteil, in: NJ 4 (1950), S. 216. 
falls ohne Einschränkung an die in der "Neuen Justiz“ und in den ab 1951 erschienenen Entscheidungssammlungen ${ }^{166}$ veröffentlichten Urteile hielten ${ }^{167}$.

Die Kassation war seit 1947 zwar als Rechtsinstitut bekannt, ihre Funktion wandelte sich indes nach der Gründung des Obersten Gerichts. Zwischen 1947 und 1949 handelte es sich im wesentlichen um ein den Generalstaatsanwälten und Oberlandesgerichtspräsidenten vorbehaltenes Mittel zur Urteilskorrektur, das im Unterschied zur Revision - auch bei fehlerhafter Strafzumessung angewandt werden konnte ${ }^{168}$, und eher zurückhaltend eingesetzt worden war: Einschließlich des ersten Halbjahres 1949 waren seit Inkrafttreten der jeweiligen Landesgesetze insgesamt 545 Kassationsanträge gestellt worden, von denen 353 bis zum 1. Juli 1949 zur Urteilskassation geführt hatten ${ }^{169}$. Im zweiten Halbjahr 1949 stellten die Oberlandesgerichtspräsidenten und Generalstaatsanwälte bereits 736 entsprechende Anträge, von denen 534 durch Aufhebung des angegriffenen Urteils erledigt wurden ${ }^{170}$.

Obgleich den Richtern des Obersten Gerichts die Ähnlichkeit zwischen der Kassation und der im Dritten Reich eingesetzten Nichtigkeitsbeschwerde sehr wohl bewußt war, lag ihnen sehr daran, den Unterschied zwischen beiden Rechtsinstituten hervorzuheben. Für Walter Ziegler ergab sich dieser aus dem Ursprung der Nichtigkeitsbeschwerde und ihrem Zweck: Diese sei „aus rein politisch-nazistischen Gründen geschaffen" worden und hätte ausschließlich das Ziel verfolgt, „politische Gegner des Naziregimes unschädlich zu machen, wenn die unteren Instanzen nicht mit der erwünschten Schärfe vorgegangen waren "171. Schumann wies darauf hin, daß sich die aus dem österreichischen Recht stammende Nichtigkeitsbeschwerde durchaus „als brauchbarer Prozeßbehelf“ hätte verwenden lassen, aber durch die Gerichtspraxis im Dritten Reich mißbraucht worden sei und daher zu Rechtsunsicherheit geführt habe. Ein derartiger Mißbrauch der Kassation sei in der DDR nicht zu befürchten, da die Richter und Staatsanwälte sie „im demokratischen Sinne anwenden" würden ${ }^{172}$. In Wirklichkeit verhielt es sich freilich genau anders als Ziegler und Schumann dargelegt hatten. Sowohl die Nichtigkeitsbeschwerde als auch die Kassation kamen (und kommen) auch in Rechtsstaaten zur Anwendung und stellen nicht per se eine Bedrohung der Rechtsstaatlichkeit dar. Entscheidend ist vielmehr, welches Gewicht diesen Rechtsinstituten von

166 Siehe Entscheidungen des Obersten Gerichts. Die Veröffentlichung der OG-Entscheidungen wurde 1978 eingestellt: zu den Hintergründen siehe Gängel, Das Oberste Gericht, S. 257, Anm. 21.

167 Diese Erwartungen wurden 1950/51 oft nicht erfüllt: siehe die Referate Schumanns auf den Arbeitstagungen des OG mit den Oberlandesgerichtspräsidenten und Richtern der Oberlandesgerichte am 2./3. 3. 1951 und am 23./24. 11. 1951, BAB, DP2 Nr. 345, 346.

168 Vgl. dazu Kap. A.V.2.

169 Bericht zur Kassationspraxis, 19. 12. 1949, BAB, DP1 VA Nr. 279, Bl. 1-3.

170 Referat Rothschilds auf der Arbeitstagung der Richter des OG und der Staatsanwälte der OStA am 18. 3. 1950, BAB, DP2 Nr. 343. Eine Zunahme der Kassationstätigkeit war bereits im 1. Halbjahr 1949 verzeichnet worden: siehe vorangehende Anmerkung.

171 Referat Zieglers auf der Arbeitstagung der Richter des OG und der Staatsanwälte der OStA am 11. 3. 1950, BAB, DP2 Nr. 343.

172 Schumann, Das Oberste Gericht als Kassationsgericht, S. 242. Vgl. auch Diestelkamp, Zur Rolle der Rechtswissenschaft, S. 100: „Die makabre Parallele [zwischen Nichtigkeitsbeschwerde und Kassation] war bekannt, wurde aber als rein formal abgetan, gewissermaßen mit dem Versprechen, daß eine demokratische Justiz zur Rechtsperversion strukturell nicht fähig sei.“ 
staatlicher Seite beigemessen wird. So bildet die Nichtigkeitsbeschwerde in der österreichischen Strafprozeßordnung nicht ein ordentliches Rechtsmittel, sondern lediglich einen Rechtsbehelf im weiteren Sinne, dessen Anwendung im Regelfall ohne negative Auswirkung auf den betroffenen Bürger bleibt ${ }^{173}$. Im Dritten Reich und der DDR hingegen wurden beide Rechtsinstitute als probate Mittel genutzt, um die Rechtskraft von Urteilen dann außer Kraft zu setzen, wenn dies aus Gründen der Herrschaftssicherung notwendig erschien. Insofern lagen die Parallelen zwischen Kassation und Nichtigkeitsbeschwerde genau da, wo Schumann ihre Existenz am entschiedensten verneinte.

Mit Errichtung des Obersten Gerichts und der Obersten Staatsanwaltschaft erhielt die Kassation eine sehr viel stärker unter dem Vorbehalt des Politischen stehende Funktion. Die Kassation wurde zu einem Steuerungsinstrument, das vor allem die Einheitlichkeit der Rechtsprechung in der DDR garantieren sollte. Daher wurde die Kassationsbefugnis den Oberlandesgerichten entzogen und allein dem Obersten Gericht zugesprochen. Zudem konnten seit dieser Zeit auch Urteile in Zivilsachen kassiert werden ${ }^{174}$. Die Kassation dürfe somit nicht mehr, wie Melsheimer vor den Generalstaatsanwälten der Länder am 16. November 1950 ausführte, als ein Rechtsmittel angesehen werden, „durch das in allen Fällen eine neue Instanz eröffnet werden kann“. Kassationen, so fuhr er fort, sollten vielmehr "grundsätzlich nur in Dingen eingereicht und durchgeführt werden, die von einer gewissen allgemeinen Bedeutung sind. Dabei kommt es keineswegs auf die Höhe des Objekts an, sondern auf das Urteil, das angegriffen wird." Die Entscheidung über die „allgemeine Bedeutung“ einer Sache war freilich von politischen Vorgaben abhängig, die somit für die Kassationsrechtsprechung oft maßgeblich wurden ${ }^{175}$.

Kassationen wurden beim Obersten Gericht zwar allein vom Generalstaatsanwalt der DDR beantragt; sie konnten aber von anderen Justizbehörden bei diesem angeregt werden. Aufgrund ihrer schwachen Besetzung war die Oberste Staatsanwaltschaft auf solche Anregungen geradezu angewiesen. In diesem Zusammenhang erwies sich auch die in den samstäglichen Besprechungen des Obersten Gerichts durchgeführte Auswertung der oberlandesgerichtlichen Rechtsprechung als nützlich. Das Oberste Gericht regte somit oftmals selbst Kassationsentscheidungen an ${ }^{176}$, wenngleich derartige Vorschläge nicht immer das Ergebnis kollektiver Beratungen sein mußten ${ }^{177}$. Die Besprechungen über die Urteile der Oberlandesgerichte ergaben jedoch durchaus auch Entscheidungen unterhalb eines Kassationsvorschlags. Da das Oberste Gericht Kassationen gezielt nur zur Aufhebung von Entscheidungen übergeordneter Bedeutung einsetzen wollte, beschränkte es sich bei weniger wichtigen Sachen auf andere Maßnahmen wie Mitteilung an den

173 Vgl. Esch, Kassation, S. 20.

174 Vgl. dazu Reich, Kassation in Zivilsachen.

175 Auszug aus dem Protokoll über die Arbeitstagung bei der Obersten Staatsanwaltschaft, 16.11. 1950, Referat Melsheimer, BAB, DP3 Nr. 25, Bl. $99 \mathrm{f}$.

176 Im ersten Halbahr 1952 etwa wurde „ein wesentlicher Teil der ergangenen Kassationsentscheidungen" vom Obersten Gericht selbst angeregt: siehe Analyse und Zusammenfassung der Gerichtstätigkeit des OG, 1. Halbjahr 1952, BAB, DP1 VA Nr. 7939.

177 Eine Kassation konnte etwa auch aufgrund einer Konsultation zwischen Benjamin und Schumann angeregt werden: vgl. Benjamin an Schumann, 3. 3. 1953, BAB, DP1 VA Nr. 5578. 
betreffenden Oberlandesgerichtspräsidenten, Kritik an einer Urteilsbegründung, Übersendung eines fehlerhaften Urteils an die Kontrollabteilung des Justizministeriums und Besprechung eines Urteils in der „Neuen Justiz“"178.

Obwohl das Oberste Gericht die Entscheidung jedes anderen Gerichts kassieren konnte, konzentrierte es sich bei seiner Beobachtung und Auswertung der Rechtsprechung auf die Oberlandesgerichte. Dies lag unmittelbar nach seiner Gründung auch nahe, ging es doch darum, seinen Vorrang gegenüber den höchsten Gerichtshöfen der Länder durchzusetzen. Nachdem dies - wie noch zu zeigen sein wird - Anfang 1952 weitgehend erreicht war, stellte die oberlandesgerichtliche Rechtsprechung keine befriedigende Grundlage der Kassationsrechtsprechung mehr dar, da auf diese Weise „nur unverhältnismäßig wenige und vielleicht auch nicht immer die bedeutsamsten Entscheidungen" erfaßt werden konnten ${ }^{179}$. Auf einer Arbeitstagung bei der Obersten Staatsanwaltschaft am 15. Mai 1952 bemängelte Ostmann, daß bisher „keine planmäßige systematische Auswahl der Kassationsfälle vorgenommen worden“ sei, und Benjamin forderte „eine systematische Kontrolle zumindest der Strafurteile“, um eine „fortschrittliche Rechtsprechung " zu entwickeln ${ }^{180}$. Eine umfassende Überprüfung der Rechtsprechung konnte nach der - wohl zutreffenden - Auffassung des Obersten Gerichts von der Staatsanwaltschaft „aus personellen Gründen“ nicht geleistet werden; statt dessen sollten „die Leiter der übergeordneten Gerichte sich mit einer intensiven systematischen Kontrolle der Rechtsprechung der ihnen untergeordneten Gerichte befassen"181. Dieser Wunsch blieb jedoch vorerst Zukunftsmusik, und das MdJ verhinderte zunächst noch eine derartig umfassende Urteilskontrolle ${ }^{182}$. Ein erster Ansatz in dieser Richtung bildete die auf der Arbeitstagung am 24. September 1952 besprochene Kontrolle der Rechtsprechung in Jugendstrafsachen im Bezirk des Landgerichts Chemnitz. Eine systematische Auswertung von Gerichtsurteilen erfolgte durch die einzelnen Senate des Obersten Gerichts erst seit Anfang 1953183. Diese Entwicklung ging Hand in Hand mit einer im Oktober 1952 eingeleiteten Neuregelung der Senatszuständigkeiten, die nun nicht mehr nur nach Deliktsgruppen, sondern auch nach Bezirken vorgenommen wurde ${ }^{184}$.

Wenngleich das Oberste Gericht bis 1952 noch nicht zu einer umfassenden Steuerung der Gerichte in der Lage war, versuchte es, durch gezielte Kassationen in wirtschaftsstrafrechtlichen Sachen die Rechtsprechung zu verschärfen. Dabei ging es zunächst um die Wirtschaftsstrafverordnung vom 23. September 1948, die in $\$ 1$, Absatz 1 über eine weit dehnbare Blankettvorschrift verfügte, derzufolge

178 Vgl. Arbeitstagung der Richter des OG und der Staatsanwälte der OStA am 3.6. 1950, BAB, DP2 Nr. 343; vgl. auch Gängel, Das Oberste Gericht, S. 256.

179 So die Analyse und Zusammenfassung der Gerichtstätigkeit des OG, 1. Halbjahr 1952, BAB, DP1 VA Nr. 7939.

180 Protokoll über die Arbeitstagung der Obersten Staatsanwaltschaft, 15. 5. 1952, BAB, DP3 Nr. 25a, Bl. $86 f ., 88$.

181 So die Analyse und Zusammenfassung der Gerichtstätigkeit des OG, 1. Halbjahr 1952, BAB, DP1 VA Nr. 7939.

182 Siehe dazu Kap. B.VIII.3.

183 Siehe Gesamtarbeitsplan des OG für das I. Quartal 1953; BAB, DP1 VA Nr. 6799; Urteilsauswertung des 1a Strafsenats des OG im 1. Quartal 1953, und 3. Strafsenat, Bericht über die Urteile des Bezirksgerichts Dresden, ebenda.

184 Siehe oben, S. 452. 
die Gefährdung „der Wirtschaftsplanung oder der Versorgung der Bevölkerung“ mit Zuchthaus und mit Vermögenseinziehung zu bestrafen war. Absatz 2 lautete: "Liegt ein minderschwerer Fall vor oder ist die Tat fahrlässig begangen, so ist auf Gefängnis und Geldstrafe oder auf eine dieser beiden Strafen zu erkennen." 185 Das Oberste Gericht beriet am 15. Juli 1950 über die Frage, ob bei der Bewertung eines Falles als "minderschwer" auch subjektive, also in der inneren Einstellung des Täters liegende Momente geltend gemacht werden könnten. Während Melz und Cohn zu dieser Auffassung tendierten, waren alle anderen Anwesenden, allen voran Schumann und Benjamin, der Auffassung, daß subjektive Momente dabei keinerlei Rolle spielen dürften, sondern ausschließlich der Grad der Gefährdung des Wirtschaftsplans oder der Versorgung zum Kriterium gemacht werden müßten. Hintergrund dieser Diskussion war, wie Schumann darlegte, „daß in vielen Fällen die Richter versuchen, einen Ausweg zu finden, um an der Vermögenseinziehung vorbei zu kommen". Nachdem am Ende der Beratung weitgehende Übereinstimmung auf der Linie des Präsidenten und des Vizepräsidenten erzielt worden war, gab Schumann die Anweisung, der zweite Strafsenat solle „die Frage grundsätzlich in einem Urteil beantworten, um den unteren Gerichten den Weg zu zeigen und ihnen die Möglichkeit zu nehmen, der Vermögenseinziehung auszuweichen" ${ }^{186}$. Bereits am 20. Juli gelangte dieser zu einem entsprechenden Urteil, in dessen Begründung ausdrücklich darauf hingewiesen wurde, daß ,ausschließlich in der Person des Täters liegende Umstände [...] bei der Entscheidung, ob ein minderschwerer Fall vorliegt, außer Betracht bleiben " müßten ${ }^{187}$.

Ähnlich ging das Oberste Gericht im Zusammenhang mit dem Handelsschutzgesetz vor, das den Warenverkehr von der DDR nach West-Berlin genehmigungspflichtig machte und in $\$ 2$, Absatz 1 das Zuwiderhandeln mit einer mindestens dreijährigen Gefängnisstrafe bedrohte; in „besonders schweren Fällen“, so Absatz 2, müsse eine mindestens fünfjährige Zuchthausstrafe und Vermögenseinziehung verhängt werden. Als besonders schwer galt ein Fall unter anderem dann, „wenn die Tat gewerbsmäßig begangen" wurde ${ }^{188}$. Das Oberste Gericht stellte nun fest, daß die Gerichte vor der Anwendung des $\$ 2$, Absatz 2 zurückschreckten, wobei offensichtlich vor allem die Frage der Gewerbsmäßigkeit meistens negativ entschieden wurde. Nach einem Referat und einer längeren Diskussion über dieses Spezialproblem auf der Arbeitstagung mit den Oberlandesgerichtspräsidenten am 23./24. November $1951^{189}$ fällte das Oberste Gericht am 7. Februar 1952 ein Urteil, in dem es hieß: „Auch ein einziger, nicht in Wiederholungsabsicht unternommener ungenehmigter Warentransport, durch den der Täter einen erheblichen Gewinn erzielen will, kann die Annahme einer gewerblichen Handlung rechtfertigen." 190 Die Richtung des Urteils war eindeutig: Durch die weite Auslegung des Begriffs „Gewerbsmäßigkeit“" mußten die Gerichte von sehr viel mehr „besonders

185 Gedruckt in: ZVOBl. 1948, S. 431.

186 Niederschrift über Arbeitstagung der Oberrichter, Richter und Staatsanwälte des OG und der OStA am 15. 7. 1950, BAB, DP2 Nr. 343.

187 Gedruckt in: NJ 4 (1950), S. $405 \mathrm{f}$.

188 Gedruckt in: GBl. 1950, S. 327.

189 2. Arbeitstagung der Richter des OG mit den OLG-Präsidenten und den Richtern der OLG am 23./24. 11. 1951, Referat Melz und anschließende Diskussion, BAB, DP2 Nr. 346.

190 Gedruckt in: NJ 6 (1952), S. 127. 
schweren Fällen" als bisher ausgehen, härtere Strafen verhängen und mehr Vermögen einziehen. Beide Urteile standen somit eindeutig im Dienst einer Wirtschaftsstrafrechtsprechung, die nicht nur strafverschärfend wirken, sondern auch Unternehmern und Gewerbetreibenden ihre Existenzgrundlage nehmen und den „volkseigenen“ Sektor in der Wirtschaft stärken sollte.

Solche Urteile fanden damals noch nicht direkt Eingang in die allgemeine Rechtsprechung. Trotz der höchstrichterlichen Auslegung des „minderschweren Falles" nach $₫ 1$, Absatz 2 der Wirtschaftsstrafverordnung mußte das Oberste Gericht auch im zweiten Halbjahr 1950 eine ähnlich hohe Anzahl von in dieser Hinsicht fehlerhaften Entscheidungen kassieren wie im ersten Halbjahr. Denn „immer wieder“, so Schumann im März 1951, werde „direkt oder indirekt der Versuch gemacht, subjektive Momente für die Begründung des minderschweren Falles heranzuziehen"191. Auch im November 1951 behandelte Stegmann auf der Arbeitstagung mit den Oberlandesgerichtspräsidenten deren „Ausweichen vor der Anwendung des Normalfalles nach $₫ 1$ Abs. 1 WStVO“, wobei wieder hauptsächlich eine Überbetonung subjektiver Momente dafür verantwortlich gemacht wurde ${ }^{192}$. Erst ab 1952, als derartige Mängel nicht mehr erwähnt wurden, scheint sich die Rechtsprechung der unteren Gerichte an diesen Rechtsgrundsatz des Obersten Gerichts gehalten zu haben. Dessen Durchsetzungsvermögen war 1951 folglich noch begrenzt, wenngleich die zunehmende Ausschaltung einer eigenständigen oberlandesgerichtlichen Rechtsprechung sich zusehends bemerkbar machte.

Das Verhältnis des Obersten Gerichts zu den Oberlandesgerichten war nach Gründung der DDR noch ungeklärt, da ersteres nicht in den traditionellen Gerichtsaufbau eingebunden wurde. Es geriet daher in Konkurrenz zu den Oberlandesgerichten, die lediglich ihre Kassationsbefugnis einbüßten, im übrigen aber auch weiterhin in der Lage waren, durch Revisionsurteile und Veröffentlichung ihrer Grundsatzurteile auf traditionelle Weise die Rechtsprechung der unteren Gerichte anzuleiten. Nachdem das Oberste Gericht über ein Jahr lang die Rechtsprechung der Oberlandesgerichte ausgewertet hatte, berief es zum 2./3. März 1951 deren Präsidenten und Richter zu einer Arbeitstagung nach Berlin ein, um seinen Führungsanspruch möglichst wirkungsvoll zu reklamieren. Schumann packte in seinem Grundsatzreferat den Stier bei den Hörnern, indem er ohne viele Umschweife die „föderalistischen Tendenzen in der Rechtsprechung“ als „ein wesentliches Hemmnis in der Entwicklung einer einheitlichen Rechtsprechung “ bezeichnete. Nach der Auflösung fast aller Landesjustizministerien versuchten einzelne Oberlandesgerichte "die geschwächte Position der Justizhoheit in noch stärkerem Maße als bisher zu verteidigen“. Ungeachtet der Stichhaltigkeit dieses Vorwurfs eignete er sich bestens, um die nun folgende harsche Kritik an den Oberlandesgerichten zu rechtfertigen. Ihre veröffentlichten Entscheidungen hätten meistens „keine Bedeutung über den Einzelfall hinaus“, trügen daher nur wenig zur Einheitlichkeit der Rechtsprechung in den einzelnen Ländern bei und ver-

191 Arbeitstagung der Richter des OG mit den OLG-Präsidenten und den Richtern der OLG am 2./ 3. 3. 1951, Referat Schumann, BAB, DP2 Nr. 345.

192 2. Arbeitstagung der Richter des OG mit den OLG-Präsidenten und den Richter der OLG am 23./ 24. 11. 1951, Referat Stegmann, BAB, DP2 Nr. 346. 
stießen außerdem mehrfach gegen das zentrale Ziel, „die Einheit der Rechtsprechung in der Republik zu schaffen". Zudem widersprächen sich die Oberlandesgerichte oft in ihrer eigenen Rechtsprechung und stifteten somit bei den unteren Gerichten eine solche Verwirrung, daß sich diese weigerten, den Revisionsgerichten zu folgen. Die Oberlandesgerichte hatten Schumann zufolge also wenig effizient und effektiv gearbeitet. Sehr viel schwerer wog jedoch der Vorwurf, sie hätten in Revisionsverfahren "unter Berufung auf die frühere Kassationsbefugnis“ nicht nur Rechtsverletzungen, sondern auch Strafzumessungsgründe nachgeprüft und damit in die Kompetenzen des Obersten Gerichts eingegriffen ${ }^{193}$. Schließlich monierte Schumann, daß auch die Oberlandesgerichte die Entscheidungen des Obersten Gerichts „über den Rahmen des Einzelfalles hinaus nicht beachteten oder vielleicht sogar völlig ignorierten" ${ }^{194}$.

Diese Ausführungen verfehlten ihre Wirkung auf die Zuhörer nicht. Die Oberlandesgerichte stellten zwar seit ihrer Konstituierung im Jahre 1945 die höchsten Gerichtsinstanzen in der SBZ/DDR dar; sie setzten sich aber 1951 bereits weitgehend aus loyalen Dienern des Systems zusammen und erwiesen sich als durchaus bereit, Urteilskorrekturen im Sinne des Regimes vorzunehmen ${ }^{195}$. Die Oberlandesgerichtspräsidenten und die Mehrzahl der ihnen unterstellten Richter verstanden sich daher keineswegs als Anwälte eines föderal gegliederten rechtsstaatlichen Justizwesens und unterwarfen sich bereitwillig dem deutlich verkündeten Führungsanspruch des Obersten Gerichts. Daher konnte Schumann auf der zweiten Arbeitstagung am 23./24. November 1951 eine aus seiner Sicht positive Bilanz der vorangegangenen Monate ziehen. So hätten die Oberlandesgerichte, von wenigen Ausnahmen abgesehen, keine Versuche mehr unternommen, „eine selbständige Rechtsprechung in den einzelnen Ländern zu finden", und darauf verzichtet, ihre eigene Grundsatzrechtsprechung zu veröffentlichen ${ }^{196}$. Auch würden sie nicht mehr „das Recht der Nachprüfung der Urteile im Revisionsverfahren nach Grundsätzen der Kassation für sich in Anspruch nehmen", und schließlich bemühten sie sich, in ihrer Rechtsprechung die vom Obersten Gericht veröffentlichten Rechtsgrundsätze zu beachten, was jedoch nicht ausschloß, „daß eine nicht geringe Zahl unterer Richter nach wie vor an den Veröffentlichungen in der ,Neuen Justiz'vorbeigeht" 197 .

Die Zusammenkünfte mit den Oberlandesgerichtspräsidenten in Berlin eigneten sich darüber hinaus, um die Rechtsprechung der unteren Gerichte auf anderem Wege als durch Kassationen zu beeinflussen. Dabei lassen sich vor allem drei unterschiedliche Möglichkeiten unterscheiden. Erstens konnten dort allgemeine

193 Dies war auch in der Arbeitstagung des Obersten Gerichts vom 16.2. 1951 im Hinblick auf ein Urteil des OLG Erfurt thematisiert worden: siehe Niederschrift der Arbeitstagung, BAB, DP2 Nr. 344.

194 Arbeitstagung der Richter des OG mit den OLG-Präsidenten und den Richter der OLG am 2./ 3. 3. 1951, Referat Schumann, BAB, DP2 Nr. 345. Vgl. auch Bericht über die 1. Arbeitstagung, S. $156 \mathrm{f}$.

195 Vgl. die Aussage des Thüringer Oberlandesgerichtspräsidenten Großmann, in: Arbeitstagung der Richter des OG mit den OLG-Präsidenten und den Richter der OLG am 2./3. 3. 1951, BAB, DP2 Nr. 345.

196 Dies war am 9./10. 3. 1951 vom MdJ festgelegt worden: siehe Arbeitstagung des MdJ, S. 166.

197 2. Arbeitstagung der Richter des OG mit den OLG-Präsidenten und den Richter der Oberlandesgerichte am 23./24. 11. 1951, Referat Schumann, BAB, DP2 Nr. 346. 
Grundsätze verkündet werden. Dies gilt vor allem für Benjamins Referat auf der ersten Tagung, in dem sie unter dem Stichwort "demokratische Gesetzlichkeit" erläuterte, „daß die Richter einerseits an die geltenden Gesetze gebunden sind, andererseits aber diese im Sinne unserer antifaschistisch-demokratischen Ordnung anzuwenden haben". Sehr viel deutlicher war ihre Ermahnung, daß die Gerichte „keine Weichheit und keine Schwäche gegenüber den Gegnern unserer Ordnung zeigen dürfen, und daß harte Strafen auch richtige Strafen sind“, wobei sie jedoch auch ein ausreichendes politisches Verständnis der obersten Gerichte forderte, um zu erkennen, wann eine weniger harte Strafe angebracht sei. Zweitens konnten bei solchen Tagungen spezielle Hinweise gegeben werden, die etwa eine Durchbrechung strafprozessualer Grundsätze bedeuteten. Angesichts einer Strafrechtsprechung, die mangels Beweisen Beschuldigte unter Berufung auf den Grundsatz „, in dubio pro reo" laufen ließ, sah die Vizepräsidentin des Obersten Gerichts beispielsweise keine Notwendigkeit mehr, nur in einem richterlichen Protokoll ein zulässiges Beweismittel zu sehen: Die „Staatsstruktur“ der DDR gebiete vielmehr, den Protokollen der ZKK und des MfS „den gleichen Beweiswert zu[zu]erkennen wie sog. richterlichen Protokollen "198. Drittens nutzte das Oberste Gericht vor allem die zweite Arbeitstagung, um anhand seiner Auswertung der oberlandesgerichtlichen Rechtsprechung die Gesetzesanwendung der unteren Gerichte in seinem Sinne zu beeinflussen: Dies betraf etwa die Rechtsprechung auf Grundlage der Wirtschaftsstrafverordnung, des Handelsschutzgesetzes und von Artikel 6 der DDR-Verfassung ${ }^{199}$. Obwohl Schumann anläßlich der ersten Arbeitstagung vollmundig verkündet hatte, die Besprechung mit den Oberlandesgerichtspräsidenten solle „eine ständige Einrichtung werden“, blieb es bei den beiden Veranstaltungen vom März und November 1951. Daher können nach wie vor bestehende, vom Obersten Gericht festgestellte ,Mängel' in der Rechtsprechung, wie etwa die Tendenz, durch Verurteilungen nach Artikel III A III von Kontrollratsdirektive Nr. 38 die Verhängung der sehr viel härteren Strafen nach Artikel 6 der Verfassung zu umgehen ${ }^{200}$, auch auf die mangelnde Intensität dieser Art der Beeinflussung zurückgeführt werden.

Mit dem neuen Gerichtsverfassungsgesetz und der neuen Strafprozeßordnung vom Oktober 1952 änderten sich die Stellung und die Justizsteuerungsmöglichkeiten des Obersten Gerichts grundlegend. Denn nunmehr wurde das Oberste Gericht in den Instanzenzug integriert, indem es die Kompetenz erhielt, über die Rechtsmittel des Protests, der Berufung 201 und der Beschwerde gegen erstinstanzliche Entscheidungen der Bezirksgerichte vorzugehen. Daneben behielt es seine Funktion als Kassationsgericht, war jedoch nicht mehr auf einen Kassationsantrag des Generalstaatsanwalts angewiesen, da auch der Präsident des Obersten Gerichts antragsberechtigt wurde. Da über zweitinstanzliche Verfahren eine direkte

198 Benjamin, Grundsätzliches zur Methode und zum Inhalt der Rechtsprechung, S. $154 \mathrm{f}$.

199 Siehe die Referate von Stegmann, Melz und Rothschild auf der 2. Arbeitstagung der Richter des OG mit den OLG-Präsidenten und den Richter der Oberlandesgerichte am 23./24. 11. 1951, BAB, DP2 Nr. 346.

200 Vgl. Analyse und Zusammenfassung der Gerichtstätigkeit des OG, 1. Halbjahr 1952, BAB, DP1 VA Nr. 7939.

201 Diese traten an die Stelle der Revision: Protest konnte vom Staatsanwalt, Berufung vom Angeklagten eingelegt werden. Vgl. $\$ 274$, Abs. 1 StPO. 
Einwirkungsmöglichkeit auf die Gerichte gegeben war - die Schumann zu nutzen gedachte ${ }^{202}$-, trat bereits im ersten Halbjahr 1953 die Kassationstätigkeit des höchsten Gerichts gegenüber seiner Tätigkeit als Rechtsmittelgericht stark in den Hintergrund ${ }^{203}$.

Das Oberste Gericht erhielt zudem mit $₫ 58$ GVG das Recht, auf Antrag seines Präsidenten, des Generalstaatsanwalts oder des Justizministers „Richtlinien mit bindender Wirkung für alle Gerichte zu erlassen“. Ebenso wie die neuen Möglichkeiten hinsichtlich der zweitinstanzlichen und Kassationsrechtsprechung war diese Kompetenz nach der bereits erwähnten Moskaureise einer DDR-Juristendelegation aus dem sowjetischen Gerichtsverfassungsgesetz übernommen worden $^{204}$. Von dieser Möglichkeit der Rechtsetzung „im Interesse einer einheitlichen Anwendung und Auslegung der Gesetze" machte das Oberste Gericht bereits 1953 vier Mal Gebrauch, wobei drei der erlassenen Richtlinien die politisierte Strafrechtsprechung betrafen. War die erste Richtlinie vom 29. April noch dazu gedacht, Gerichte daran zu hindern, die harten Mindeststrafen der Wirtschaftsstrafgesetze durch eine bedingte Strafaussetzung de facto zu mildern, zielten Richtlinien Nr. 3 und 4 im Zuge des „Neuen Kurses“ darauf ab, der harten Strafrechtsprechung nach dem Volkseigentumsschutzgesetz und dem Handelsschutzgesetz entgegenzuwirken, indem ihre Anwendung nur noch für die schweren Verstöße vorbehalten blieb205. Die letzten beiden Richtlinien gingen direkt auf eine Weisung der Sowjetischen Hohen Kommission zurück. Während Benjamin Ende Juli/Anfang August 1953 gegenüber Oberst Titow noch dafür eingetreten war, das Volkseigentumsschutzgesetz durch die Volkskammer abändern zu lassen, bestand dieser auf einer Richtlinie des Obersten Gerichts ${ }^{206}$. Am 10. August folgte ein entsprechendes "Merkblatt"; ein weiteres galt der Anwendung des Handelsschutzgesetzes $^{207}$. Vor diesem Hintergrund betraute Benjamin Abteilungsleiter Reinartz mit der Ausarbeitung der beiden Richtlinien, die das Oberste Gericht dann formell auf Antrag des Justizministeriums am 28. und 30. Oktober 1953 erließ208. Die Verabschiedung dieser Richtlinien kann somit nicht als Ausdruck eigenständiger Rechtsetzungskompetenz des Obersten Gerichts bewertet werden; die Beteiligung anderer Instanzen an der Ausarbeitung auch der ersten zwei Richtlinien des Jahres 1953 läßt sich freilich nicht nachweisen, so daß bei generellen Aussagen über deren Ursprung Vorsicht geboten erscheint ${ }^{209}$. Insgesamt wurde von der

202 Vgl. Niederschrift über die Arbeitstagung der Richter des OG und der OStA am 4. 10. 1952, BAB, DP2 Nr. 347; vgl. Gängel, Das Oberste Gericht, S. 260.

203 Analyse und zusammenfassender Bericht über die Tätigkeit des OG im 1. Halbjahr 1953, BAB, DP1 VA Nr. 176, Bl. 4.

${ }^{204} \mathrm{Vgl}$. Vorläufiger Bericht der Studiendelegation der Juristen und Auswertung der Ergebnisse, o.D., BAB, DP1 VA Nr. 175; Müller-Römer, Zur Rechtsnatur der Richtlinien, S. 152.

205 Vgl. ebenda, S. 153; Richtlinie Nr. 2 vom 20. 5. 1953 betraf die Bemessung der Frist zur Einlegung und Begründung der Berufung im arbeitsgerichtlichen Verfahren.

206 Benjamin an Titow, 29. 7. 1953 (mit Bezug auf eine Unterredung am 28. 7.), Benjamin an Grotewohl, 1. 8. 1953, BAB, DP1 SE Nr. 3321.

207 Die beiden „Merkblätter" vom 10.8. 1953, ebenda.

208 Bericht, 19. 11. 1953, AdsD, Ostbüro 0048a.

${ }_{209}$ Dies gegen Frank, Justizministerium, S. 92, der aufgrund der Aussage eines geflohenen MdJ-Mitarbeiters davon ausgeht, daß die "Richtlinien zumindest in der Zeit vor 1953 [sic] nicht beim Obersten Gericht, sondern in der Gesetzgebungsabteilung des Justizministeriums erarbeitet wurden“. Ähnlich Gängel, Das Oberste Gericht, S. 262. 
Möglichkeit, Richtlinien zu erlassen, spärlich Gebrauch gemacht; bis 1958 waren es lediglich elf, bis $198834^{210}$.

Die neue Strafprozeßordnung führte mit der sogenannten „Gerichtskritik“ und der Möglichkeit der Erteilung von Weisungen mit bindender Kraft weitere Methoden der Justizsteuerung ein, die generell von zweitinstanzlichen Gerichten also auch vom Obersten Gericht - genutzt werden konnten. Gerichtskritik nach $\$ 4$, Absatz 1 StPO konnte nur geübt werden, wenn das übergeordnete Gericht eine Gesetzesverletzung eines unteren Gerichts bei Durchführung eines Strafverfahrens feststellte. Dies kam zumindest im ersten Halbjahr 1953 nur selten vor ${ }^{211}$. Nach $\$ 293$, Absatz 3 StPO wurde dem Gericht zweiter Instanz die Möglichkeit eingeräumt, bei Zurückverweisung eines Urteils im Rechtsmittelverfahren „Weisungen mit bindender $\mathrm{Kraft}^{\text {“ }} \mathrm{zu}$ erteilen. Zwar wurden diese Weisungen „in der Regel beachtet“212, sie konnten aber auch 1953 noch zu Konflikten führen. Beispielsweise hatte das Oberste Gericht ein Urteil des Bezirksgerichts Suhl vom 17. Februar 1953 aufgehoben und mit der Weisung höherer Strafe zurückverwiesen; in seinem neuen Urteil vom 26. März war das Bezirksgericht der Weisung jedoch nicht gefolgt und begründete seine Auffassung damit, „daß eine Weisung des höheren Gerichts nicht die Überzeugung des einzelnen Richters ersetzen kann und der Richter mit seiner Unterschrift unter das Urteil die Verantwortung trägt und sich nicht auf die Weisung des höheren Gerichts berufen kann"213.

Das Oberste Gericht, das nach GVG als Gericht zweiter Instanz und als Kassationsgericht auch „die Aufsicht über die Rechtsprechung der unteren Gerichte ausübt", beteiligte sich ebenfalls mit den eigenen Richtern an den bis zu diesem Zeitpunkt dem MdJ vorbehaltenen Gerichtsrevisionen ${ }^{214}$. Freilich wollte es nicht bei der Feststellung von Mängeln stehen bleiben, sondern erteilte auch Hinweise an die Bezirksgerichte. Benjamin ordnete in einer Arbeitstagung am 1. November 1952 nach dem Bericht Heinrich Löwenthals über die Revision des Bezirksgerichts Dresden an, diese Hinweise in Abschrift dem MdJ zu übersenden und zu sammeln, „um feststellen zu können, inwieweit das Oberste Gericht zur Entwicklung der Rechtspraxis beigetragen hat " ${ }^{215}$. Das Oberste Gericht wollte also unter Nutzung der ihm 1952 eingeräumten Möglichkeiten sehr viel stärker als bisher der Rechtsprechung seine eigene Prägung aufdrücken und versuchte dabei auch, seinen direkten Kontakt zu den Gerichten zu intensivieren.

210 Siehe die Liste der Richtlinien ebenda, S. 284-286.

211 Analyse und zusammenfassender Bericht über die Tätigkeit des OG im 1. Halbjahr 1953, BAB, DP1 VA Nr. 176, Bl. 104.

212 Dies gilt zumindest für das 1. Halbjahr 1953: vgl. ebenda, Bl. 109.

${ }^{213}$ Siehe dazu Böhme an Fechner, 23. 5. 1953, Benjamin an Fechner, 24. 4. 1953, Urteilsabschrift des BG Suhl, BAB, DP1 SE Nr. 3145, Bl. 153-162 (Zitat Bl. 162). Nach Böhmes Auffassung war das Oberste Gericht nur hinsichtlich der rechtlichen Würdigung, nicht aber hinsichtlich der Beweiswürdigung zu Weisungen mit bindender Kraft befugt. Der Ausgang der Angelegenheit ist nicht überliefert.

214 Im ersten Halbjahr 1953 nahmen Richter des OG an der Revision der Bezirksgerichte in Frankfurt/Oder, Rostock, Schwerin, Potsdam, Leipzig und Magdeburg teil: Analyse und zusammenfassender Bericht über die Tätigkeit des OG im 1. Halbjahr 1953, BAB, DP1 VA Nr. 176, Bl. 108.

215 Niederschrift der Arbeitstagung der Richter des OG und der Staatsanwälte der OStA am 1.11. 1952, BAB, DP2 Nr. 347. 
Insgesamt konnte es bis 1952/53 seine Position bei der Anleitung der Justiz erheblich ausbauen. Dies bezog sich zum einen auf seine Stellung gegenüber den Oberlandesgerichten, die sich dem höchsten Gericht trotz dessen mangelnder Einbindung in den Instanzenzug nach den Arbeitstagungen vom März und November 1951 fast vorbehaltlos unterordneten. Dazu hatte eine gezielte Kassationsrechtsprechung beigetragen, deren Anspruch auf allgemeine Beachtung und Verbindlichkeit in zunehmendem Maße auch eingelöst wurde. Erste Ansätze zu einer systematischen Anleitung der Gerichte durch Kassationen wurden 1952/53 verwirklicht; freilich kam das Oberste Gericht auch in den folgenden Jahren damit nicht recht weiter ${ }^{216}$. Ohne die seit langem geplante, aber erst 1952 unter weitgehender Anlehnung an das sowjetische Vorbild durchgeführte Umgestaltung des GVG wäre das Oberste Gericht jedoch nie in die Lage versetzt worden, ein Steuerungszentrum zu werden, das dem Justizministerium ernsthaft Konkurrenz machen konnte.

\section{Die Oberste Staatsanwaltschaft und die Staatsanwaltschaft in der DDR: Zentralisierung, Aufgabenerweiterung und Justizsteuerung}

Die Staatsanwaltschaft in der DDR entwickelte sich zwischen 1949 und 1952 von einer bei den Gerichten angesiedelten und der Dienstaufsicht und Leitung des jeweils zuständigen Landesjustizministers unterstehenden Behörde zu einem nach sowjetischem Vorbild konstruierten, selbständigen und streng zentralistisch organisierten Justizorgan. Schon im Februar 1949 nahm Nathan nach Absprache mit dem Chef der SMAD-Rechtsabteilung den „Entwurf eines Staatsanwaltschaftsgesetzes" in den Arbeitsplan seiner Abteilung auf ${ }^{217}$. Die am 17. März übersandten "Grundsätze für die Aufstellung des Entwurfs eines Staatsanwaltschaftsgesetzes“ ließen bereits eine erste Annäherung an sowjetische Verhältnisse erkennen. Allein die Aufgabenbestimmung - „der Schutz der demokratischen Rechtsordnung und die Aufsicht über die Einhaltung ihrer Gesetze" - erinnerte an Artikel 113 der Stalinschen Verfassung der UdSSR über die „allgemeine Aufsicht“ über die Durchführung der Gesetze und die Einhaltung der Gesetzlichkeit als Aufgabe der Staatsanwaltschaft. Bei deren Konkretisierung stellte sich freilich heraus, daß diese in der SBZ weiterhin primär als Strafverfolgungsbehörde fungieren sollte. Indem Grundsatz Nr. 4 festhielt, daß die „Organe der Staatsanwaltschaft [...] nur dem Generalstaatsanwalt der Republik unterstellt und [...] in ihren Amtsverrichtungen von den Gerichten unabhängig" sein sollten, entfernte man sich jedoch erheblich von den deutschen Organisationsprinzipien ${ }^{218}$.

216 Vgl. Gängel, Das Oberste Gericht, S. 262, mit den entsprechenden Zitaten aus den OG-Tätigkeitsberichten von 1955, 1956 und 1957.

217 Arbeitsplan der Abteilung III/5 für das 1. Halbjahr 1949, 4. 2. 1949, BAB, DP1 VA Nr. 6214. Am 3. 2. 1949 hatte eine Besprechung zwischen Nathan und Karassjow stattgefunden: siehe Chef der DJV an Chef der SMAD-Rechtsabteilung, 17.3. 1949, BAB, DP1 VA Nr. 7158.

218 Ebenda. Siehe auch Punkt 14: „Die unteren staatsanwaltschaftlichen Behörden haben den dienstlichen Anweisungen der jeweils oberen Behörde nachzukommen.“ 
Obwohl mit Blick auf die DDR-Gründung vorbereitet, kamen die "Grundsätze“ nur teilweise im Gesetz über die Gründung des Obersten Gerichtshofes und der Obersten Staatsanwaltschaft zur Anwendung. Es begründete zwar die Oberste Staatsanwaltschaft als selbständige Behörde und das Weisungsrecht des DDR-Generalstaatsanwalts gegenüber den anderen Staatsanwaltschaften ${ }^{219}$, ließ aber deren anderweitige Unterstellung unter die Landesjustizminister unberührt. $\mathrm{Daß}$ es sich bei dieser Organisationsform nur um ein Provisorium handelte, war den führenden Justizpolitikern durchaus bewußt. 1950 jedenfalls wurden die Planungen für ein Staatsanwaltschaftsgesetz unter Einbeziehung der SKK fortgesetz $^{220}$. Zeitweise erwog Melsheimer, bereits im Vorfeld eine Ausführungsverordnung zum Gesetz über das Oberste Gericht und die Oberste Staatsanwaltschaft zu erlassen, derzufolge die Anweisungen des DDR-Generalstaatsanwalts auf personelle und organisatorische Angelegenheiten sowie auf "die Behandlung von Strafsachen im Allgemeinen und im Einzelfall“ ausgeweitet werden sollten; verwirklicht wurde diese Überlegung jedoch nicht ${ }^{221}$. Im Herbst 1950 beklagte sich Heinze auf Arbeitstagungen der Obersten Staatsanwaltschaft, daß die Generalstaatsanwälte der Länder ihre Behörden nicht richtig anleiteten und noch nicht einmal deren Stellenpläne kannten, da die Landesjustizministerien diese nicht zur Verfügung stellten ${ }^{222}$. Die Oberste Staatsanwaltschaft, die in zunehmendem Maße in die Lenkung der Justiz einbezogen wurde, sah offensichtlich in der mangelnden Zentralisierung der Staatsanwaltschaft auf Landesebene ein erhebliches organisatorisches Defizit, das baldmöglichst zu beseitigen war.

Vor diesem Hintergrund erfolgte im ersten Halbjahr 1951 eine Reorganisation und Vereinheitlichung der staatsanwaltschaftlichen Strukturen, die nach den Ausführungen Heinzes eine bessere Übersicht und eine „bessere Entwicklung der Kader" ermöglichen würde223. Mit Rundverfügung vom 9. Mai 1951 mußten bei allen Staatsanwaltschaften einschließlich der Behörden der Generalstaatsanwälte Abteilungen eingerichtet werden, von denen die erste für Strafverfahren nach Befehl Nr. 201 - also politische Strafverfahren -, die zweite für Wirtschaftsstrafsachen und die dritte für sonstige Strafsachen zuständig war ${ }^{224}$. Dies bedeutete insofern eine Neuregelung, als bis zu diesem Zeitpunkt eine Aufteilung der Staatsanwaltschaften in Abteilungen unüblich war; auch die nur in Mecklenburg existierenden, nicht einem Gericht zugeordneten Kreisstaatsanwaltschaften wurden im Zuge dieser Neuorganisation abgeschafft, durch die, wie Melsheimer schrieb, "eine einheitliche Anklagepolitik und eine einheitliche Rechtspolitik gefördert" werde ${ }^{225}$. Zusammen mit der Umstrukturierung der Obersten Staatsanwaltschaft

${ }^{219} \mathrm{Vgl}$. $\iint 8$ und 10 des Gesetzes über die Errichtung des Obersten Gerichtshofes und der Obersten Staatsanwaltschaft. Für Nathan ergab sich das Weisungsrecht des Generalstaatsanwalts aus dessen Befugnis, gegebenenfalls schwebende Strafverfahren an sich zu ziehen.

220 Die Vorschläge sind nicht alle erhalten; Fechner übersandte am 12.12. 1950 den 4. Entwurf eines Staatsanwaltschaftsgesetzes an die SKK-Justizabteilung, BAB, DP1 VA Nr. 7158.

221 Der Entwurf Melsheimers wurde am 19.6. 1950 mit Begleitschreiben Nathans Fechner vorgelegt, ebenda.

222 Protokolle der Arbeitstagungen vom 29. 9.und 16. 11. 1950, BAB, DP3 Nr. 25, Bl. 54, 82.

${ }^{223}$ So Heinze auf der Arbeitstagung vom 31.3. 1951, ebenda, Bl. 188.

${ }^{224}$ Rundverfügung Nr. 19, 9. 5. 1951, BAB, DP3 Nr. 19, Bl. $68 \mathrm{f}$.

225 Verfügung des Generalstaatsanwalts, 4. 7. 1951, mit Begründung, BAB, DP1 VA Nr. 612, Bl. 2931 (Zitat Bl. 31). 
waren nun die Voraussetzungen geschaffen, um Weisungen sehr viel effektiver von Berlin über die Länder zu den Oberstaatsanwaltschaften, durchstellen' zu können. Ebenfalls im ersten Halbjahr 1951 hatte die Oberste Staatsanwaltschaft „im Einvernehmen mit dem Ministerium der Justiz im wesentlichen die Leitung der staatsanwaltschaftlichen Tätigkeit in der Republik übernommen“. Dies schloß lediglich den größten Teil der Statistiken, einen Teil des Berichtswesens und die Bearbeitung der Personalangelegenheiten aus, die vorerst bei der Justizverwaltung verblieben226. Dieser Zustand war jedoch nicht von langer Dauer. Bereits am 24. Juli 1951 vereinbarten Melsheimer und Fechner, daß die Staatsanwaltschaft ein völlig eigenständiges „Organ der Justiz" werden sollte ${ }^{227}$. Nachdem das Sekretariat des $\mathrm{ZK}$ am 16. August zugestimmt hatte ${ }^{228}$, konnte die in der Obersten Staatsanwaltschaft ausgearbeitete „Verordnung über Maßnahmen zur Vereinfachung der Justiz" am 27. September von der Regierung erlassen werden²29. Dieser äußerst knapp gehaltene Rechtsakt besiegelte die Selbständigkeit der Staatsanwaltschaft, ihren zentralistischen Aufbau und vor allem die alleinige Entscheidungsgewalt des DDR-Generalstaatsanwalts in Personalangelegenheiten.

Die mit Regierungsverordnung vom 27. März 1952 und dem Gesetz vom 23. Mai 1952 festgelegte Ausweitung der staatsanwaltschaftlichen Befugnisse geht auf eine sowjetische Weisung zurück, die im "Justizbeschluß" des Politbüros vom 11. Dezember 1951 aufgegriffen und anschließend umgesetzt wurde. Ausgangspunkt bildete ein „Memorandum“ der SKK vom November 1951, in dem diese unter anderem die Untersuchungsorgane, die Justiz und die Staatsanwaltschaft heftig kritisierte 230 und anwies, die Mängel unter anderem dadurch abzustellen, daß die Staatsanwaltschaft "mit der Überwachung der Untersuchung und der Hafträume zu beauftragen“ "sei. Außerdem sollten "in nächster Zeit" die Arbeit an einer Reihe von Kodifikationen, unter anderem an der „Verordnung über die Staatsanwaltschaft" beendet werden ${ }^{231}$. Beide Anweisungen wurden im SED-Justizbeschluß aufgegriffen und präzisiert. Der Ministerrat sollte bis zum 31. März 1952 beschließen, daß der Staatsanwaltschaft die Aufsicht über alle Strafanstalten und „über alle Untersuchungen [...], die von den einzelnen Untersuchungsorganen (Polizei, Staatssicherheit, Staatl. Kontrolle, Amt für Kontrolle des Warenverkehrs) durchgeführt werden", übertragen wurde232. Es war vor allem auf das Drängen der SKK zurückzuführen ${ }^{233}$, daß dieser Zeitplan eingehalten und die Regierung am 27. März 1952 den „Beschluß über die Maßnahmen zur weiteren

226 Referat Melsheimers auf der Arbeitstagung am 21. 9. 1951, BAB, DP3 Nr. 25, Bl. 306.

${ }^{227}$ Vgl. dazu eine Notiz der Hauptabteilung Gesetzgebung im MdJ vom 8. 9. 1951, BAB, DP1 VA Nr. 7158.

228 Protokoll der Sekretariatssitzung, 16. 8. 1951, SAPMO, DY 30 J IV 2/3/224.

229 Melsheimer übersandte den Entwurf „wunschgemäß“ am 31.8.1951 mit einer Begründung dem MdJ, BAB, DP1 VA Nr. 7158. Zum Erlaß der Verordnung siehe Protokoll der 43. Regierungssitzung, BAB, DC 20 I/3, Nr. 69, Bl. 3. Die Verordnung in: GBl. 1951, S. 877.

$230 \mathrm{Vgl}$. dazu im Zusammenhang Kap. B.IX.1.

231 Dokument ohne Titel in russischer Sprache, o.D., SAPMO, NY 4090/301, Bl. 75 f.; die deutsche Übersetzung ebenda, Bl. 73 f., mit handschriftlicher Datierung „Nov. 51“.

232 Protokoll der Politbürositzung, 11. 12. 1951, SAPMO, DY 30 J IV 2/2/182, Anlage Nr. 3, Bl. 30.

${ }^{233}$ Siehe Vermerk über eine Besprechung am 5. 2. 1952 mit Melsheimer, Plenikowski, Fuchs, Mielke, Ruh, Ernst Lange, Fechner, SAPMO, DY 30 IV 2/13/408. 
Festigung der demokratischen Gesetzlichkeit" faßte ${ }^{234}$. Wie die Präambel verkündete, sollten damit nicht nur „die demokratische Gesetzlichkeit und die Rechtsordnung weiterhin“ gefestigt, sondern auch „die Unantastbarkeit der Persönlichkeit und die demokratischen Rechte der Bürger" gesichert werden: Die sowjetische Vorstellung, daß mehr Rechtssicherheit vor allem durch die Ausweitung staatsanwaltschaftlicher Aufsichtsrechte zu erreichen war, wurde somit auch in das Rechtsleben der DDR übernommen. Außerdem sollte durch das Recht des Staatsanwalts, Fristen zu setzen, eine straffere Arbeitsweise der Untersuchungsund Justizorgane erreicht werden. Der Generalstaatsanwalt konkretisierte am 31. März in den Rundverfügungen Nr. 7 bis 10235 über Verhaftung und vorläufige Festnahme, über die Aufsicht über die Untersuchungsorgane in Strafsachen, über die Festsetzung von Fristen für die Bearbeitung von Strafsachen und über die Aufsicht über die Haft- und Vollzugsanstalten die sehr allgemeinen Vorgaben der Verordnung 236. Die Rundverfügungen Nr. 11 und 12 vom selben Tag - über die Melsheimer nicht öffentlich informierte 237 - betrafen die „Aufsicht über die Untersuchungen in Strafsachen der Untersuchungsorgane des Ministeriums für Staatssicherheit" und die "Aufsicht über die Haftanstalten der Organe des Ministeriums für Staatssicherheit “238. Die staatsanwaltschaftlichen Aufsichtsrechte gegenüber dem MfS als Untersuchungsorgan waren auch auf dem Papier sehr viel stärker eingeschränkt als gegenüber den anderen Untersuchungsorganen: Der aufsichtsführende Staatsanwalt hatte zwar das Recht, jederzeit in die Untersuchungsakten des MfS Einsicht zu nehmen und sich an den Vernehmungen zu beteiligen, durfte jedoch nicht, wie etwa gegenüber der Polizei, konkrete Anweisungen im Einzelfall erteilen oder gar die Untersuchung an sich ziehen. Bei festgestellten Verletzungen der Gesetzlichkeit mußte sich der Staatsanwalt sowohl gegenüber dem MfS als auch gegenüber den anderen Untersuchungsorganen darauf beschränken, ,auf dem Dienstweg', also vor allem über die Benachrichtigung der Vorgesetzten der untersuchungführenden Personen, zur Abstellung dieser Mängel zu sorgen; die Einleitung eines Strafverfahrens gegen die Ermittlungsorgane selbst war nicht vorgesehen. Mehr Rechtssicherheit für den Beschuldigten war auf diese Weise gewiß nicht zu erreichen.

Die Ausarbeitung des Staatsanwaltschaftsgesetzes, das laut SED-Justizbeschluß zusammen mit den Neufassungen des Gerichtsverfassungsgesetzes, der Strafprozeßordnung und des Strafgesetzbuches vorbereitet werden sollte ${ }^{239}$, war insofern eine Besonderheit, als eine derartige Kodifikation noch nicht existierte. Die dafür zuständige Unterkommission der Gesetzgebungskommission konnte dabei unter anderem auf die Verordnung vom November 1951 zurückgreifen; außerdem zog

${ }^{234}$ Gedruckt in: Ministerialblatt 1952, S. 35.

${ }^{235}$ Melsheimer legte am 6. 3. 1952 Plenikowski Entwürfe des Ministerratsbeschlusses und der Rundverfügungen Nr. 7 bis 10 vor. Ruh, Fritz Lange und Fechner hatten bereits vorher zugestimmt: siehe SAPMO, DY 30 IV 2/13/408.

236 Rundverfügungen Nr. 7/52 bis $10 / 52$ des Generalstaatsanwalts der DDR, in: BAB, DP3 III, Nr. 121.

${ }_{237}$ Melsheimer informierte in seinem Artikel „Über die Arbeit der Staatsanwaltschaft" auf S. 206-208 nur über den Beschluß vom 27. 3. 1952 und die Rundverfügungen Nr. 7/52 bis 10/52.

238 Rundverfügungen Nr. 11/52 und 12/52 in: BAB, DP3 III, Nr. 121.

${ }_{239}$ Protokoll der Politbürositzung, 11. 12. 1951, SAPMO, DY $30 \mathrm{~J} \mathrm{IV} \mathrm{2/2/182,} \mathrm{Anlage} \mathrm{Nr.} \mathrm{3,} \mathrm{Bl.} 31 \mathrm{f}$. 
sie die entsprechenden Gesetze aus der RSFSR aus dem Jahre 1922, aus Polen und aus Bulgarien heran ${ }^{240}$. Nach den Beratungen der Unterkommission im März und April lag ein Gesetzentwurf vor, in den noch Anregungen von Jakupow und der SED-Abteilung Staatliche Verwaltung eingingen ${ }^{241}$, bevor er am 5. Mai 1952 vom Sekretariat, am 13. Mai vom Politbüro und zwei Tage darauf vom Ministerrat beschlossen wurde 242. Das von Ministerpräsident Grotewohl am 23. Mai 1952 in der Volkskammer persönlich begründete und einstimmig angenommene Gesetz ${ }^{243}$ wurde nicht zuletzt aufgrund des besonderen Interesses der SKK an diesem Justizorgan sehr viel früher verabschiedet als die anderen Justizgesetze. Die entscheidende Neuerung, die mit dem Staatsanwaltschaftsgesetz in der DDR durchgesetzt wurde, bildete die nach sowjetischem Vorbild eingeführte „Aufsicht über die Gesetzlichkeit": Der Staatsanwalt stand nun nicht mehr primär im Dienst der Verbrechensbekämpfung, sondern hatte, wie Grotewohl es ausdrückte, „über die Einhaltung der Gesetze durch alle Organe unseres demokratischen Staates und alle Bürger zu wachen "244. Dies bezog die Staatsverwaltung mit ein, so daß die Staatsanwaltschaft in gewisser Weise an die Stelle der Verwaltungsgerichtsbarkeit trat; die Gesetzlichkeitsaufsicht beschränkte sich freilich nicht auf die Verwaltung, sondern war prinzipiell auf alle staatlichen Tätigkeitsbereiche bezogen. Die Staatsanwaltschaften mußten also auf allen Ebenen zusätzlich eine Abteilung über die Einhaltung der Gesetzlichkeit und zur Bearbeitung von Beschwerden einrichten245: eine Aufgabenausweitung, die eine drastische und rasche Erhöhung der Anzahl der Staatsanwälte erforderte, so daß Sekretariat und Politbüro gemeinsam mit dem Staatsanwaltschaftsgesetz die "sofortige und kurzfristige Ausbildung von 220 Arbeitern zu Staatsanwälten" in einem dreimonatigen Sonderlehrgang beschlossen $^{246}$. Insgesamt klaffte bei diesem Aufgabenfeld der Staatsanwaltschaften jedoch eine erhebliche Lücke zwischen Ziel und Wirklichkeit. „Wir streben auch hier", so Melsheimer im August 1952, „dem Vorbild der Sowjetunion nach, wo die Arbeit der Staatsanwaltschaft zu $80 \%$ in der Ausübung dieser ,Allgemeinen Aufsicht' besteht und wo die Tätigkeit im gerichtlichen Verfahren nur $20 \%$ seiner Arbeitsleistung ausmacht, wobei wiederum $80 \%$ dieser Tätigkeit im gerichtlichen Verfahren sich auf die Tätigkeit im Zivilprozeßverfahren bezieht“"247. De facto

240 Siehe Protokoll der 1. Sitzung der Grundkommission zur Überprüfung strafrechtlicher Gesetze, 1. 3. 1952, BAB, DP1 VA Nr. 7785; Protokoll der Sitzung der Unterkommission für die Ausarbeitung des Staatsanwaltschaftsgesetzes, 8. 3. 1952, BAB, DP1 SE Nr. 412.

${ }^{241}$ Zur Tätigkeit der Unterkommission siehe ebenda und BAB, DP3 III, Nr. 121; zur Beteiligung Jakupows und der SED-Abteilung Staatliche Verwaltung siehe Melsheimer an Plenikowski, 22. 4. 1952, BAB, DP1 SE Nr. 412.

242 Protokoll der Sekretariatssitzung, 5. 5. 1952, SAPMO, DY 30 J IV 2/3/287, TOP 16; Protokoll der Politbürositzung, 13. 5. 1952, SAPMO, DY 30 J IV 2/2/211, TOP 9; Protokoll der Regierungssitzung, 15. 5. 1952, DC $20 \mathrm{I} / 3$, Nr. 107, TOP 17.

${ }^{243}$ Volkskammer, Sitzungen 1952, S. 601-606.

${ }^{244}$ Ebenda, S. 601; vgl. dazu nach wie vor Hellbeck, Staatsanwaltschaft, S. 28-37.

${ }^{245}$ Es handelte sich um die Abteilung V (die Abteilung IV war seit dem Regierungsbeschluß vom 27. März 1952 für die Aufsicht über die Haftanstalten zuständig): vgl. Bericht über die Tätigkeit der Staatsanwaltschaften in der DDR im 2. Halbjahr 1952, BAB, DP3 I Nr. 133.

246 Protokoll der Sekretariatssitzung, 5. 5. 1952, SAPMO, DY 30 J IV 2/3/287, TOP 16; Protokoll der Politbürositzung, 13. 5. 1952, SAPMO, DY 30 J IV 2/2/211, TOP 9.

247 Bericht über die Durchführung des Gesetzes über die Staatsanwaltschaft der DDR, August 1952, BAB, DP3 III, Nr. 121. 
blieb die Gesetzlichkeitsaufsicht jedoch stets eine gegenüber den anderen Funktionen der Staatsanwaltschaft untergeordnete Aufgabe ${ }^{248}$.

Die zentralistische Struktur der DDR-Staatsanwaltschaft ermöglichte im Vergleich zur Gerichtsbarkeit sehr viel intensivere Anleitungsformen von ,oben' nach ,unten'. Die Steuerung der Justiz war somit über die Oberste Staatsanwaltschaft auf sehr viel direkterem Wege möglich als über das Oberste Gericht. Dabei spielten Arbeitstagungen mit den Generalstaatsanwälten der Länder eine wesentliche Rolle. Während das Oberste Gericht bis 1952 lediglich zwei große Konferenzen mit den Oberlandesgerichtspräsidenten veranstaltete, kamen die Generalstaatsanwälte bzw. die Bezirksstaatsanwälte zwischen September 1950 und Oktober 1952 $21 \mathrm{Mal}$ in der Obersten Staatsanwaltschaft zusammen. Bei den Treffen waren meistens auch das Oberste Gericht, das Justizministerium, die Volkspolizei, das MfS, die ZKK und die SKK-Justizabteilung vertreten, so daß diese ebenfalls informiert wurden und gegebenenfalls Einfluß nehmen konnten. Anfänglich sollte die Wirkung dieser Arbeitstagungen zusätzlich noch dadurch erhöht werden, daß nach den Sitzungen den Generalstaatsanwälten Protokollauszüge mit den wesentlichen Inhalten der Besprechungen zugingen ${ }^{249}$. In dem Bestreben, diese Kommunikationsstrukturen auf die Staatsanwaltschaft insgesamt zu übertragen, ordnete die Oberste Staatsanwaltschaft am 9. Januar 1951 sowohl bei den Generalstaatsanwälten als auch bei den Oberstaatsanwälten regelmäßige Dienstbesprechungen an: alle 14 Tage beim Generalstaatsanwalt behördenintern und einmal im Monat mit den Oberstaatsanwälten des Landes, die sich ebenfalls vierzehntägig mit den Staats- und Amtsanwälten ihres Bezirks treffen sollten. Termine und Tagesordnung der Besprechungen waren dem Generalstaatsanwalt der DDR so rechtzeitig bekanntzugeben, daß einer seiner Mitarbeiter teilnehmen konnte250. Die Dienstbesprechungen bei den Generalstaatsanwälten fanden, so Melsheimers Eindruck im September 1951, regelmäßig statt, waren aber anscheinend oft ungenügend vorbereitet. An eine Teilnahme von Vertretern der Obersten Staatsanwaltschaft war aufgrund des Personalmangels nicht zu denken ${ }^{251}$.

Genauso wichtig wie die mündlichen waren die schriftlichen Kommunikationsstrukturen innerhalb der Staatsanwaltschaft. Dabei spielte das Berichtswesen eine ungleich wichtigere Rolle als die Rundverfügungen des DDR-Generalstaatsanwalts, die oft gemeinsam mit dem $\mathrm{MdJ}$ an die Landesjustizministerien und an die Generalstaatsanwälte verschickt wurden und generelle Hinweise enthielten. Durch das Berichtswesen wurde die Zentrale nicht nur über bedeutsame Verfahren informiert, sondern auch befähigt, diese gegebenenfalls im Einzelfall zu leiten, $\mathrm{zu}$ kontrollieren und sogar an sich zu ziehen ${ }^{252}$. Daher wurde diese Thematik in Rundverfügungen und Arbeitstagungen vor allem im ersten Jahr der sogenannten

${ }^{248} \mathrm{Vgl}$. Grasemann, Der sozialistische Staatsanwalt, S. 62; Behlert, Generalstaatsanwaltschaft, S. 327 f.; Mollnau, Staatsanwaltschaftliche Gesetzlichkeitsaufsicht, S. 268-270.

${ }^{249}$ Siehe die Protokolle und Protokollauszüge in: BAB, DP3 Nr. 25, 25a.

250 Rundverfügung Nr. 17, 9. 1. 1951, BAB, DP3 Nr. 19, Bl. 59 f. Auf der Arbeitstagung vom 8. Juni 1951 wurden die Generalstaatsanwälte angewiesen, ihre Dienstbesprechungen in der zweiten Monatshälfte durchzuführen, da die Arbeitstagungen in Berlin in der ersten Monatshälfte abgehalten würden: siehe GStA der DDR an Generalstaatsanwälte der Länder, BAB, DP3 Nr. 25, Bl. 253.

251 Referat Melsheimers auf der Arbeitstagung am 21. 9. 1951, ebenda, Bl. $330 \mathrm{f}$.

252 Vgl. ebenda., Bl. 333. 
,operativen' Tätigkeit der Obersten Staatsanwaltschaft wiederholt behandelt, wobei diese regelmäßig die ungenügenden Informationen bemängelte ${ }^{253}$. Am 31. März 1951 legte Heinze erstmals fest, daß die Oberste Staatsanwaltschaft immer rechtzeitig zu unterrichten sei, wenn in einem Prozeß 15 oder mehr Jahre Zuchthaus, lebenslänglich oder die Todesstrafe beantragt werde ${ }^{254}$. Vor allem die rechtzeitige Berichterstattung über beabsichtigte hohe Strafen bei Kapitalverbrechen blieb mangelhaft, so daß etwa im September 1951 ein Oberstaatsanwalt die Todesstrafe beantragte, obwohl die Oberste Staatsanwaltschaft dies nicht für angemessen hielt ${ }^{255}$. Am 10. Oktober 1951 erfolgte eine grundlegende Neuregelung und eine bis dahin nicht übliche Präzisierung des Berichtswesens nach der Verordnung über Maßnahmen zur Vereinfachung der Justiz vom 27. September. Zunächst ergab sich aus der Verordnung, daß die Berichte nur an den Generalstaatsanwalt der DDR, aber nicht länger an die Justizverwaltung zu richten waren. Die Rundverfügung ordnete des weiteren an, über alle Verfahren zu berichten, in denen eine mindestens zehnjährige Freiheitsstrafe beantragt werden sollte ${ }^{256}$, sowie über alle sonstige Verfahren von besonderer Bedeutung und zählte diese im folgenden auch auf: Im Rahmen der Abteilung I waren dies Straftaten „faschistischer Gruppen“ und „im Auftrage imperialistischer Agentenzentralen“ tätiger Personen und solche, die „die Interessen der bei der Regierung der Deutschen Demokratischen Republik vertretenen Staaten" - also im wesentlichen der Sowjetunion - berührten; im Rahmen der Abteilung II vor allem Verbrechen, die nach SMAD-Befehl Nr. 160 und nach dem Handelsschutzgesetz strafbar waren, und im Rahmen der Abteilung III insbesondere Mordsachen ${ }^{257}$.

Die Anweisungen aus Berlin beschränkten sich nicht nur auf die Genehmigung oder Ablehnung einer hohen Strafe, sondern konnten im Ermittlungsverfahren, bei der Anfertigung der Anklageschrift oder beim Hauptverhandlungstermin erfolgen. Die Einwände der Generalstaatsanwälte von Brandenburg und SachsenAnhalt, daß mit der Erteilung von Einzelweisungen die „Verantwortungsfreudigkeit“ herabgemindert und die „Eigeninitiative“ gelähmt würde, ließ Melsheimer aber nicht gelten: Mit solchen Weisungen würden lediglich „dem sachbearbeitenden Staatsanwalt die Gesichtspunkte gezeigt, nach denen im betreffenden Verfahren zu arbeiten ist“" 258. Konkrete Angaben zur Intensität der Überwachung und Anleitung einzelner Verfahren durch die Oberste Staatsanwaltschaft existieren erst für das 2. Halbjahr 1952. So wurden damals für 426 Verfahren der Abteilung 1 Berichtsvorgänge angelegt, die "laufend überwacht und z.T. mit dem zuständigen Staatsanwalt besprochen" wurden, wobei die Berliner Zentrale auch hinsichtlich der Strafanträge Weisungen erteilte. In der Abteilung 2 waren 382 Verfahren bei der Obersten Staatsanwaltschaft bekannt; auch dabei wurden in einigen „beson-

${ }^{253}$ Rundverfügungen Nr. 4/145/50 vom 3.6. 1950 (fälschlich mit Datum 3.6. 1951), Nr. 9/145/50 vom 12. 9. 1950 , $\mathrm{Nr}$. $12 / 125 / 50$ vom 20. 10. 1950, BAB, DP3 Nr. 19, Bl. 70, 9 f., $32 \mathrm{f}$.

254 Protokoll der Arbeitstagung, 31. 3. 1951, BAB, DP3 Nr. 25, B1. 192-194. Bis zu diesem Zeitpunkt war auf jeder Arbeitstagung die Berichterstattung thematisiert worden.

255 Referat Melsheimers auf der Arbeitstagung am 21. 9. 1951, ebenda, Bl. 328.

256 Die Verkürzung von 15 auf 10 Jahre war nach dem Prozeß gegen die Werdauer Oberschüler vom Sekretariat festgelegt worden: siehe dazu Kap. B.VIII.3.

${ }_{257}$ Rundverfügung Nr. 32 vom 10. 10. 1950, BAB, DP3 Nr. 19, Bl. 135-137.

258 Referat Melsheimers auf der Arbeitstagung am 21. 9. 1951, BAB, DP3 Nr. 25, Bl. 307 f., $334 \mathrm{f}$. 
ders bedeutungsvolle[n] Verfahren" konkrete Hinweise und Anweisungen gegeben. Trotz der vermehrten Einstellung von Staatsanwälten bei der Obersten Staatsanwaltschaft im Jahre 1952 reichte das Personal dem Bericht zufolge nicht für eine effektive „operative“ anleitende Tätigkeit aus ${ }^{259}$.

Neben den Rundverfügungen waren für eine längerfristige, zielgerichtete Justizsteuerung nach Auffassung der Obersten Staatsanwaltschaft Absprachen über aufzustellende Arbeitspläne erforderlich. Bereits im November 1950 kritisierte Heinze auf einer Arbeitstagung die von den Generalstaatsanwälten eingereichten Arbeitspläne für das kommende Quartal und machte im Anschluß daran eine Reihe von Vorgaben, um auf diese Weise eine gewisse Koordinierung zu erreichen ${ }^{260}$. Zentrale Vorgaben in Form eines Rahmenarbeitsplanes machte die Oberste Staatsanwaltschaft erst für das 2. Halbjahr 1951: Als Schwerpunkte benannte sie dabei die Durchführung des Handelsschutzgesetzes, Straftaten, die der staatlichen Handelsorganisation (HO) und den Konsumgenossenschaften schadeten, sowie die Durchführung von Vermögensbeschlagnahmungen und Vermögenseinziehungen. Die Generalstaatsanwälte hatten in ihren Arbeitsplänen - die auf der Arbeitstagung vom 25. Juni 1951 besprochen wurden - diese Schwerpunktaufgaben für ihre Länder zu konkretisieren und weitere landesspezifische Aufgaben hinzuzufügen ${ }^{261}$.

Um die Durchführung der zentral gegebenen Weisungen zu überprüfen, stand der Obersten Staatsanwaltschaft das Mittel der Revision zur Verfügung. Angesichts des Personalmangels bei dieser zentralen Behörde war eine flächendeckende Überprüfung ausgeschlossen; die wenigen Revisionen, die etwa 1951 durchgeführt wurden, konzentrierten sich auf die Abteilungen I der Generalstaatsanwälte der Länder und einiger Oberstaatsanwälte. Dabei zeigte sich, daß Anweisungen oft nur sehr unvollkommen umgesetzt wurden: Bei der Magdeburger Staatsanwaltschaft etwa fiel anläßlich einer Überprüfung im ersten Halbjahr auf, daß zahlreiche Vorgänge unbearbeitet waren, daß zu viele Verfahren eingestellt wurden und daß die Anklageschriften nur in ganz wenigen Fällen die gesellschaftliche, berufliche und politische Entwicklung der Angeklagten berücksichtigten. Auf ähnliche Mängel stießen die Revisoren der Obersten Staatsanwaltschaft bei der Abteilung I des Oberstaatsanwalts in Dresden ${ }^{262}$. Insgesamt war das ganze Kontrollsystem in den frühen fünfziger Jahren trotz der zentralistischen Struktur der Staatsanwaltschaft unzureichend. Dies hing, wie bei einer Kontrolle der Abteilungen I der Gerichte und Staatsanwaltschaften durch eine Sonderkommission festgestellt wurde, nicht nur mit dem allenthalben beklagten Personalmangel, sondern auch mit der schlechten Arbeit der Staatsanwälte Rodewald und Pustalla in der Berliner Zentrale zusammen, die sich widersprechende Anweisungen gegeben und die we-

259 Bericht über die Tätigkeit der Obersten Staatsanwaltschaft im 2. Halbjahr 1952, BAB, DP3 I Nr. 133.

260 Protokoll der Arbeitstagung vom 16. 11. 1950, BAB, DP3 Nr. 25, Bl. 109-112; Mitteilung an die Generalstaatsanwälte, 19. 1. 1951, ebenda, Bl. 165; Referat Melsheimers auf der Arbeitstagung am 21. 9. 1951, ebenda, Bl. 329.

261 Mitteilung an die Generalstaatsanwälte, 9. 6. 1951, ebenda, Bl. 253f.; Entwurf eines Rahmenarbeitsplanes für die Staatsanwaltschaften im 2. Halbjahr 1951, BAB, DP1 VA Nr. 1139, Bl. $168 \mathrm{f}$.;

Niederschrift über die Besprechung beim Generalstaatsanwalt, 15. 6. 1951, ebenda, Bl. 167.

262 Referat Melsheimers auf der Arbeitstagung am 21. 9. 1951, BAB, DP3 Nr. 25, Bl. 318-321. 
nigen durchgeführten Revisionen nicht ausgewertet hätten. Die Abteilungen I bei den Landesstaatsanwälten ${ }^{263}$, die ja im wesentlichen auf Landesebene kontrollieren mußten, beschränkten sich weitgehend auf „bürokratische Schreibtischarbeit" 264 . Zwar bezieht sich dieser Bericht vom April 1952 ausschließlich auf die Abteilungen I; angesichts der Bedeutung der politischen Strafsachen ist jedoch zu vermuten, daß die Lage bei den anderen Abteilungen noch weniger den Vorstellungen der Zentrale entsprach. Insgesamt scheint die Oberste Staatsanwaltschaft ihre ,operative Tätigkeit' in der zweiten Jahreshälfte verstärkt zu haben: In einem einschlägigen Bericht werden jedenfalls zahlreiche Aktivitäten von Staatsanwälten der Abteilungen I/1 und I/2 der Obersten Staatsanwaltschaft in den Bezirken aufgeführt, die eigenständige Untersuchungstätigkeit, politische und gleichzeitig justizrelevante Referate, Revisionen von Bezirksstaatsanwaltschaften und Kreisstaatsanwaltschaften umfaßten ${ }^{265}$.

Die Oberste Staatsanwaltschaft war bis $1952 / 53$ in zweierlei Hinsicht anleitend tätig: Zum einen gab sie generelle Hinweise, um aufgefallene Mängel in der Arbeit der Staatsanwaltschaften abzustellen, und zum anderen legte sie - in der Regel gemeinsam mit den anderen leitenden Justizinstanzen - die Schwerpunkte der staatsanwaltschaftlichen Arbeit fest und beteiligte sich an bestimmten Kampagnen. Ihre Hinweise betrafen in zahlreichen Fällen die Arbeitsweise der Staatsanwälte, insbesondere die zu lange Bearbeitungsdauer der Strafverfahren und die Überschreitung von vorgegebenen Fristen. Daneben war die Praxis vieler Staatsanwälte, bei der Abfassung der Anklageschrift einfach den Schlußbericht der Ermittlungsorgane zu übernehmen, ein Mißstand, auf den die Oberste Staatsanwaltschaft mehrfach auf den Arbeitstagungen hinwies ${ }^{266}$. Die gemeinsam mit dem MdJ herausgegebenen Rundverfügungen betrafen entweder die Auslegung und Anwendung bestimmter strafrechtlicher Vorschriften oder strafprozessuale Praktiken: Genannt seien hier nur die am 26. September 1950 erteilten Richtlinien über die „Bestrafung des ungesetzlichen Überschreitens der Staatsgrenzen und der Demarkationslinie“ ${ }^{267}$ sowie Hinweise zu „Verfahren vor erweiterter Öffentlichkeit“ vom 3. Januar 1952268. Im letzteren Fall ging es vor allem darum, Pannen bei Schauprozessen zu vermeiden, indem man unter anderem dem Staatsanwalt vorschrieb, einen Antrag auf Verfahren vor erweiterter Öffentlichkeit nur dann zu

${ }^{263}$ Nach Erlaß der Verordnung vom 27. 9. 1951 wurden die Generalstaatsanwälte der Länder als Landesstaatsanwälte bezeichnet.

${ }^{264}$ Bericht über die Überprüfung der Gerichte und Staatsanwaltschaften Abt. I gemäß Politbürobeschluß vom 11. 12. 1951, 2. 4. 1952, BStU, MfS AS 24/55, Bl. $201 \mathrm{f}$. Zur Entstehung des Berichts siehe Kap. B.IX.3.

${ }_{265}$ Bericht über die Tätigkeit der Obersten Statsanwaltschaft im 2. Halbjahr 1952, BAB, DP3 I Nr. 133. Einschränkend wird darin auch erwähnt, daß die Revisionstätigkeit der Hauptabteilung I aufgrund des Übergangs von der Landes- auf die Bezirksstruktur nicht planmäßig durchgeführt werden konnte.

266 Siehe die Protokolle der Arbeitstagungen vom 31.3., 16. 11. und 4. 12. 1951, BAB, DP3 Nr. 25, Bl. 202, 364, 424.

${ }^{267}$ Gemeinsame Rundverfügung Nr. 126/50 (MdJ) bzw. 11/50 (OStA), 26. 9. 1950, BAB, DP3 Nr. 19, Bl. 25-28.

${ }^{268}$ Gemeinsame Rundverfügung Nr. 25/52 (MdJ) bzw. 1/52 (OStA), 3. 1. 1952, in: ANBl. des MdJ 1952, S. 37-40. 
stellen, „wenn er dazu vorher die Genehmigung des Landesstaatsanwalts eingeholt hat" ${ }^{269}$.

Die erste justizsteuernde Kampagne der Obersten Staatsanwaltschaft, die zugleich den Beginn ihrer ,operativen 'Tätigkeit markiert, stand im Zusammenhang mit den Volkskammerwahlen am 15. Oktober 1950. Da die SED-Führung angesichts der Wahlen nach Einheitsliste Störversuche und Unruhen befürchtete, galt es, diese auch durch die Justiz abzusichern. Ulbricht hatte am 7. September Pieck einen Plan zukommen lassen, der in einem Abschnitt über die „Verteidigung der demokratischen Ordnung und Gesetze in der Deutschen Demokratischen Republik“ zum einen Prozesse „gegen die Agenten des angloamerikanischen Geheimdienstes, die Wahlen und den friedlichen Aufbau in der Deutschen Demokratischen Republik verhindern wollen", insbesondere gegen CDU- und LDP-Mitglieder vorsah; zum anderen sollten Untersuchungen und Strafzumessungen bei feindlicher Tätigkeit durch Staatsanwaltschaft, Gerichte und Kriminalpolizei besser als bisher kontrolliert werden ${ }^{270}$. Bereits sieben Tage später ordneten MdJ und Oberste Staatsanwaltschaft in einer Rundverfügung an, „den Gegnern unserer demokratischen Entwicklung mit der größtmöglichen Entschlossenheit entgegenzutreten und ihnen zu beweisen, daß unser junger Staat mächtig genug ist, die Feinde der Republik zu vernichten“. Die Staatsanwaltschaft wurde insofern aufgewertet, als dieser Erlaß ebenfalls verfügte, daß für das Ermittlungsverfahren und die weitere Überwachung der politischen Strafverfahren ein besonderes Dezernat bei den Generalstaatsanwaltschaften der Länder zu bilden sei271. Damals schwamm die Oberste Staatsanwaltschaft jedoch noch im Fahrwasser des Justizministeriums. Denn nicht Melsheimer, sondern Fechner lud Vertreter der Landesjustizministerien und der Staatsanwaltschaften zu einer ersten Besprechung über diese Rundverfügung am 16. September 1950 nach Berlin ein, wo die MdJ-Vertreter die entscheidenden Weisungen erteilten ${ }^{272}$. Zur Berichterstattung über die Rundverfügung berief Melsheimer am 29. September die erste Tagung mit den Generalstaatsanwälten der Länder in die Oberste Staatsanwaltschaft ein, auf der er nicht nur die bisherigen mangelhaften Berichte kritisierte, sondern auch für „weit höhere Strafen“ und dafür plädierte, daß Gerichtsurteile und Anträge der Staatsanwälte übereinstimmen sollten ${ }^{273}$.

Hatte sich die Oberste Staatsanwaltschaft im Herbst 1950 damit zufrieden gegeben, an einer im wesentlichen vom Justizministerium getragenen Aktion mitzuwirken, trat sie zu Beginn des Jahres 1951 mit gewachsenem Selbstbewußtsein auf. Nun ging es um die Verfahren nach dem Handelsschutzgesetz. Wie Otto Grube in der Arbeitstagung am 9. Januar feststellte, hatte bis zu diesem Zeitpunkt das MdJ

${ }^{269}$ Die Rundverfügung war - wie so viele Maßnahmen dieser Zeit - Ergebnis des SED-Justizbeschlusses vom 11. 12. 1951: siehe Protokoll der Politbürositzung, 11. 12. 1951, SAPMO, DY $30 \mathrm{~J}$ IV 2/2/182, Anlage Nr. 3, Bl. 28.

270 Information Ulbrichts an Pieck über einen Plan September-Oktober 1950 vom 7. 9. 1950, in: Badstübner/Loth, Pieck-Aufzeichnungen, S. 356-360, hier 359.

271 Rundverfügung Nr. 121/50, 14. 9. 1950, BAB, DP1 SE Nr. 1199; zu dieser Rundverfügung auch Scheele, Die Justiz muß wachsamer, schneller und entschlossener den Kampf führen.

272 Vermerk betreffend Einladung zur Besprechung, 15. 9. 1950, BAB, DP1 VA Nr. 5573; Protokoll von der Sitzung mit den Generalstaatsanwälten am 16. 9. 1950, ebenda.

273 Protokoll der Arbeitstagung vom 29. 9. 1950, BAB, DP3 Nr. 25, Bl. 7. 
diese Strafverfahren auf der Grundlage einer Rundverfügung gelenkt ${ }^{274}$; nunmehr, so Grube, müsse "diese Funktion von unserer Behörde übernommen werden“. Heinze sekundierte dem Oberstaatsanwalt und verlangte, in allen Ländern die Durchführung des Handelsschutzgesetzes „als besondere[n] Schwerpunkt zu behandeln" 275 . Daß dies keine leere Ankündigung blieb, zeigen mehrere einschlägige Aktivitäten der Obersten Staatsanwaltschaft: Die Verfahren nach dem Handelsschutzgesetz wurden an prominenter Stelle in den Arbeitsplan für das zweite Halbjahr aufgenommen, auf einer Dienstbesprechung am 8. Juni 1951 hielt Ilse Kühne ein Referat über die typischen Fehler von Staatsanwälten und Gerichten bei diesen Gerichtsverfahren, und die Oberste Staatsanwaltschaft trat als Organisatorin einer zentralen Konferenz zu der Thematik am 27. Juli 1951 hervor ${ }^{276}$.

Als letzte derartige Kampagne sei das justitielle Vorgehen gegen sogenannte "Großbauern" angeführt, insbesondere nach einem von Ulbricht persönlich im Politbüro am 31. Oktober 1952 aufgebauschten Zwischenfall anläßlich einer LPG-Gründung in Friedrichsaue, Kreis Seelow 277. Nach weiteren Ausführungen auf der 10. ZK-Tagung am 20. November schickte die Oberste Staatsanwaltschaft Staatsanwälte in die ländlichen Gebiete, wo sie vor den Kreis- und Bezirksstaatsanwälten Referate über die „Lehren“ aus diesen Äußerungen für die Justiz hielten. Außerdem wurden am 20. und 21. November 1952 die Kreisstaatsanwaltschaften in Perleberg, Bützow, Gadebusch, Hagenow, Ludwigslust, Güstrow, Parchim und Lübz - also ausschließlich in den ländlichen Gebieten Mecklenburgs - kontrolliert: Diesmal ging es eindeutig darum, Bauern, die nicht in die LPGs eintreten wollten, entsprechend hart zu verurteilen, wobei deren Enteignung das eigentliche Ziel der Aktion war. Dennoch, so der Bericht der Obersten Staatsanwaltschaft, kamen auch nach den Referaten „immer noch Fälle vor, in denen gegen offensichtliche Feinde des Aufbaus des Sozialismus nicht die erforderlichen harten Strafen beantragt und verhängt wurden" 278 .

Mit dem Aufbau des Obersten Gerichts und der Obersten Staatsanwaltschaft erwuchsen dem DDR-Justizministerium Konkurrenten an der Spitze des Justizsystems. Beide Behörden steckten 1950/51 freilich erst in den Kinderschuhen und mußten eine Reihe von Anfangsschwierigkeiten bewältigen, bevor sie sich endgültig als justizanleitende Instanzen von einigem Gewicht etabliert hatten. Dabei waren sie von Anfang an als Instrumente der SED-Führung konzipiert, was sowohl an ihrer gesetzlichen Grundlage als auch an ihrer Besetzung deutlich wird. Der

274 Rundverfügung Nr. 122/50, 21. 9. 1950, BAB, DP1 SE Nr. 1199.

275 Protokoll der Arbeitstagung am 9. 1. 1951, BAB, DP3 Nr. 25, Bl. 155.

276 Protokoll der Arbeitstagung am 8.6. 1951, ebenda, Bl. 257-260; Niederschrift Böhmes über die Arbeitstagung, BAB, DP1 VA Nr. 1139, Bl. 170 f.; Entwurf eines Rahmenarbeitsplanes für die Staatsanwaltschaften im 2. Halbjahr 1951, 23. 6. 1951, ebenda, Bl. 168 f.; Niederschrift über die Arbeitstagung beim Generalstaatsanwalt am 13.7. 1951, ebenda, Bl. $163 \mathrm{f}$.; Niederschrift über die Konferenz beim Generalstaatsanwalt am 27. 7. 1951, ebenda, Bl. 160-162.

277 Protokoll der außerordentlichen Politbürositzung, 31. 10. 1952, SAPMO, DY 30 J IV 2/2/242, TOP 3. Hintergrund bildete eine Besprechung bei Pieck am 20.10. 1952: siehe Badstübner/Loth, Pieck-Aufzeichnungen, S. 407. Zur Überprüfung der Durchführung des Beschlusses vgl. Mitter, Am 17. 6. 1953, S. 86.

278 Bericht über die Tätigkeit der Obersten Staatsanwaltschaft im 2. Halbjahr 1952, BAB, DP3 I Nr. 133. Zu dem justitiellen Vorgehen gegen die Bauern in dieser Zeit siehe auch Werkentin, Politische Strafjustiz, S. $81 \mathrm{f}$. 
Kontrast zwischen dem gescheiterten LDP-Entwurf und dem weitgehend realisierten Regierungsentwurf des Gesetzes über die Errichtung des Obersten Gerichtshofes und der Obersten Staatsanwaltschaft verweist auf den grundsätzlichen Unterschied im Rechtsverständnis und in den Rechtstraditionen, aus denen beide Vorlagen hervorgingen: Während der LDP-Entwurf in den deutschen rechtsstaatlichen Traditionen der Zeit vor dem Dritten Reich wurzelte, war der Regierungsentwurf eher am sowjetischen Vorbild orientiert und vor allem auf seine Handhabbarkeit durch die SED hin konzipiert. Auch die Personalbesetzung lag de facto ausschließlich in der Hand der SED, auch wenn de jure die Richter von der Volkskammer gewählt werden mußten. Das „Blockprinzip“, das bei der Besetzung des Obersten Gerichts 1949/50 noch befolgt wurde, diente dabei, wie in anderen Bereichen auch, lediglich der Verschleierung der SED-Dominanz.

Die Besetzung der beiden neuen zentralen Justizorgane mit dem geeigneten Personal stellte in den Anfangsjahren eines der größten Probleme dar, kam es doch darauf an, daß die Mitglieder des Obersten Gerichts und der Obersten Staatsanwaltschaft gleichermaßen Professionalität und Loyalität zur DDR aufwiesen. Bei der Rekrutierung der Richter für das Oberste Gericht konnte Benjamin aufgrund ihrer Personalkenntnisse zumindest im Jahre 1950 nicht nur weitgehend politisch loyale, sondern auch fachlich qualifizierte Richter für ihre Behörde gewinnen; erst mit der Erweiterung des Obersten Gerichts mußte sie Abstriche von der Professionalität hinnehmen und auch minderqualifizierte Volksrichter einstellen. Die Oberste Staatsanwaltschaft hingegen griff seit ihrer Gründung fast ausschließlich auf Volksrichter zurück, deren politische Loyalität außer Frage stand, so daß dort - im Unterschied zum Obersten Gericht - Fluchtfälle nicht vorkamen. Freilich wurde das Funktionieren der Obersten Staatsanwaltschaft in höherem Maße als das des Obersten Gerichts durch behördeninterne Spannungen und Intrigen, Fluktuation aufgrund moralischen Fehlverhaltens und mangelnde Qualifikation seiner Angehörigen beeinträchtigt. Personalprobleme hingen freilich eng mit den spezifischen Strukturproblemen dieser im Aufbau befindlichen Behörden zusammen: Durch Erweiterung und Ausdifferenzierung benötigten beide, vor allem aber die Oberste Staatsanwaltschaft, sehr viel mehr qualifiziertes Personal, als in der DDR damals vorhanden war. Die Aufblähung des Apparats der Obersten Staatsanwaltschaft - und zum Teil des Obersten Gerichts - war vor allem auf die in beiden Fällen wirksamen Zentralisierungsprozesse und das damit einhergehende Bedürfnis nach einer lückenlosen Steuerung nicht nur der Justiz zurückzuführen.

Von beiden zentralen Justizorganen war zweifellos die Oberste Staatsanwaltschaft mit den umfassendsten Rechten ausgestattet und besaß allein aufgrund der gesetzlichen Grundlagen erhebliche Vorteile gegenüber dem Obersten Gericht, das sich als zentrales Anleitungsorgan für die Rechtsprechung vor Erlaß des GVG vom 2. Oktober 1952 gegenüber den Oberlandesgerichten erst einmal durchsetzen mußte. Während ihm dies bis zum November 1951 gelang, und sich seine Stellung im Gerichtssystem mit dem GVG festigte, blieb sein Verhältnis zum Justizministerium - worauf im nächsten Kapitel noch einzugehen sein wird - auch nach dem Oktober 1952 noch ungeklärt. Sehr viel einfacher hatte es da die Oberste Staatsanwaltschaft, die von 1949 an in ihrer engen Anlehnung an das sowjetische 
Modell die volle Unterstützung der SKK genoß. Ihre Verselbständigung und Zentralisierung war jedoch im Hinblick auf die Stellung der Staatsanwaltschaft im System der Justizsteuerung zweischneidig. Sie verschaffte ihr zwar die Unabhängigkeit vom Justizministerium und ein bis dahin in Deutschland nie gekanntes Maß an Zentralisierung sowie zahlreiche Kompetenzen; die neuen Befugnisse bedeuteten jedoch, sowohl was die Anleitungsfunktionen als auch die immer umfassender werdenden Kontrollfunktionen betrifft, eine erhebliche Belastung. Die Oberste Staatsanwaltschaft vermittelt daher insgesamt für die Jahre 1950 bis 1952 den Eindruck einer überforderten Behörde, die aufgrund des Mangels an hinreichend qualifiziertem Personal ihren sich ständig ausweitenden Aufgaben nur mit Mühe nachkommen konnte und sich dabei auf bestimmte Wirkungsbereiche konzentrieren mußte. Den Schwerpunkt ihrer Tätigkeit bildete die politische und die Wirtschaftsstrafjustiz, und auf diesem Arbeitsfeld trug sie - wie auch das Oberste Gericht mit seinen oft strafverschärfenden Kassationen - durchaus zur Konformität der Rechtsprechung bei. 